\title{
IST EVALUATION AND MONITORING
}

Link to publication record in Manchester Research Explorer

\section{Citation for published version (APA):}

Vonortas, N. S., Baudouin , P., Feller, I., Georghiou, L., Green, L., Lemola, T., Licht, G., Papaconstantinou, G., Puissochet, A., Rigby, J., \& Soderquist, KE. (2006). IST EVALUATION AND MONITORING. European Commission, Directorate-General Information Society and Media.

http://ec.europa.eu/dgs/.../evaluation/data/.../s2005_04_d01_inceptionreport.d...

\section{Citing this paper}

Please note that where the full-text provided on Manchester Research Explorer is the Author Accepted Manuscript or Proof version this may differ from the final Published version. If citing, it is advised that you check and use the publisher's definitive version.

\section{General rights}

Copyright and moral rights for the publications made accessible in the Research Explorer are retained by the authors and/or other copyright owners and it is a condition of accessing publications that users recognise and abide by the legal requirements associated with these rights.

\section{Takedown policy}

If you believe that this document breaches copyright please refer to the University of Manchester's Takedown Procedures [http://man.ac.uk/04Y6Bo] or contact uml.scholarlycommunications@manchester.ac.uk providing relevant details, so we can investigate your claim.

\section{OPEN ACCESS}




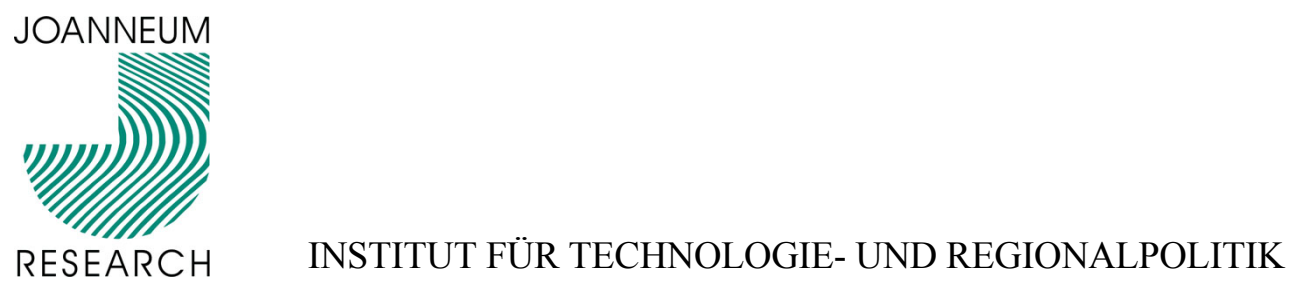

\section{IST EVALUATION AND MONITORING}

WOLFGANG POLT (JOANNEUM RESEARCH), NICHOLAS VONORTAS (G.WASHINGTON UNIVERSITY-MSL/AUEB) (COORDINATORS)

PHILIPPE BAUDOUIN (IDATE), IRWIN FELLER (PENN STATE UNIVERSITY), LUKE GEORGHIOU (PREST), LAWRENCE GREEN (PREST), TARMO LEMOLA (ADVANSIS OY), GEORG LICHT (ZEW), GEORGE PAPACONSTANTINOU (MSL/AUEB), ALAIN PUISSOCHET (IDATE), JOHN RIGBY (PREST), KLAS ERIC SODERQUIST (MSL/AUEB) 
Disclaimer: The opinions expressed in this report are those of the authors and do not necessarily reflect the views of the European Commission. 


\section{PREAMBLE}

Our Panel was tasked to explore future perspectives of an evaluation strategy for IST RTD and put forward a proposal for a coherent, systematic evaluation framework in which the required milestone evaluations, core methodologies, and content specifications are clearly identified together with the background supporting material (supporting evaluative studies) in relation both to the concluding FP6 and to FP7 schedules and deadlines.

This report describes the results of the Panel's deliberations during 2006. In recognition of the Herculian task - long time-span, several complex evaluation exercises, the Panel decided to concentrate the bulk of its deliberations on two evaluation milestones: the Ex-post Evaluation of FP6 in 2008 and the Interim Evaluation of FP7 in 2010. Reflecting on the identified needs of these two, the Panel also formulated what can be seen as an early opinion/guidance for the Ex-Post Evaluation of FP7 in 2015. In addition, on the basis of related work by PREST on the selection criteria for FP7 proposals, other work by AUEB and IDATE on the set of operational unit selfassessments in the context of the last annual monitoring exercise, and on its own proposals for continuing monitoring of the Programme, the Panel has also put forward its thoughts about the future Annual Monitoring exercises of the FP.

The Panel wishes to thank the Commission officers, Messrs Peter Johnston and Costas Paleologos from the unit C3 of DG INFSO, for the excellent support they have provided throughout the calendar year in which the panel met. It also wishes to thank other Commission officers who participated in various workshops and public consultations, held private conversations and, more generally, assisted the members of the Panel and the broader working team in carrying out its work. These include Massimo Mina, Neville Reeve, Mikael Garellic, Evangelos Ouzounis, Paul Hearn, Tiziana Arcarese and Peter Fatelnig.

Last, but not least, the Panel wishes to express its sincere thanks to several external experts who participated in the workshops and other public consultation meetings including: John Barber, AnnMarie Nisson, Terttu Luukkonen, Ken Guy and Michael Stampfer. 
Table 1: Timeline of evaluations for FP7, IST and CIP

\begin{tabular}{|c|c|c|c|c|c|c|c|c|c|c|c|}
\hline & 2005 & 2006 & 2007 & 2008 & 2009 & 2010 & 2011 & 2012 & 2013 & 2014 & 2015 \\
\hline \multirow{3}{*}{ FP7 } & $\begin{array}{l}\text { ExAnte FP7 Impact } \\
\text { assessment }\end{array}$ & & Start FP7 & $\begin{array}{l}\text { Ex - Post } \\
\text { Evaluation FP6 }\end{array}$ & $\begin{array}{l}\text { (envisaged) Progress } \\
\text { Report and Quality } \\
\text { Assessment for EP }\end{array}$ & $\begin{array}{l}\text { Mid - Term } \\
\text { Evaluation FP7 }\end{array}$ & $\begin{array}{l}\text { (envisaged) Progress } \\
\text { Report and Quality } \\
\text { Assessment for EP }\end{array}$ & & End of FP7 & & $\begin{array}{l}\text { Ex-Post Evaluation } \\
\text { of FP7 }\end{array}$ \\
\hline & & $\begin{array}{l}\text { Montioring and } \\
\text { Evalution } \\
\text { Strategy IST } \\
\text { FP7 }\end{array}$ & & & & \begin{tabular}{|l} 
possibly \\
Evaluation of the \\
Scientific aspects \\
for the Council) \\
\end{tabular} & & & & & \\
\hline & & & \multicolumn{7}{|c|}{ internal continous monitoring process with annual check_points [implementation] } & & \\
\hline FP8 & & & & & & & $\begin{array}{l}\text { (End of) Ex-Ante } \\
\text { Impact Assessment of } \\
\text { FP8 }\end{array}$ & $\begin{array}{l}\text { Proposal for FP8 } \\
\text { submitted to } \\
\text { coucil and EP }\end{array}$ & & Start of FP8 & \\
\hline \multirow{3}{*}{ Specific IST programmes } & & $\begin{array}{l}\text { eTEN Final } \\
\text { evaluation }\end{array}$ & & & & & & & & & \\
\hline & & $\begin{array}{l}\text { eContent Final } \\
\text { evaluation }\end{array}$ & & & & & & & & & \\
\hline & & $\begin{array}{l}\text { eEurope Action } \\
\text { Plan Final } \\
\text { evaluation }\end{array}$ & & & & & & & & & \\
\hline CIP / CIP ICT PSP & & $\begin{array}{l}\text { Monitoring and } \\
\text { Evaluation } \\
\text { Strategy CIP } \\
\text { IST PSP }\end{array}$ & & $\begin{array}{l}\text { Interim Evaluation } \\
\text { of CIP ICT PSP }\end{array}$ & $\begin{array}{l}\text { (end of) Interim- } \\
\text { Evaluation of CIP }\end{array}$ & & $\begin{array}{l}\text { (end of) Final } \\
\text { Evaluation of CIP }\end{array}$ & & & & \\
\hline ¡2010 Policy Framework & & \multicolumn{4}{|c|}{ Monitoring of the i2010 policy framework } & $\begin{array}{l}\text { Evaluation of the } \\
\text { i2010 policy } \\
\text { Framework }\end{array}$ & & & & & \\
\hline
\end{tabular}




\section{EXECUTIVE SUMMARY}

The European research policy is oriented towards the 'Lisbon objectives' of transforming the European Union into the most competitive and dynamic knowledge-based economy in the world, capable of sustainable economic growth with more and better jobs and greater social cohesion. Investments in research have key role in this transformation and the Framework Programme (FP) in Research, Technological Development and Demonstration (RTD) is the key research policy instrument of the European Union.

FP research is focused on specific themes (Thematic Priorities) that are strategically important for Europe's future. Thematic Priorities typically cross over several scientific disciplines but do not map completely any one of them. A core priority since the early 1980s, and one that remains central in the Seventh Framework Programme (FP7), has been the 'Information Society Technologies (IST) Thematic Priority' or 'Information and Communication Technologies' (ICT) theme. A budget of 12,670 Mio $€$ has been proposed for the IST Thematic Priority during the FP7 period 2007-2013.

Our Panel was tasked to explore future perspectives of an evaluation strategy for IST RTD and put forward a proposal for a coherent, systematic evaluation framework in which the basic evaluative questions, core methodologies, and content specifications are identified together with the background supporting material in relation both to the just concluded FP6 and to the new FP7 schedules and deadlines. This report describes the results of the Panel's deliberations on this subject during 2006.

\section{IST RTD ASSESSMENT IS KEY FOR PROMOTING GOOD INVESTMENTS}

The achievement of Europe's vision for information and communication technologies (ICT), as delineated by the Lisbon objectives and the 2010 plan, is not only a matter of more investment. It is also a matter of more effectively targeted investment. Europe needs to redouble its effort but it also needs to carefully allocate resources to activities with the highest expected rates of return. In order to optimize the RTD effort, policy decisions must be based on sound appraisals of the state of affairs in technology and markets, of the European relative strengths and weaknesses, of the public and private sector roles in the context of evolving global environments, and of the possibilities of the FP to contribute to the establishment of European industry as a global leader in IST. In short, 'intelligent' policy decision-making must be based on the systematic assessment (evaluation) of IST RTD.

Research evaluation becomes increasingly important as the competitive stakes for European economies and industries increase, as the size of FP7 RTD budget grows and as demands for transparency, accountability and performance across EU entities and among member nations increase. The Framework Programme as a whole and its constituent parts are subject to systematic appraisal that includes all three facets of evaluation: ex ante evaluation, interim evaluation (plus monitoring), and ex post evaluation. 


\section{EX-POST EVALUATION OF IST RTD IN FP6 (2008) STARTS NOW}

This (closing) stage of the evaluation cycle for FP6 is the main chance for evaluators to concentrate on the results (short-term), intermediate impacts (medium-term) and global impacts (long-term) of the Programme. This task calls for methodologies that go well beyond the traditional analyses based on surveys and case studies. The required methodologies for appraising intermediate and global impacts include more aggregative statistical/econometric approaches based on combinations of publicly available objective data and increasingly differentiated and customized survey data. The latter also include data to be developed and maintained by the Commission. The required methodologies will reflect a mix of quantitative and qualitative analytical approaches. Input, output, and behavioural additionality effects must be equally addressed.

The fact that the IST Programme in FP6 is organized in 23 thematic priorities must also be reflected in an ex-post evaluation: while some parts of the generic effects can, for instance, be covered in a standard questionnaire, the types of outputs and impacts will vary considerably between projects of the different strategic objectives (e.g., those aiming at societal goals as e-Inclusion, those with strong infrastructural output components such as 'broadband for all', and those with a higher share of privately appropriable results such as 'embedded systems').

FP6 has introduced new instruments, namely the Integrated Projects (IP) and Networks of Excellence (NoE), but also the ERANets, that have been funded alongside 'traditional' forms of collaboration such as the Specific Targeted Research Projects (STReP). The new instruments pose new challenges for evaluation - it must take into account the differences in their organization, rationales, and intended outcomes. The funding instruments are so different that the Panel has proposed to conduct different evaluative studies on each. While the evaluation of all instruments will be based on a mixture of qualitative and quantitative evaluation methodologies, the relative weights may differ across instruments.

The main ex post evaluative questions for IST RTD would include:

1. Programme Rationale

- Objectives, rationale and intervention logic for the IST-RTD Programme

- Policy Mix / Portfolio

2. Programme Implementation

- Has the implementation of the Programme been satisfactory?

$\rightarrow$ Were the activities carried out efficiently and were they cost effective?

$\rightarrow$ Did the activities constitute the best way of achieving the objectives set?

$\rightarrow$ Were the overall legal framework (including rules for participation and contracts), policy instruments and the modalities for implementation clear, appropriate and effective?

$\rightarrow$ Were the level of funding and other available resources adequate?

$\rightarrow$ Were the targeted industrial and research communities, including SMEs, able to respond appropriately? 
3. Programme Achievements

- What have been the outcomes/outputs and early impacts of the IST-RTD Programme?

- Has the Programme affected the industrial organization and behaviour of individual players in the affected sectors? These could be reflected in:

$\rightarrow$ Achieving critical mass

$\rightarrow$ Disseminating knowledge more efficiently

$\rightarrow$ Integrating core organizations with more peripheral ones

$\rightarrow$ Integrate European organizations with global "knowledge hubs"

$\rightarrow$ Advancing regional innovativeness and entrepreneurship

$\rightarrow$ Advancing ERA

- Has the Programme made a difference? Did it induce participants to activities that would not have been carried out without the Programme?

The final report will be the outcome of the deliberations of a high-level expert Panel, based on the evidence from a number of supporting studies, which have to be timed and planned meticulously Panel's members must be composed by technical and evaluation experts and experts in the areas of science and technology (S\&T) policy, strategy, and economics/business. A mixture of representatives from the ICT industries and academia is advised.

\section{INTERIM EVALUATION OF IST RTD IN FP7 (2010) ONLY A SHORT WHILE AWAY}

The Interim Evaluation should concentrate on the following aspects of the Programme:

- Research Quality: The extent to which the Programme sponsors world-class research that helps propel Europe to a leadership position globally

- Efficiency: The extent to which the Programme has been managed and operated efficiently, whether there has been good communication of objectives and progress, and the ability to address problems as they arose.

- Effectiveness: The progress towards meeting the objectives set.

Clearly, programme implementation is at the core of this stage of the evaluation exercise. An additional relevant evaluation theme underlying those listed above is acceptability that concerns the extent to which stakeholders accept the IST RTD Programme as a whole, the ICT technology challenges and the ICT research challenges driven by socio-economic goals, and the corresponding funding schemes.

At the time of this evaluation very few, if any, of the research projects funded by FP7 will have been completed. Only a few outputs may have already materialized. The available sources of information would include both objective data - primarily DG INFSO on the composition of the 
RTD consortia, contracts and internal processes - and subjective data - primarily stakeholder opinions on the Programme. Subjective data collection methodologies would include surveys, the annual reports of programme participants, interviews, focus groups, and case studies. An important innovation would also be to collect information from a control group of non-participants, i.e., organizations that for one reason or another decided against participating in the FP or did not know about the possibilities of participating.

FP7 also introduces innovations in terms of instruments. Four funding schemes are defined in the work programme for IST RTD during 2007-2008:

- Collaborative Projects (CP), including both STRePs and IPs

- Networks of Excellence (NoE)

- Coordination and Support Actions (CSA)

- Joint Technology Initiatives (JTI)

Again, the funding schemes are so different that the Panel proposes to have different evaluative studies on each. While the evaluation for all schemes will be based on a mixture of qualitative and quantitative evaluation methodologies, the relative weights may differ across schemes.

The main evaluative questions for IST RTD would include:

1. Research Quality

- Is the quality of the research activities under way satisfactory?

2. Programme Implementation

- Has the implementation of the Programme been satisfactory?

$\rightarrow$ Has the implementation of the Programme by the Commission been satisfactory and has it lessened the burden to the constituents?

$\rightarrow$ Were the activities carried out efficiently and were they cost effective?

$\rightarrow$ Did the activities constitute the best way of achieving the objectives set?

$\rightarrow$ Were the overall legal framework (including rules for participation and contracts), policy instruments and the modalities for implementation clear, appropriate and effective?

$\rightarrow$ Were the level of funding and other available resources adequate?

$\rightarrow$ Were the targeted industrial and research communities, including SMEs, able to respond appropriately?

3. Progress Towards Objectives

- Has there been progress towards achieving the objectives set for the Programme?

The Panel considered that the time is ripe for instituting and improving four data self-reporting instruments, including:

- The Annual Reports of RTD projects

- An Entry Survey 
- An Exit Survey (different than the Ex-post Participant Survey]

- Case Studies of individual participating organizations and consortia

The Annual Monitoring exercise (see below) can be utilized to streamline these data self-reporting instruments.

Particular attention must be paid to JTIs which are in a category of their own in terms of evaluation requirements. Given the size and intended breadth of JTIs, however, little more than describing their objectives and intended operational/organizational approach can be achieved at the time of this Interim Evaluation.

The final report will be the outcome of the deliberations of a high-level expert Panel whose members must be composed by technical and evaluation experts as well as experts in the areas of S\&T policy, strategy, and economics/business. A mixture of representatives from the ICT industries and academia is advised. The deliberations of the Panel should be largely based on the evidence from the supporting studies.

\section{EX-POST EVALUATION OF IST RTD IN FP7 (2015) SOMETIME AWAY}

The plan of the Commission for the Seventh Framework Programme calls for an independent evaluation concentrating on the Programme's rationale, implementation and achievements. The evaluative questions would be formulated as follows in order to reflect the three foci of the evaluation:

1. Programme Rationale

- Objectives, rationale and intervention logic for the IST-RTD Programme

- Policy Mix / Portfolio

2. Programme Implementation

- Has the implementation of the Programme been satisfactory?

$\rightarrow$ Has the implementation of the Programme by the Commission been satisfactory and has it lessened the burden to the constituents?

$\rightarrow$ Were the activities carried out efficiently and were they cost effective?

$\rightarrow$ Did the activities constitute the best way of achieving the objectives set?

$\rightarrow$ Were the overall legal framework (including rules for participation and contracts), policy instruments and the modalities for implementation clear, appropriate and effective?

$\rightarrow$ Were the level of funding and other available resources adequate?

$\rightarrow$ Were the targeted industrial and research communities, including SMEs, able to respond appropriately?

3. Programme Achievements

- What have been the outcomes/outputs and early impacts of the IST-RTD Programme?

- Has the Programme affected the industrial organization and behaviour of individual players in the affected sectors? These could be reflected in: 
$\rightarrow$ Achieving critical mass

$\rightarrow$ Inducing participants to activities that would not have been carried out without the Programme (input and behavioural additionality)

$\rightarrow$ Disseminating knowledge more efficiently

$\rightarrow$ Integrating core organizations with more peripheral ones and integrating European organizations with global "knowledge hubs"

$\rightarrow$ Advancing regional innovativeness and entrepreneurship

$\rightarrow$ Advancing ERA

These evaluative questions drive the partial evaluative studies that should be commissioned in order to support the final evaluative report. As in the case of the Interim Evaluation above, the four funding schemes of FP7 are different enough to deserve different evaluative studies for each. While all schemes will be based on a mixture of qualitative and quantitative evaluation methodologies, the relative weights may differ across instruments.

These studies will form again the basis for a final report to be delivered by a high-level expert Panel composed in the same way as the previous ones.

\section{IST RTD PROGRAMME MONITORING CAN BE ESSENTIAL FOR EVALUATION}

The Annual IST-RTD Programme Monitoring must continue and must be streamlined with other forms of evaluation, including Interim, and Ex Post. It has a triple purpose:

i. To appraise the implementation and progress with respect to the work programme for the IST thematic priority and its specific programmes;

ii. To appraise the overall effectiveness and management of the Calls for research proposals and, especially, the efficiency of the process of proposal evaluation and selection;

iii. To ensure the continuing collection of data as-you-go that will then feed into the Interim and Ex-Post Evaluations of the thematic priority.

The traditional approach of self-assessment has been proven over the years to have significant weaknesses. The Panel thus considered a combination of three other approaches to hold better promise for arriving at a more effective and useful programme monitoring. They include:

1. Annual monitoring based on the collection of output and impact indicators. Monitoring of longitudinal performance indicators enables collection of aggregated data on the key output and outcome indicators within and across programmes. This will produce an evolutionary picture of the developments and directions of changes emerging from the programmes, thus enabling the monitoring of progress towards the goals set.

2. Monitoring of key process implementation, notably the calls for proposals and proposal selection. This enables to control, evaluate and improve the critical processes of call for 
proposals, proposal evaluation and proposal selection. Besides monitoring the critical operational aspects of these processes (e.g., clarity, transparency, and effective use of expert panels), this exercise should emphasize the potential of projects to deliver longerterm, system-level impacts stemming from portfolio effects of related projects being executed in parallel, and a better than hitherto balance of technology push and market pull dynamics

3. Ad hoc monitoring exercises to appraise specific aspects of the Programme. These will enable rapid and/or more in-depth evaluation of particularly critical characteristics, aspects or procedures of specific programmes.

Taken together, these three approaches have the potential of making up a holistic and between complementary perspectives and procedures mutually supportive monitoring framework. 


\section{Table of Contents}

PREAMBLE

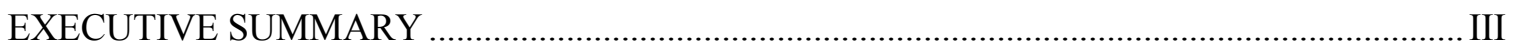

1 STRATEGIC IMPORTANCE AND CHALLENGES OF IST RTD EVALUATION ............. 12

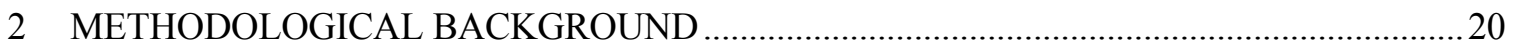

3 ASSESSMENT (MONITORING AND EVALUATION) STRATEGY FOR IST RTD .........25

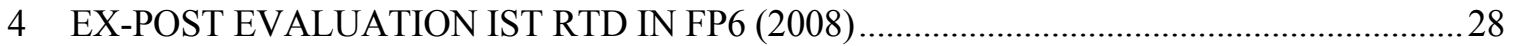

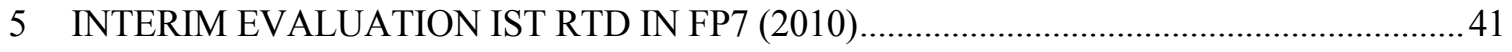

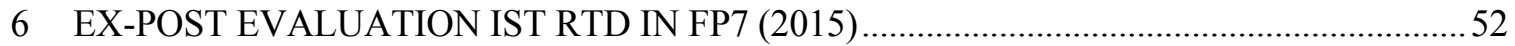

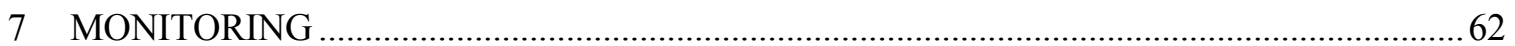

8 PROGRESS REPORT AND (SCIENCE) QUALITY ASSESSMENT $(2009,2011)$

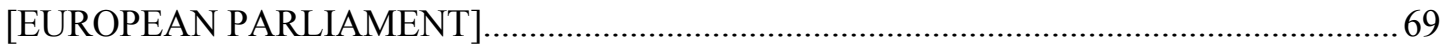

ANNEX I: SEVENTH FRAMEWORK PROGRAMME - STRUCTURE AND NEW DEVELOPMENTS 70

ANNEX II: POLICY DEVELOPMENTS IMPACTING UPON IST IN THE SEVENTH FRAMEWORK PROGRAMME 75

ANNEX III: JUSTIFICATION OF PUBLIC FUNDING OF RTD …............................................ 76 ANNEX IV: LOGIC MODELING AS AN EVALUATION FRAMEWORK .................................. 81 ANNEX V: CURRENT CONCEPTS OF RTD EVALUATION IN EUROPE ................................ 84

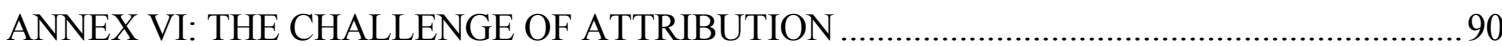




\section{Figures}

Figure 1: High Level Objectives and IST in $7^{\text {th }}$ Framework Programme with Some Possible Causal

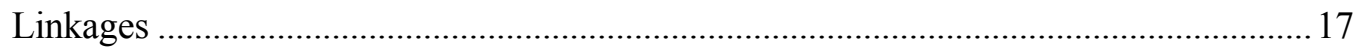

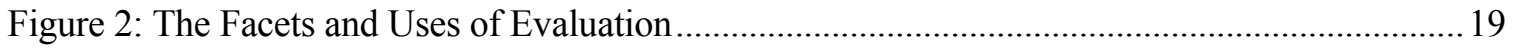

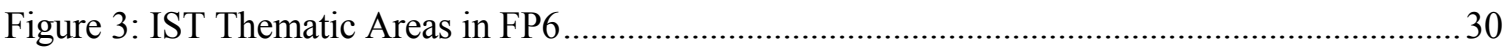

Tables

Table 1: Timeline of evaluations for FP7, IST and CIP ..................................................................ii

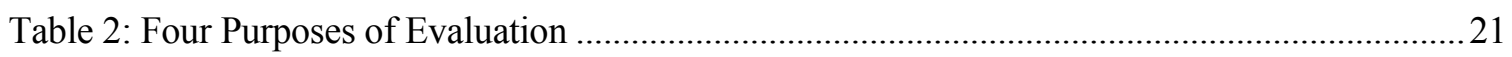

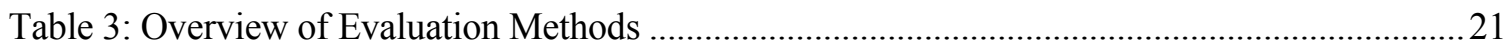

Table 4: Evaluative Questions, Analytical Methodologies, Principal Indicators -

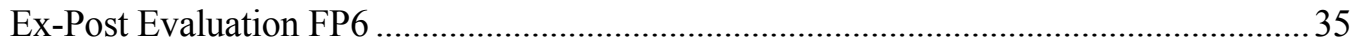

Table 5: CP: Evaluative Questions, Analytical Methodologies, Principal Indicators -

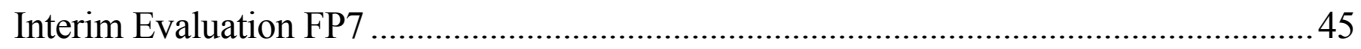

Table 6: Evaluative Questions, Analytical Methodologies, Principal Indicators -

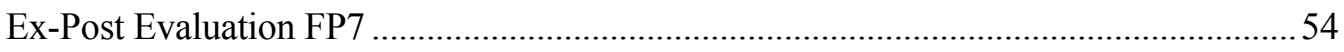




\section{Strategic Importance and Challenges of IST RTD Evaluation}

\subsection{IST IS QUITE IMPORTANT}

The importance of information society technologies (IST) for the welfare of European Union citizens cannot be overemphasised. Information and communication technologies (ICT) are considered to be a key element of productivity growth and a source of growth and competitiveness. ${ }^{1}$ According to the i2010 High Level Group, "[T]he ICT sector contributes to productivity growth through technological change. The sector is innovative and undertakes significant amounts of knowledge investments, with RTD shares largely exceeding the average shares of most other industries. ICT RTD effort in Europe is $25 \%$ of total RTD in the business sector, well above the weight of the sector in the economy amounting to 5\% of GDP."2

ICT effects are introduced through several channels:

- The ICT producing industries are important, dynamic sources of investments in RTD for new products and services and rapid adopters of technological innovations into their production processes.

- Efficiency gains in the ICT sector pass on to the users through the rapid price decline of ICT products.

- Non-ICT sectors also carry out significant amounts of focused ICT development.

- Greater use of ICTs raises efficiency across all sectors of the economy.

- Ever wider use of ICT by individuals in all aspects of daily life makes them more efficient and productive.

The Gago report ${ }^{3}$, among many others, stresses that it is vital for Europe to have an RTD programme in Information Society at the EU level. ICTs are also a cornerstone of both the original and revised Lisbon agendas aspiring to establishing Europe as one of the most dynamic knowledgebased economies in the world capable of sustainable economic growth and more and better jobs. As a result, the priorities for ICT research proposed by the Commission have received wide support in Council and Parliament. The Lisbon Annual Progress report has launched concrete proposals to increase investments in knowledge and innovation. The new Competitiveness and Innovation Programme (CIP), adopted by the Commission, includes a distinct ICT priority support programme for the take-up of ICT.

\footnotetext{
${ }^{1}$ European Commission (2006b): Communication from the Commission to the Council, the European Parliament and Social Committee and the Committee of the Regions: i2010 First Annual Report SEC

2 i010 High Level Group (2006): The economic impact of ICT : Evidence and Questions

3 European Commission, DG Information Society and Media (2005): Five-Year Assessment 1999-2003. Research and Technology Development, in: Information Society Technologies, Final Panel Report
} 


\subsection{EUROPE LAGS BEHIND IN ICT RTD}

Yet, Europe is a follower in terms of investing in ICTs. Recent reports have confirmed what has been widely recognised for sometime: European efforts in ICT RTD are well behind those of the United States. A recent report with detailed data (European Union of 15 Member States) stressed that Europe needs to redouble its effort since: ${ }^{4}$

- ICT RTD investment in the United States is twice that of Europe in absolute value.

- Europe is three times less "ICT RTD intensive" than Japan and the US in terms of RTD expenditure per inhabitant.

- The gap in ICT RTD expenditures between Europe and the US is widening.

\subsection{CHALLENGES IN ASSESSING IST}

To achieve Europe's objectives in IST it is not only a matter of more investment; it is also one of more effectively and efficiently targeted investment. Europe needs to redouble its effort but it needs also to carefully allocate resources to activities with the highest expected rate of return. In order to optimize the RTD effort, policy decisions must be based on effective appraisals of the state of affairs in technology and markets, of the European strengths and weaknesses, of the public and private roles in the context of evolving global environments, and of the possibilities of EU-level programmes to contribute in the establishment of European industry as a global leader in IST. In other words, policy decision-making must be increasingly based on assessment (evaluation) of IST RTD in Framework Programmes. ${ }^{5}$

Such assessment, however, is subject to important challenges, some of which are well established and some of which are only now being understood. Already recognised challenges include the following:

\section{Complexity of the Innovation Process}

The accelerated change, both technological and economic, strongly impacts research objectives and effectiveness. Technologies are rapidly evolving. The way ICT products are defined and used in society also is changing rapidly. The policy context is changing as is the broader economic context. The business environment has changed as firms increasingly engage in global input and output markets, including strategically acquiring and deploying their RTD activities on a global basis. Technological leadership still offers substantial benefits, but the application of research results promises much more. Such application relies on a complex innovation system, however, where

4 Conseil Stratégique des Technologies de l'Information (2006): Research and development in information science and technology in large industrialised countries. Statistical analysis of investments. A study commissioned by the Ministère délégué à l'enseignement supérieur et à la recherche. Realized by the Groupement Français de l'Industrie de l'Information (GFII) (French Information Industry Association), http://www.recherche.gouv.fr/rapport/rdsti.htm

5 For reference purposes, Annex I presents the main structural features of the 7th Framework Programme. Annex II lists the main policies affecting the Programme. Annex III summarizes the arguments in support of government intervention in RTD. 
demand plays a central role. In addition, several other policy tools may impact at different levels, local, regional, national or European. In order to increase the impact of IST RTD within the Information Society, the overall policy mix related to European IST-RTD needs to be improved. ${ }^{6,7}$

\section{Time Scale}

The socio-economic impacts of technological advancements (productivity, employment, competitiveness, societal, etc) take time to materialize. The time lag varies from an industry to another and from one type of research to another. Predicting or controlling the impacts of ICT on broader societal activities is likely to be even more difficult, and variable, because ICT innovations derive their value from being utilized as an input to the processes of all other sectors - often leading to a redefinition of those processes.

\section{From the Project Level to the Programme Level to the Technology (ICT) Level}

While the assessment is naturally directed towards capturing the overall impact of a programme or a set of programmes, in practice research projects are independent and small relative to the whole. They also tend to be managed on an individual, project-by-project basis. Inferring global assessment from the evaluation of several participating projects is an issue with no straightforward solution at this point. While various methodologies to address portfolio effects have been developed, additional work is needed to achieve consistency between project- and programmebased assessments.

\section{Technology Systems}

ICTs are often embedded in larger technological systems which may be characterized by interoperability and network economies. In such settings the socio-economic impact of a specific technological innovation is dependent on its ability to be integrated with other technology components, and the value of the technological system is dependent on the total number of users of the system. The importance of interoperability also tends to lead to technical performance standards, whether through the self-organizing actions of producer organizations and users, government regulation, or some combination of both. The economic "prize" in races related to information and communications' technologies, thus, may not go to the swiftest actor (e.g., first to invent, first to market, more advanced technology) but to the one whose technology becomes the dominant paradigm, possibly as a result of factors different than the technology itself.

\footnotetext{
6 "Five-Year Assessment 1999-2003: Research and Technology Development in Information Society Technologies", Final Panel Report, European Commission, DG Information Society and Media, January 2005, ISBN 92-894-8410-1.

7 Similar conclusions can be found in the ECOTEC report which argued that regulatory and deployment measures are not currently innovative enough to stimulate investment in ICT research: ECOTEC (2005): Preliminary analysis of the contribution of EU information society policies and programmes to the Lisbon and Sustainable Development Strategies, Final Report.
} 


\section{IST Programmes and the ICT Sector}

The traditional view that the ICT sector is the main place where ICT RTD takes place is no longer valid. ICT RTD is by no means concentrated on ICT economic sector. A large amount of software RTD, for instance, is done in sectors such as automotive, aerospace or medical. Organisations participating in ICT production come from almost all economic sectors. On the other hand, the IST thematic area programmes are not the only ones supporting ICT RTD. While the EU funding for IST RTD amounts to 1BEUR per year, national public funding amounts to about 8 BEUR, and private funding to 18 BEUR. In consequence, several types of funding are combined, whether in parallel or sequentially. Programme participants develop strategies and methods for combining funding from different sources most efficiently. Efforts to achieve better integration, complementarities and synergies between the Framework programme and national and multilateral initiatives further exacerbate the problem from an evaluation point of view. This reality essentially highlights the well understood problem of attribution.

\section{Qualitative Effects, Additionality}

Additionality - the extent to which a public RTD programme adds value to the system - is a complex notion. One can differentiate among three types of additionality: input additionality (more resources available), output additionality (more RTD outputs due to the support), and behavioural additionality (change in agent behaviour/capabilities). Additionality is often difficult to address with precision in all its facets, especially in terms of the third. Most recently, a project launched by $\mathrm{OECD}^{8}$ developed and synthesized methods for measuring behavioural additionality, considering among other points key impacts of collaborative efforts.

\section{Assessing Collaboration}

The European IST-RTD programme emphasizes collaboration among firms, universities and other research institutes. Hence, monitoring and evaluation must include examination of both formal and informal processes of cooperation as well as tangible and intangible outcomes generated by this collaboration. Tangible outcomes can include specific programme-related, measurable impacts such as cost reduction, increased frequency of discontinuous innovations, and faster times to market. Collaboration may also generate longer-term, less tangible benefits that may take the form of increased trust/information, and enhancement of relative capabilities. While contributing to the programme's objective of improving the competitive position of participating organizations, these benefits extend beyond the IST programme itself and are, thus, more difficult to capture.

8 OECD (2006a): Government RTD Funding and Company Behaviour:Measuring Behavioural Additionality. 


\section{Evolving instruments and objectives}

The policy instruments used by the Framework programme have evolved and changed significantly throughout the years and will probably continue to do so in the future. They differ widely in terms of size of the projects, participants, objectives, and so forth. There is little in common, for example, between Networks of Excellence, Integrated Projects, Specific Targeted Research Projects, not to mention the new Joint Technology Initiatives. Combined funding, both from the European Commission and national or international organisations is being considered (it has already being done in a restricted way such as the Eureka cluster JESSI). Assessment procedures must be able to accommodate various instruments in a common frame, or at least to be usable across, instead of being strictly fitted to an existing set of tools.

\section{Programme Logic}

The challenge of an evaluation framework is to link the broader policy objectives, the common currency of a programme's political sponsors, with the diverse range of programme effects. Figure 1 shows the first step in programme logic modeling as applied to IST. It depicts an effort to take the EU's high-level objectives (the Lisbon Agenda for economic reform and the information society vision, i2010) as a reference point and explores how this link up to the proposals for the Seventh Framework Programme (FP7). Hence, at the top level we see the targets of growth and jobs; in the middle layer, the i2010 shows actions to develop and roll-out information and communication technologies; finally, the boxes in the lower portion represent the major proposed lines of work in FP7 (which themselves range from fairly basic research to applications). ${ }^{9}$

9 See Annex II for major policy developments impacting upon IST in FP7. 
Figure 1: High Level Objectives and IST in $7^{\text {th }}$ Framework Programme with Some Possible Causal Linkages

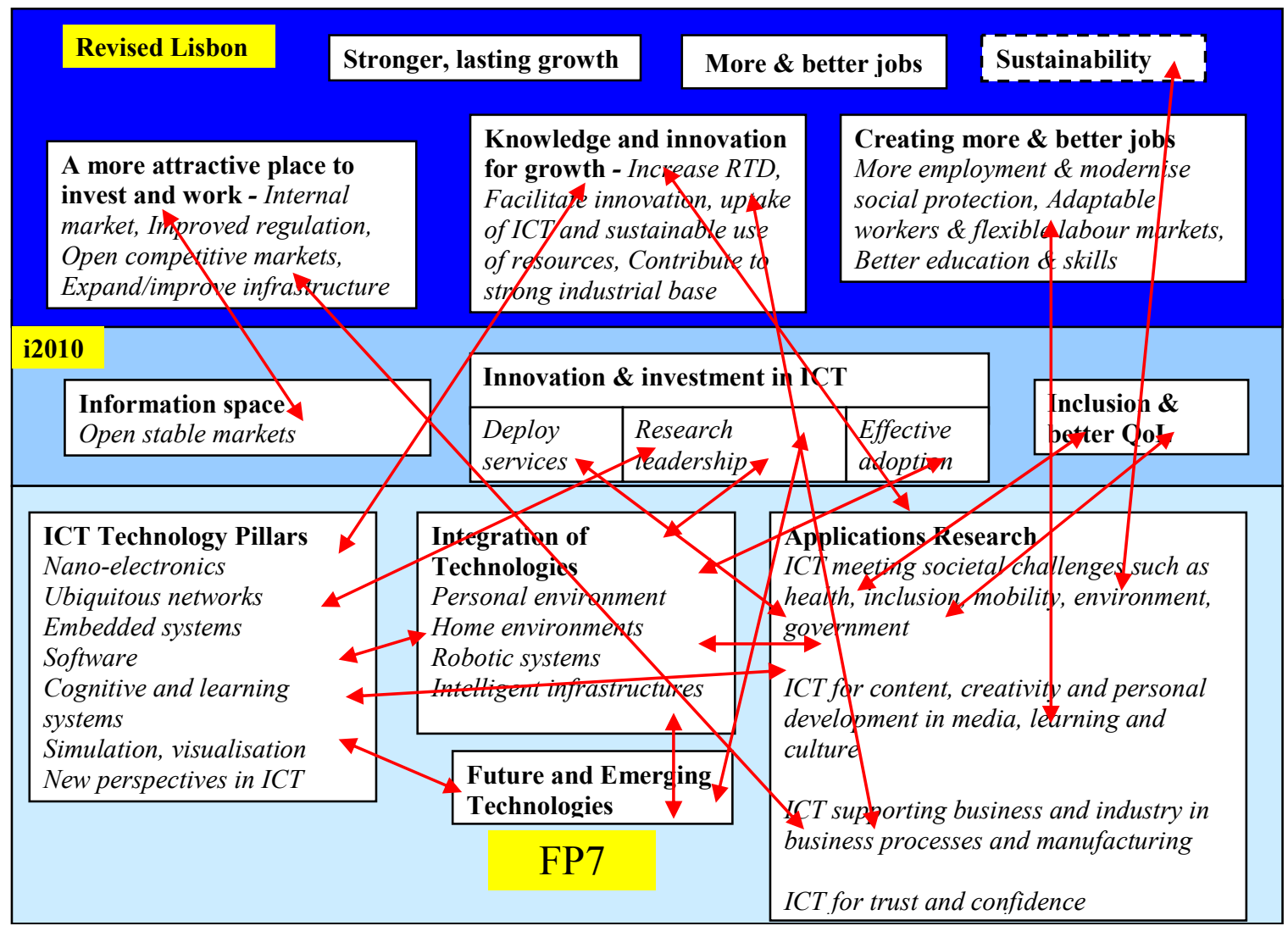

The arrows in Figure 1 illustrate the problem confronted when trying to trace direct links and causality between the levels. Numerous linkages can be drawn, but it is hard to make any systematic sense of them, or to know which are really valid. A lot more can and should be done to better articulate RTD programmes and their objectives. Annex IV shows an application.

New challenges that are currently being better understood include:

\section{A New Complete Assessment Cycle}

Combining ex-post, ex ante and monitoring activities in a coherent framework is a key recent evolution in required assessment activities for FP7. This implies coherence in terms of both data used and in applied methods. Such a coherent infrastructure will:

- Allow to combine evaluation work from one period to the next

- Propose necessary quantitative and qualitative indicators

- Provide a time frame approach with well linked evaluation exercises 


\section{New Constraints}

New constraints are introduced by the new orientations of the $7^{\text {th }}$ Framework Programme. They include more focus on social and economic impacts and on "systemic" effects, notably in the research-innovation-competitiveness link and on "knowledge networks". Extant evaluation practice as well as available data is admittedly not up to par with such aspirations. Significant methodological advances are called for. Moreover, intermediate and, even more, global impacts play out in the long term. In order to capture such impacts adequately, evaluations must be undertaken several years after the completion of a programme, which is not always possible. Other complications include the need to

- Allow for new instruments such as Joint Technology Initiatives (JTI)

- Support a more flexible implementation

- Check the coherence with other policies and policy level

\subsection{ASSESSMENT IS A KEY POLICY TOOL}

The above notwithstanding, there is little argument regarding the necessity of assessment of public funds. Research evaluation becomes increasingly important as the competitive stakes for European economies and industries increase, as the size of FP7 RTD budget increases, and as demands for transparency, accountability and performance across EU entities and among member nations increase.

Figure 2 summarizes the interconnected facets of evaluation and the use of the results in policy decision-making. The facets of the evaluation proper include:

- Priority setting and ex ante impact appraisal

- Monitoring of progress - interim evaluation

- Evaluation of results and impacts (ex post)

Cumulatively, they aim at:

- Measuring performance

- Supporting performance-based management and performance-based budgeting

- Enhancing accountability and transparency

- Improving the communication of program activities and outcomes to policy decision makers and sponsors 
Figure 2: The Facets and Uses of Evaluation

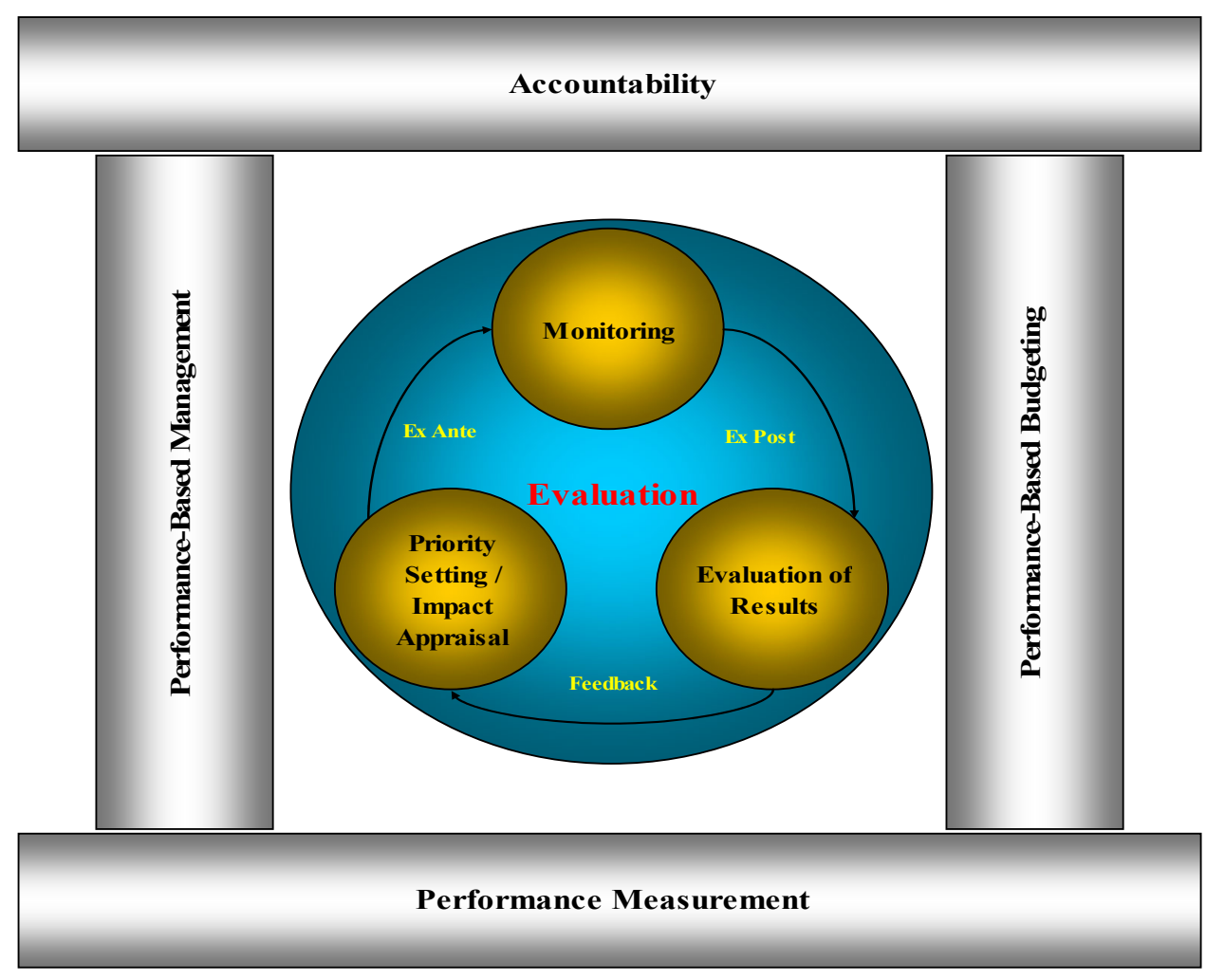

Evaluation, thus, provides a powerful tool with many potential uses. The Framework Programme as a whole and its constituent parts are now subject to systematic appraisal that includes all three facets of evaluation. An especially important current development is the attempt to couple the ex ante assessment exercise, traditionally linked to strategic planning and coordination to appraise policy options, with the ex post appraisal of results and socio-economic impacts in the spirit of Figure 2.

Annex V summarizes the current thinking on the various facets of evaluation, provides necessary definitions, and indicates the suggested applications by Commission Services. 


\section{Methodological Background}

Within the context of programme objectives, programme structure, and available and emerging evaluation methodologies, the task in designing an evaluation plan for the IST RTD programme is to select those methodologies that provide the most precise, accurate, timely and relevant information about its progress and impacts. This Chapter reviews the multiple purposes for evaluation, outlines the characteristics of several mainstream techniques used in evaluating RTD programmes, and highlights how several of these techniques could be used to evaluate the IST RTD programme.

A well stocked toolkit of methodologies exists to evaluate the higher level objectives and casual linkage paths. Among the mainstream evaluation techniques of likely applicability to the IST programme are surveys, statistical/econometric estimation, patent analysis, bibliometrics, network analysis, case studies, historical tracings, and expert judgment. ${ }^{10}$ The descriptive and explanatory power - and thus utility - of each technique, however, will vary according to the range, specificity and relative importance of the objectives set forth for the IST RTD program. The applicability of individual techniques also will vary with the programme's chronological evolution, as the technological, economic and societal impacts anticipated from the RTD programme entail different gestation periods. Thus, retrospective analyses of previous EU RTD programmes or earlier IST or cognate RTD programmes, interviews with prospective participants and end users, and preliminary surveys can be expected to precede techniques useful for garnering data on intermediate phases and indicators of progress, such as patents and innovations, which, in turn, will precede more extensive and diverse forms of data collection and causal analysis of modes of intersectoral collaboration and international economic competitiveness.

Selection of the most appropriate methodologies, singly or in combination, therefore will depend on the specific objectives and uses for which the evaluation is designed and the audiences for whom the evaluation is intended. Table 1 outlines the four major purposes of evaluation: assessing merit and worth; program and organizational improvement; oversight and compliance; and knowledge development. In what follows, it is assumed that IST's interests in evaluation encompass each of these purposes, with greatest weight likely attached to program and organizational improvement and assessing merit and worth.

\footnotetext{
10 For recent extensive surveys of evaluation techniques see Ruegg, R., Feller, I. (2003): A Toolkit for Evaluating Public RTD Investment, NIST GCR 03-875 (National Institute of Standards and Technology); Fahrenkrog, G., Polt, W., Rojo, J., Tubke, A, Zinnoecker, K. (eds) (2002): RTD Evaluation Toolbox: Assessing the Socio-Economic Impact of RTD Policies (EPUB), European Commission, Joint Research Centre; Georghiou, L., Rigby, J., Cameron, H. (eds) (2002): Assessing the Socio-Economic Impacts of the Framework Programme (ASIF), European Commission, DG Research. See also: Bozeman, B; Melkers, J. (eds.) (1993): Evaluating R\&D Impacts: Methods and Practice.
} 
Table 2: Four Purposes of Evaluation

\begin{tabular}{|l|l|l|l|l|}
\hline & $\begin{array}{l}\text { Assessing Merit } \\
\text { and Worth }\end{array}$ & $\begin{array}{l}\text { Program and } \\
\text { Organizational } \\
\text { Improvement }\end{array}$ & $\begin{array}{l}\text { Oversight and } \\
\text { Compliance }\end{array}$ & $\begin{array}{l}\text { Knowledge } \\
\text { Development }\end{array}$ \\
\hline Focus & $\begin{array}{l}\text { Support of judgment } \\
\text { about value }\end{array}$ & $\begin{array}{l}\text { Enhancement of } \\
\text { program services } \\
\text { expectations }\end{array}$ & $\begin{array}{l}\text { Generation or testing } \\
\text { of social science theory }\end{array}$ \\
\hline $\begin{array}{l}\text { Typical mode of } \\
\text { inquiry }\end{array}$ & $\begin{array}{l}\text { Causal analysis and } \\
\text { values inquiry }\end{array}$ & $\begin{array}{l}\text { Description, with } \\
\text { timely observation and } \\
\text { feedback }\end{array}$ & $\begin{array}{l}\text { Description, including } \\
\text { program activities and } \\
\text { outcomes }\end{array}$ & $\begin{array}{l}\text { Classification and } \\
\text { causal analysis }\end{array}$ \\
\hline Usual audience & $\begin{array}{l}\text { Democratic } \\
\text { institutions, } \\
\text { the public }\end{array}$ & $\begin{array}{l}\text { Administrators and } \\
\text { program staff }\end{array}$ & Legislators, funders, the \\
public & $\begin{array}{l}\text { Social scientists, } \\
\text { conventional wisdom"c }\end{array}$ & \\
\hline
\end{tabular}

Source: Mark, M. M., G. T. Henry, \& G. Julnes (2000). Evaluation: An Integrated Framework for Understanding, Guiding, and

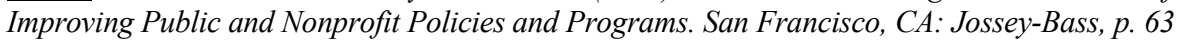

As noted, an extensive toolkit of methods exists to evaluate RTD programs. Table 2 presents an overview of these methods, a brief description of their contents, and selected examples drawn from the published literature of how the techniques have been used to examine various facets of a public sector RTD programme.

Table 3: Overview of Evaluation Methods

\begin{tabular}{|c|c|c|}
\hline METHODS & BRIEF DESCRIPTION & EXAMPLE OF USE \\
\hline $\begin{array}{l}\text { Analytical/conceptual } \\
\text { modeling of underlying } \\
\text { theory }\end{array}$ & $\begin{array}{l}\text { Investigating underlying concepts and } \\
\text { developing models to advance understanding of } \\
\text { some aspect of a program, project, or } \\
\text { phenomenon. }\end{array}$ & $\begin{array}{l}\text { To describe conceptually the paths through } \\
\text { which spillover effects may occur. }\end{array}$ \\
\hline Survey & $\begin{array}{l}\text { Asking multiple parties a uniform set of } \\
\text { questions about activities, plans, relationships, } \\
\text { accomplishments, value, or other topics, which } \\
\text { can be statistically analyzed. }\end{array}$ & $\begin{array}{l}\text { To find out how many companies have } \\
\text { licensed their newly developed technology } \\
\text { to others. }\end{array}$ \\
\hline $\begin{array}{l}\text { Case study - } \\
\text { descriptive }\end{array}$ & $\begin{array}{l}\text { Investigating in-depth a program or project, a } \\
\text { technology, or a facility, describing and } \\
\text { explaining how and why developments of } \\
\text { interest have occurred. }\end{array}$ & $\begin{array}{l}\text { To recount how a particular joint venture } \\
\text { was formed, how its participants shared } \\
\text { research tasks, and why the collaboration } \\
\text { was successful or unsuccessful. }\end{array}$ \\
\hline $\begin{array}{l}\text { Case study - } \\
\text { economic } \\
\text { estimation }\end{array}$ & $\begin{array}{l}\text { Adding to a descriptive case study } \\
\text { quantification of economic effects, such as } \\
\text { through benefit cost analysis. }\end{array}$ & $\begin{array}{l}\text { To estimate whether, and by how much, } \\
\text { benefits of a project exceed its costs. }\end{array}$ \\
\hline $\begin{array}{l}\text { Econometric } \\
\text { and statistical } \\
\text { analysis }\end{array}$ & $\begin{array}{l}\text { Using tools of statistics, mathematical } \\
\text { economics, and econometrics to analyze } \\
\text { functional relationships between economic and }\end{array}$ & $\begin{array}{l}\text { To determine how public funding affects } \\
\text { private funding of research. }\end{array}$ \\
\hline
\end{tabular}




\begin{tabular}{|l|l|l|}
\hline & $\begin{array}{l}\text { social phenomena and to forecast economic } \\
\text { effects. }\end{array}$ & \\
\hline $\begin{array}{l}\text { Sociometric and } \\
\text { social network } \\
\text { analysis }\end{array}$ & $\begin{array}{l}\text { Identifying and studying the structure of } \\
\text { relationships by direct observation, survey, and } \\
\text { statistical analysis of secondary databases to } \\
\text { increase under-standing of social organizational } \\
\text { behavior and related economic outcomes. }\end{array}$ & $\begin{array}{l}\text { To learn how projects can be structured to } \\
\text { increase the diffusion of resulting } \\
\text { knowledge. }\end{array}$ \\
\hline $\begin{array}{l}\text { Bibliometrics - } \\
\text { Counts }\end{array}$ & Tracking the quantity of research outputs. \\
\hline $\begin{array}{l}\text { Bibliometrics - } \\
\text { Citations }\end{array}$ & $\begin{array}{l}\text { Assessing the frequency with which others cite } \\
\text { publications or patents and noting who is doing } \\
\text { the citing. }\end{array}$ & $\begin{array}{l}\text { To find how many publications per } \\
\text { research dollar a program generated. }\end{array}$ \\
\hline $\begin{array}{l}\text { Bibliometrics - } \\
\text { content analysis }\end{array}$ & $\begin{array}{l}\text { Extracting content informatent and pattern of project's publications } \\
\text { techniques such as co-word analysis, database } \\
\text { tomography, and textual data mining, } \\
\text { supplemented by visualization techniques. }\end{array}$ & $\begin{array}{l}\text { To identify a project's contribution, and the } \\
\text { timing of that contribution, to the evolution } \\
\text { of a technology. }\end{array}$ \\
\hline $\begin{array}{l}\text { Historical } \\
\text { Tracing }\end{array}$ & $\begin{array}{l}\text { Tracing forward from research to a future } \\
\text { outcome or backward from an outcome to } \\
\text { precursor contributing developments. }\end{array}$ & $\begin{array}{l}\text { To identify apparent linkages between a } \\
\text { public research project and something of } \\
\text { significance that happens later. }\end{array}$ \\
\hline $\begin{array}{l}\text { Expert } \\
\text { judgment }\end{array}$ & $\begin{array}{l}\text { Using informed judgments to make } \\
\text { assessments. }\end{array}$ & $\begin{array}{l}\text { To hypothesize the most likely first use of } \\
\text { a new technology. }\end{array}$ \\
\hline
\end{tabular}

Source: R. Ruegg and I. Feller, (2003). A Toolkit for Evaluating Public RTD Investment NIST GCR 03-875 (National Institute of Standards and Technology), pp.30-31

These techniques may be used singly or in combination (mixed methods/ triangulation); may entail collection of primary data or use of secondary data; may be based on simple linear or complex, nonlinear relationships; and may be directed at one or more of the outputs, outcomes, and impacts associated with a programme's objectives.

The context and objectives for which the IST-RTD evaluation is being conducted will also shape the relative emphasis on quantitative and qualitative methodologies. In broad terms, quantitative methods emphasize "the effects of a program or policy as measured through quantitative indicators"; qualitative methods emphasize "participant's experience of a program or policy as revealed through their own words". (Mark, et.al, op.cit.) Each broad approach, as well as its constituent components, is regarded as having both strengths and weaknesses in illuminating specific descriptive, empirical or casual aspects of a program's activities or impacts. Patent data, for example, provide measures of technical output, linkages to scientific and technical publications, a means of constructing network relationships (among firms; between publications and patents), and, when capitalized in asset prices have been used as predictors of economic value. Their utility in any and all of the above uses however depends upon firm and industry's propensity to patent. Similar balance sheet statements of credits and debits exist for other methodologies.

In recognition of conceptual and empirical strengths and weaknesses of each specific methodology, evaluations of large-scale, complex RTD programs frequently employ mixed method designs. 
Under such an approach, multiple techniques are combined to offset the limitations of specific approaches, to complement one another such that the findings generated by one approach (e.g., surveys) are used as data sets in constructing variables (e.g., dependent or independent variables) used in other approaches (e.g., econometric estimation), and to triangulate findings as a means of increasing the confidence that program impacts have been correctly identified and located.

A number of qualitative techniques have been used singly or in combination with other qualitative or quantitative techniques to evaluate RTD programs. Among the main techniques found in recent studies and reports are expert judgment (which can include peer review to select projects for funding; panels to engage in monitoring and formative assessments, and summative assessments); interviews with program participants, stakeholders, or end users; case studies (single cases or multiple cases permitting cross-case analysis), and historical tracing (or retrospective reviews).

As an illustration, interviews can be used to generate background information on scientific and technological matters, firm and industry strategies, and interest in and expectations relating to the new RTD interview. They can also be used to preview evaluation design/questions; identify appropriate respondents for subsequent surveys ("snowball technique"); identify new variables/relationships; provide context/nuances for aggregate relationships; explicate complex/anomalous findings; and pre-market findings to relevant stakeholders.

Surveys also are a widely used technique in evaluations of RTD programs, especially in collecting contemporary data on variables not provided for in existing data sets. They are typically used to collect data on: characteristics of program participants; extent of program usage; participant and/or end user satisfaction; construction and measurement of dependent and independent variables.

As noted in Chapter 1, complex pathways are frequently pointed out by the logic models used to describe a programme's strategy. Moreover, no matter how carefully built about existing theoretical or empirical research, logic models may miss important variables or relationships that condition connections between programme inputs and outputs, outcomes, and impacts.. In terms of the IST RTD programmes, analytical and policy discontinuities may exist between evaluations of its scientific and technological impacts and either or both of its economic or societal impacts. The first set of outputs and outcomes relate to the new knowledge, variously measured, generated by the IST programme; the second and third sets to outcomes that follow upon the introduction and diffusion of this new knowledge as mediated by firm strategies, industry market structures, public policies, and exogenous variables. An evaluation design must address both complexity and unknowns. In each of the above cases, evaluation of an RTD program requires a sound theoretical specification of the casual paths linking program activities and subsequent outputs, outcomes, and impacts; specification of a set of estimation equations, and collection of relevant data.

Quantitative methods are generally used to address three types of evaluative questions: (1) the economic value of a program, variously gauged in terms of benefit-cost ratios, rate of return calculations, additionality, or options values; (2) the effectiveness, efficiency, or performance of a programme in which various output indicators - publications, patents, innovations - are used as intermediate proxies for "ultimate" economic or societal outcomes; and (3) causal relationships, in which the hypothesized connections posited in a priori program logic models are subjected to formal modeling and statistical testing. 
The importance of quantitative methods in evaluating RTD programmes follows from the need to transform relationships posited in logic models into testable hypotheses about causal relationships. The first order effect of any RTD program is to create new knowledge. Conceptually, this new knowledge can take several forms - it may be embodied in the human resources or capital; it may take the disembodied form of new best practices, which lead to a more efficient deployment of existing resources. The benefits of the new knowledge may be directly and fully captured by the entity (firm/industry) supporting or performing the RTD; it may spill over to benefit other parties. The economic benefits of the new knowledge may be fully captured and measured in the benefitcost calculations of private actors (e.g., rates of return); however, because of spillover effects or market conditions, divergences may occur between private and social benefits. New products and processes introduced as a result of RTD may rapidly and extensively diffuse through the marketplace; alternatively, market penetration may be slow and limited.

The benefits of an historical approach to evaluating an RTD program are that it contributes to "perspective" about the timing, magnitude and forms of impacts, economic or otherwise. The character of these benefits is captured by the following recent statement. "Historical thinking matters for many reasons. Perspective helps us avoid looking myopically at only immediate issues and missing the larger contexts in which they reside and traditions from which they arose, missing forces and agents of change that will continue to shape future actions and values...In particular, history illuminates the processes and forces that shape and effect change in science and policy". ${ }^{11}$

The remaining Chapters which contain this Panel's suggestions for the future evaluation exercises for IST RTD takes into consideration both the rich background in RTD evaluation summarized in this Chapter and the specificities of the Framework Programme.

11 Maienschein, J. (2006): On the Value of History of Science for the Social Science of Science Policy”, National Science Foundation Workshop, July 13-14 


\section{Assessment (Monitoring and Evaluation) Strategy for IST RTD}

The advent of f FP7 poses new challenges for monitoring and evaluation. To date, evaluation methods and approaches employed for Framework Programmes have traditionally focused primarily on inputs, outputs and outcomes of individual RTD projects, on the identification of additionalities, on the management and administrative conduct of the Programme, and on the degree of satisfaction of participants. In recent years, attention has broadened to include 'behavioural additionality', that is, the lasting effects of participation on the behaviour of participants ${ }^{12}$.

The extant approaches to monitoring and evaluation continue to be relevant in the context of FP7, but they leave some major evaluative questions relatively unanswered:

- Both the assessment of the impacts of RTD projects on innovation performance and innovation capacity as well as the assessment of the impacts and returns in terms of broader economic, social and environmental benefits are still not sufficiently covered - to effectively enable policy decision making in view of increased competitive pressure and the 'Lisbon' objectives.

- The intervention's logic and rationale have to be established - and evaluated - much better than in the past, given that the number of different instruments with different targets, target groups and effects has increased in FP6 and will increase further in FP7.

- The interplay of different instruments and different policies like RTD, innovation, technology transfer and diffusion increasingly requires the development of tools and methods that allow for the systemic assessment of portfolios of instruments and policies this is especially pertinent if evaluation of RTD programmes is to be done against the background of broader policy agendas (e.g. the Lisbon process or the i2010 strategy) of which the RTD programmes are just one part.

- The interplay of the different stages of evaluation (ex-post, interim, ex-ante) and monitoring among themselves and with policy making could see much improvement if designed in a coherent fashion as an overall monitoring and evaluation strategy.

The plan for FP7 includes new orientations for evaluation along these lines. E.g., it calls for additional emphasis on: outputs and impacts; verifiable objectives and indicators; a higher quality evidence base; the capturing of systemic effects, notably in the research-innovation-competitiveness links and on knowledge networks; EU added value; and linked ex ante and ex post evaluations. In recognition of the necessity to increase respective efforts, it also calls for an expanded programme of evaluation studies.

12 For an overview of recent work in this direction see: OECD (2006a): Government RTD Funding and Company Behaviour:Measuring Behavioural Additionality 
In recent years the evaluation unit of DG INFSO has pursued a three-track strategy in terms of developing its own capabilities to address such concerns: it has been developing capabilities in network analysis, in understanding intervention logics and causality, and in simulating economic and innovation system dynamics. The result has been a much more extensive appreciation of the issues involved in determining the input, output and behavioural additionality of European RTD programmes and challenges in pinning down European added value accurately. ${ }^{13}$ This monitoring and evaluation strategy incorporates these recent developments and lays out and suggests further steps and developments needed to meet the new challenges for evaluation in FP7.

\subsection{EVALUATING IST-RTD}

\section{Objectives}

The Work Programme for ICT 2007-2008 states that:

"The objective of the ICT theme under FP7 is to improve the competitiveness of European industry and enable Europe to master and shape the future developments of Information and Communication Technologies (ICT) so that the demands of its society and economy are met. Activities will strengthen Europe's scientific and technology base and contribute to securing its global leadership in ICT, help drive and stimulate innovation through ICT use and ensure that ICT progress is rapidly transformed into benefits for Europe's citizens, businesses, industry and governments."

Moreover, the renewed Lisbon agenda and the i2010 plan state the importance of ICT for providing the backbone of the knowledge economy and help addressing key socio-economic challenges. Included here are the achievement of higher economic growth through improved innovation performance, competitiveness and productivity; the achievement of future sustainability; the modernization of public services; and challenges in health, ageing and inclusion. Achieving world class performance in research and innovation in ICT and closing the gap with Europe's leading competitors are key objectives of the ICT thematic priority in RTD under the specific programme "Cooperation" of FP7.

These objectives continue and build upon the main objectives for IST-RTD in the Sixth Framework Programme, including: ${ }^{15}$

- To ensure European leadership in generic and applied technologies

- To increase innovation in European businesses and industry

- To increase competitiveness of European businesses and industry

- To ensure concentration of effort and achieve critical mass in key domains

13Johnston, P. (2006): A Strategy for Evaluating the Impact of IST-RTD Actions in the EU Framework Programmes, Head - Evaluation and Monitoring, DG Information Society and Media, Speech January 2006.

14 European Commission “ICT - Information and Communication Technologies: Work Programme 2007-2008”, Draft 1, 2006.

15 As referenced in the recent study: Technopolis (2005): Developing a Methodological Framework for High Quality Assessment of the IST-RTD Effects (Results and Impacts) at the "Strategic Objective" Level, Final Report to DG Information, Society and Media 
- To facilitate the integration of public and private RTD effort

- To contribute to greater benefits for the European citizens and address the key social and economic challenges

- To reinforce and complement the eEurope 2005

It is not expected that each of these objectives will be appraised in all evaluation studies across all various ICT challenges, future emerging technologies and horizontal actions in FP7. There will also be differentiation in terms of major evaluation themes in accordance to the timing of the evaluation exercise. Interim evaluations, on the one hand, will focus more on relevance, efficiency, and effectiveness, stressing implementation; they can only capture operational objectives, the relationship between inputs and outputs and some early phase results. Ex-post evaluations, on the other hand, should additionally emphasize utility and sustainability and try to capture specific, intermediate, and global impacts to the extent possible. They should reflect on rates of return and unintended consequences.

Also, the multi-facetted objectives and the increased diversity of instruments ask for a wider range of evaluation methods and approaches and a differentiation of the application of these methods by funding scheme (especially concerning the intervention logic and the rationale) and broad technology area (especially concerning the broader economic, social and environmental benefits).

\section{Timeline of evaluations}

Table 1 provides the timeline of the major evaluation milestones for FP7, IST and CIP. It is understood that the milestones for FP7 and for the CIP also apply to IST. The final reports addressing each evaluation milestone will naturally be supported by a set of analytical studies.

The next four Chapters turn to the methodological approaches and the evaluative questions to be employed in the studies supporting three major evaluation milestones, followed by indications of the most important variables/ indicators that will be implicated in the analysis. We focus on the Expost Evaluation for IST RTD in FP6, the Interim Evaluation for IST RTD in FP7, the Ex-post Evaluation for IST RTD in FP7, and the Annual Monitoring of the IST RTD Programme.

The Panel has refrained from discussing the Ex-ante Evaluation of IST RTD in FP8 as it considered that there already is a well laid out methodology for that purpose. 


\section{Ex-post ${ }^{16}$ Evaluation IST RTD in FP6 (2008)}

The keywords that should drive the ex-post evaluation of IST RTD in the sixth Framework Programme fall out directly from the array of objectives of the Programme summarized in the previous Chapter. These included leadership, effectiveness, innovation capabilities of industry, competitiveness, critical mass, key social (environment, cohesion) and economic (growth, employment) challenges, efficiency in programme implementation, better integration of public and private RTD effort, and strengthening the ERA.

The evaluation should concentrate on the Programme's rationale, implementation, and achievements. The evaluative questions could be formulated as follows:

\section{Programme Rationale}

- Objectives, rationale and intervention logic for the IST-RTD Programme

- Policy Mix / Portfolio

2. Programme Implementation

- Has the implementation of the Programme been satisfactory?

$\rightarrow$ Were the activities carried out efficiently and were they cost effective?

$\rightarrow$ Did the activities constitute the best way of achieving the objectives set?

$\rightarrow$ Were the overall legal framework (including rules for participation and contracts), policy instruments and the modalities for implementation clear, appropriate and effective?

$\rightarrow$ Were the level of funding and other available resources adequate?

$\rightarrow$ Were the targeted industrial and research communities, including SMEs, able to respond appropriately?

3. Programme Achievements

- What have been the outcomes/outputs and early ${ }^{17}$ impacts of the IST-RTD Programme?

- Has the Programme affected the industrial organization and behaviour of individual players in the affected sectors? These could be reflected in:

$\rightarrow$ Achieving critical mass

$\rightarrow$ Disseminating knowledge more efficiently

$\rightarrow$ Integrating core organizations with more peripheral ones

\footnotetext{
16 In the following, the notions 'ex-post' and 'final' are used interchangeably, though in some EU documents a distinction is made between 'final' as immediately happening after the programme (and thus confined to an analysis of outcomes and outputs) and 'expost' which is supposed to take place after some time has elapsed and would cover also impacts.

17 Commercial impacts of R\&D projects typically materialize some time after the completion of the research (if at all). An ex-post evaluation strategy should, therefore, include not only an assessment shortly after the completion of the Programme but also a more long-term follow up (e.g. some 7-10 Years later).
} 
$\rightarrow$ Integrate European organizations with global "knowledge hubs"

$\rightarrow$ Advancing regional innovativeness and entrepreneurship

$\rightarrow$ Advancing ERA

- Has the Programme made a difference? Did it induce participants to activities that would not have been carried out without the Programme?

Before proceeding to the analytical methodologies and possible indicators for addressing such evaluation questions, it is appropriate to discuss several issues of critical importance to the appraisals of Framework Prorammes.

\section{Additionality}

Measurement of additionality is a 'base-line' in the assessment of the FPs. On top of the standard approach to capture additionality (i.e. by a broad survey among participants), we propose to:

(i) Refine and further develop the approach by employing a control-group approach (e.g. in the form of 'matched pairs' such as successful vs unsuccessful applicants or successful vs unsuccessful projects of the same organization). Such an approach would provide a much better view and analysis of input additionality than currently available. By employing such an approach, one might even arrive at numerical values of leverage effects.

(ii) Place special emphasis on the dimension of 'behavioural additionality', as the new instruments especially address or imply changes in strategic behaviour of participants. Here, a mixture of survey (probably differentiated by type of instrument), advanced network analysis and case studies will be most appropriate to capture these effects. The focus on behavioural additionality seems especially suited for NoEs and could - at least partly - rely on the self-assessments carried out in (some?) NoEs.

\section{Impact Assessment}

With respect to the assessment of impacts, this stage of the evaluation cycle is the main chance for evaluators to concentrate on the results (short-term), intermediate (medium-term) impacts and global impacts of the programme (Annex Figures A3-A5). This task calls for methodologies that go well beyond the traditional analyses (surveys, case studies) which tend to work reasonably well at the project level but encounter great difficulty in aggregating to the programme level. The required methodologies for appraising global impacts include more aggregative econometric analyses as well as advanced statistical analysis based on combinations of publicly available objective data and increasingly differentiated and customized survey data. The latter (survey data) also include data developed and maintained by the Commission as explained below. The required methodologies will be a mix of quantitative and qualitative analytical approaches. Input, output, and behavioural additionality effects must be addressed. 
With respect to IST in FP6, the fact that the Programme is organized in 23 thematic priorities must also be reflected in an ex-post evaluation: while some parts of the generic effects can be covered in a standard questionnaire, the types of outputs (and hence impacts) will vary considerably between projects of the different strategic objectives (e.g. those aiming at societal goals as e-Inclusion, those with strong infrastructural output components as 'broadband for all' and those with a higher share of privately appropriable results as those in 'embedded systems'). We doubt that such a strong variety in outputs and impacts can be covered with a one-size-fits-all survey. Since the thematic priorities are too many, however, we consider that for practical reasons one might have to aggregate at the level of thematic areas which the DG has already done (Fig. 3). Therefore, we envision a two-stage assessment:

(i) Assessment differentiated by Thematic Areas (groups of SO's) (Figure 3)

(ii) Social cost-benefit analyses (CBAs) for larger projects such as selected IPs and NoEs in the form of case studies to capture broader economic (both private and social), societal and / or environmental impacts. ${ }^{18}$

Figure 3: IST Thematic Areas in FP6

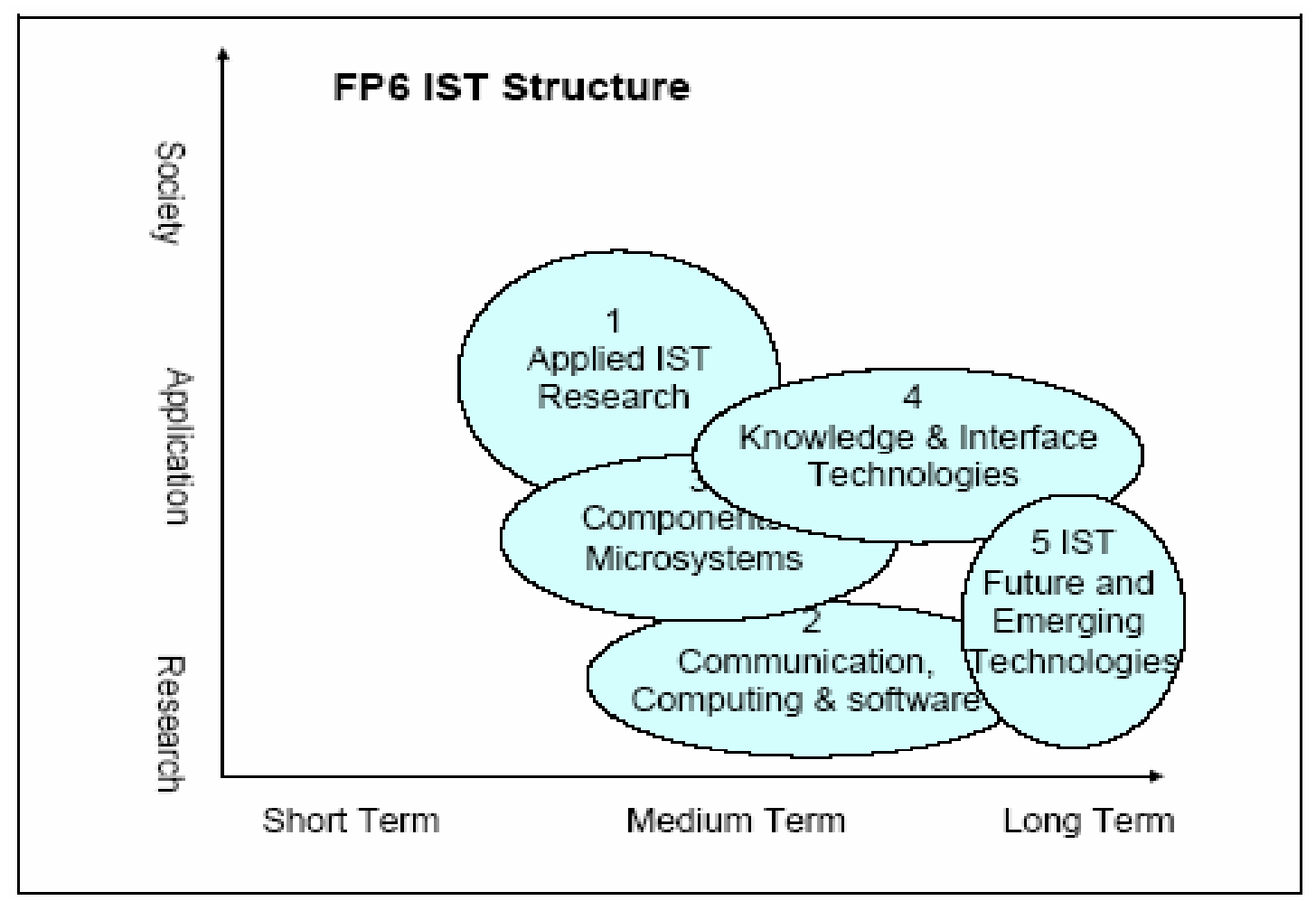

18 See, for example, the respective CBAs carried out for the ATP: Fahrenkrog, G., Polt, W., Rojo, J., Tubke, A, Zinnoecker, K. (eds) (2002): RTD Evaluation Toolbox: Assessing the Socio-Economic Impact of RTD Policies (EPUB), European Commission, Joint Research Centre 
With respect to economic impacts in the form of private returns, the impact assessment of the expost evaluation should also take into account the results obtained from two current projects of DG Enterprise (INNOVATION IMPACT and IMPLORE) which are developing approaches to measuring the impact of FP projects on the innovative capabilities and the innovative performance of participants. If measured in a way compatible with the CIS, such impact assessment would also allow for econometric analysis of input and output additionality as well as for effects on competitiveness.

\section{Intervention Logic and Rationale}

The test on the rationale of the instruments applied within FP6 should be much more prominent than in previous FPs: while the potentially positive effects of collaboration in RTD on participating organizations have been well established in the literature, ${ }^{19}$ the main rationale(s) behind the new instruments would have to be seriously and thoroughly tested as they introduce novel and relatively unexplored dimensions, especially regarding portfolio effects. The rationales behind these moves were the assumptions that:

- 'Critical mass' would be needed for European research to be more competitive in industrial terms or to achieve 'scientific excellence' when benchmarked against the leaders in the respective fields.

- Pooling of resources and coordination of strategies at the European and Member State levels would increase synergies and the leverage of RTD policies.

Thus, necessary ingredients (to be commissioned in early 2007 and carried out in the same year) for the ex-post evaluations would be a number of background studies which would:

- clarify the concepts and rationales on which the programme rested (e.g. studies about the theoretical and empirical meaning of the concept of 'critical mass' for each sector as well as a study on the theoretical and empirical meaning of the concept of 'excellence')

- provide up-to date information about the markets that the respective SOs were addressing (e.g. broadband, embedded systems, ...) to be able to check the change in competitive position of Europe in these markets. This is also important in order to capture unintended potentially negative - effects on market structures, e.g. in the form of increased concentration.

Another important dimension of the ex-post evaluation of FP6 would be the organization and administration of the Programme - especially the ability of the Commission to react to early findings of enterprises facing higher entry barriers (most of all the SMEs) and that the administrative burden of coordinating and running large, complex projects such as an Integrated

19 See, for example, Polt, W., Schibany, A (2001): Innovation and Networks: An Introduction to the Theme, in: OECD Innovative Networks; Hagedoorn, J., Link, A., Vonortas, N. (2000): Research Partnerships, Research Policy, 29(4-5): 567-586; Hemphill T., Vonortas, N. (2003): Strategic Research Partnerships: A Managerial Perspective, Technology Analysis and Strategic Management, 15(2): 255-271 
Project or a Network of Excellence was a burden not easily born by enterprises. Also, it would have to be checked whether administrative efforts in total (that is, on the side of the commission and the project participants together have increased or decreased - one has to be reminded that a simplification of administration on the side of the commission was one intended effect)

\section{Assessment of mixes and portfolios: projects, instruments and policies}

As has been stated above, greater diversity in terms of instruments and different types of activities carried out as well as the necessary link of R\&D to other policy issues asks for an evaluation of the efficiency and effectiveness of programmes in a 'systemic' manner. The analysis currently being developed by DG Research on the methods to assess policy mixes should be incorporated.

\section{Interplay and coherent approach to evaluation}

The demands on coherence of the evaluation approach have risen significantly with the increased complexity of the Programme. It must be remembered that not only does the increased number of instruments within the FP ask for more, but coordinated, evaluation approaches but so do the larger policy frames (Lisbon process, i2010 agenda). In addition, the evaluation efforts of a number of stakeholders in the FPs (DG Research, Enterprise etc.) must be articulated in an optimal way. Therefore, coherence among the evaluation approaches used must be sought with respect to:

- Timing (Table 3)

- Different stakeholders

- Other overarching policy frames and goals

\section{Evaluating the different instruments of FP6}

FP6 has introduced new instruments, namely the Integrated Projects (IP) and Networks of Excellence (NoE) (but also the ERANets). Alongside these new instruments, 'traditional' forms of co-operations have also been funded in the form of the Specific Targeted Research Projects $(\mathrm{STReP}) .{ }^{20}$ These new instruments pose new challenges for evaluations - they must take into

20 Specific Targeted Research Projects (STRePs) reflect smaller consortia and more narrowly focused research that is innovative within a predetermined work-plan. They are self-contained and the closest Instrument to the typical collaborative research that has been traditionally supported by the FPs.

Integrated Projects (IPs) are large projects with holistic workplans that connect a range of research, development and deployment activities. They have limited internal flexibility. Overall workflow is fairly well laid out from the beginning. The coordinating organization has a key role and mediates participation - and thus has most "bargaining power". IPs are likely to involve a wide range of organizations from the research and business communities.

Networks of Excellence (NoEs) are large projects with much more internal flexibility to pursue 'portfolio' exploration from a range of alternatives. They are primarily intended to combine and cross-fertilize existing strands of research around a common core issue. Their internal financing provides strong incentives for active and ongoing collaborative efforts. They are more likely to involve publiclysupported research organizations and to have less centralized or hierarchical structures. NoE research is perhaps more likely to favour "outreach" collaboration beyond the original network.

In addition, there are Coordinated Actions (CAs) and Specific Support Actions (SSAs). These instruments provide support or coordination to ongoing research efforts in other Instruments. For evaluation purposes they may be subsumed in the STReP group. 
account this variety of instruments, their different rationales and the differences in intended outcomes.

In fact, the funding instruments are so different that we consider it appropriate to propose that different evaluative studies should be conducted for each of them. While all instruments will be evaluated based on a mix of qualitative and quantitative evaluation methodologies, their relative weights may differ across instruments. For example:

- The STRePs can be covered at the project/organization level by the same approaches (mainly questionnaires, sometimes supported by case studies) that have been used in the evaluations of FP5. The most important addition to these should probably be more aggregate statistical/econometric analysis that would also combine the subjective data obtained through surveys to objective data obtained from publicly available databases. The methodologies are well-tested, their scope and limits well-known. ${ }^{21}$

- For the IPs and - most of all - for the NoEs, the assessment of behavioural additionality and portfolio effects will have an even greater importance than in previous programmes, because these new instruments are precisely targeting 'strategic behavior' (or even institutional change) of the actors involved. E.g. the NoEs were aiming at a 'strategic reorientation and alignment of research agendas' of their members. Here, either a separate survey will need to be undertaken and/or in-depth case studies for each IP/NoE would have to be carried out. These case studies can draw on the existing self-assessments of the IPs/NoEs and the metrics developed therein in the form of a 'meta-assessment' of the selfassessments. $^{22}$

- In the same vein, the ERANets were aiming at bottom-up, self-organized coordination of policies and programmes hitherto solely in the sphere of national RTD policy making. Here, the test would be to see different patterns of policy making as compared to the absence of the ERANets. Metrics for assessment of the individual ERAnets are currently under development (CISTRANA project). Also, qualitative and quantitative measures of policy coherence could be applied to assess the effects of the ERAnets. ${ }^{23}$

21 See Chapter 2 of this Report. Also, for descriptions relating to the most recent 5-Year Assessment Reports (1999-2003) for the Framework Programme see: Vonortas, N., Hinze, S. (eds.) (2005): Evaluation of European Union Framework Programmes: The 2004 Five-Year Assessment, Special Issue, Science and Public Policy, 32(5).

22 See, for example, Luukkonen, T. et al (2006): Understanding the dynamics of networks of excellence, in:, Science and Public Policy, Vol. 33, No. 4. (1 May 2006), pp. 239-252..

The assessment of behavioural additionality can draw on recent work presented in: OECD (2006a): Government RTD Funding and Company Behaviour:Measuring Behavioural Additionality

23 See OECD (2006b): Governance of Innovation Systems, Vol. 1: Synthesis Report; OECD (2006c) Vol. 2: Case Studies in Innovation Policy; OECD (2006d): Vol. 3: Case Studies and Cross-Sectoral Policy. 


\subsection{APPROACHES TO EVALUATING THE DIFFERENT INSTRUMENTS IN IST RTD}

In the following, we provide an overview of evaluative questions, analytical methodologies, principal indicators and sources of data for the Ex-Post Evaluation of IST RTD in FP6. Table 4 below starts from the evaluative questions as listed at the beginning of this Chapter and matches them with the appropriate analytical methodologies and respective principal indicators. We conclude with a brief discussion of the organization for the final Ex-post Evaluation Report. 
Table 4: Evaluative Questions, Analytical Methodologies, Principal Indicators - Ex-Post Evaluation FP6

\begin{tabular}{|c|c|c|c|c|}
\hline $\begin{array}{l}\text { Evaluative } \\
\text { Questions }\end{array}$ & Analytical Methodologies & Principal Indicators & Sources of Data & Timing \\
\hline $\begin{array}{l}\text { 1. Has the } \\
\text { programme made a } \\
\text { difference? Did it } \\
\text { induce participants } \\
\text { to activities that } \\
\text { would not have been } \\
\text { carried out without } \\
\text { the programme? } \\
\text { (question for } \\
\text { additionality: input } \\
\text { and behavioural } \\
\text { additionality) }\end{array}$ & $\begin{array}{l}\text { - Surveys (all instruments, esp. STRePs) } \\
\text { - Case studies (esp. among selected IPs and } \\
\text { NoEs) } \\
\text { - } \text { (Social) Network analysis for consortia in } \\
\text { FP6 and in comparison to FP } 4 \text { and } 5 \\
\text { - Control group approaches (e.g. matched } \\
\text { pairs) to compare successful participants } \\
\text { with non-successful applicants and non- } \\
\text { participants [or FP projects with non-FP } \\
\text { projects] }\end{array}$ & $\begin{array}{l}\text { - Quantitative: leverage effects } \\
\text { (input additionality), measures } \\
\text { of full / partial / negative } \\
\text { additionality, network relations } \\
\text { (centrality etc) } \\
\text { - Qualitative: degree of alignment } \\
\text { of strategic research agendas }\end{array}$ & $\begin{array}{l}\text { - } \text { Survey among participants } \\
\text { - } \quad \text { Narratives from case studies } \\
\text { - } \quad \text { Self-Assessments of NoEs } \\
\text { - } \quad \text { RTD project and participant } \\
\text { data from Commission }\end{array}$ & \\
\hline $\begin{array}{l}\text { 2. What have been } \\
\text { the } \\
\text { outcomes/outputs } \\
\text { and early impacts of } \\
\text { the IST-RTD } \\
\text { Programme? }\end{array}$ & $\begin{array}{l}\text { - Surveys among participants }- \text { but } \\
\text { differentiated between the SOs } \\
\text { - Case studies of representative consortia, } \\
\text { organizations } \\
\text { - aggregative econometric analyses as well } \\
\text { as advanced statistical analysis based on } \\
\text { combinations of publicly available } \\
\text { subjective data (CIS) and increasingly } \\
\text { differentiated and customized survey } \\
\text { data. } \\
\text { CBA and } \\
\text { for larger projects such as selected IPs. } \\
\text { (maybe also NoEs) }\end{array}$ & $\begin{array}{l}\text { - Indicators for scientific } \\
\text { achievements: } \\
\text { - Conference appearances, } \\
\text { conference proceedings } \\
\text { - Scientific papers, working } \\
\text { and published } \\
\text { - HR dimension (attracting } \\
\text { PhDs, leading scientists in } \\
\text { the programmes, etc } \\
\text { Indicators for innovative } \\
\text { performance and innovation } \\
\text { capacity ("CIS indicators"): } \\
\text { - patents } \\
\text { - products at planning stage, } \\
\text { - prototypes, }\end{array}$ & $\begin{array}{l}\text { - project data (reporting and } \\
\text { monitoring) developed and } \\
\text { maintained by the Commission } \\
\text { - CIS } \\
\text { - Surveys among participants } \\
\text { - International statistic about } \\
\text { relevant markets and } \\
\text { technology areas }\end{array}$ & \\
\hline
\end{tabular}




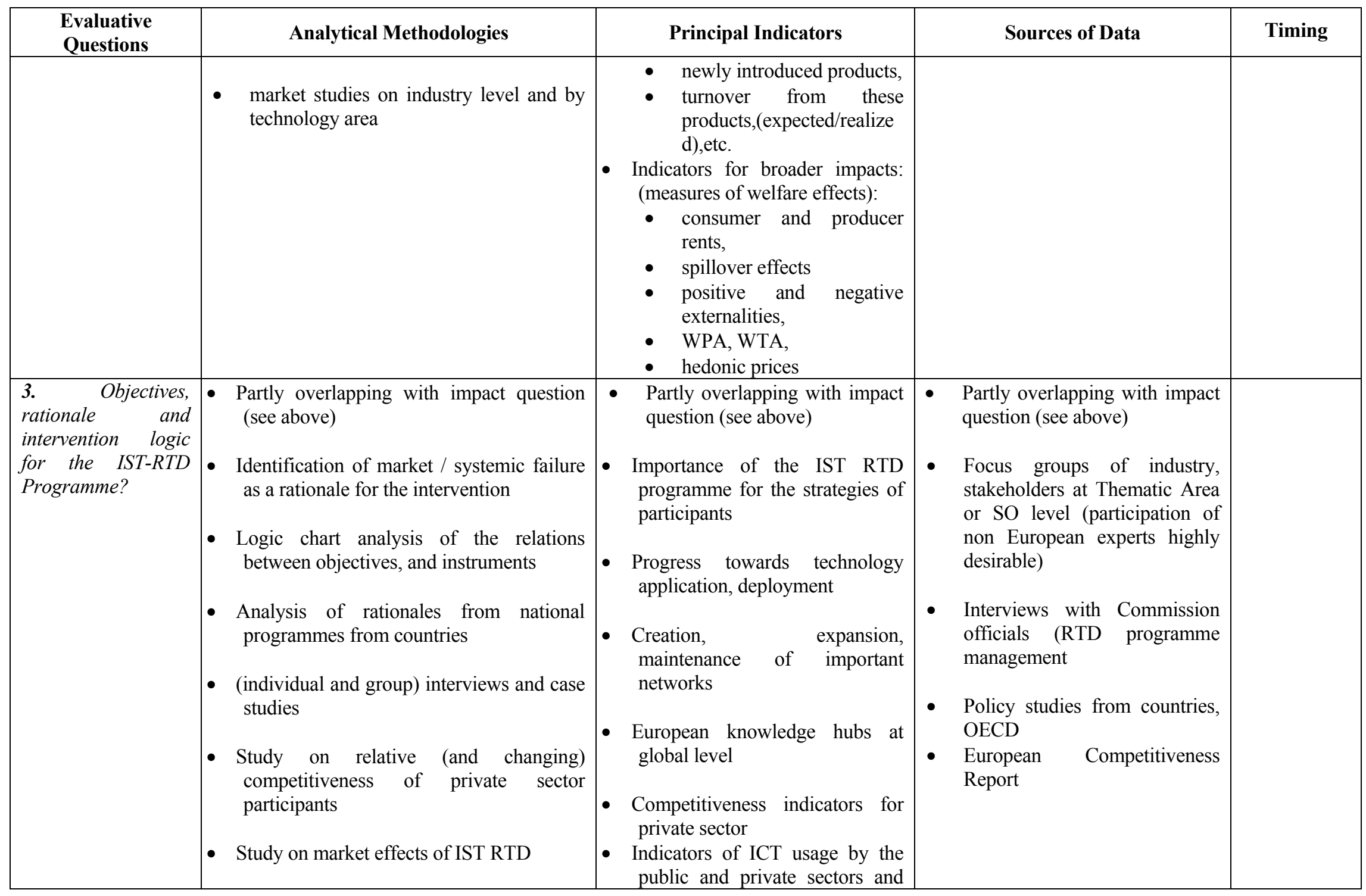




\begin{tabular}{|c|c|c|c|c|}
\hline $\begin{array}{l}\text { Evaluative } \\
\text { Questions }\end{array}$ & Analytical Methodologies & Principal Indicators & Sources of Data & Timing \\
\hline & & by households & & \\
\hline $\begin{array}{l}\text { 4. Policy Mix / } \\
\text { Portfolio }\end{array}$ & $\begin{array}{l}\text { - Analysis of the national/sectoral } \\
\text { innovation system } \\
\text { - Logic chart analysis } \\
\text { - Focus groups with programme } \\
\text { administrators, policy makers (e.g. those } \\
\text { involved in i2010 articulation) } \\
\text { - Policy studies from member countries }\end{array}$ & $\begin{array}{l}\text { - Qualitative analysis of policy } \\
\text { goals attached to individual } \\
\text { instruments } \\
\text { - Global context of IST RTD } \\
\text { policies vs diffusion oriented } \\
\text { policies vs ... }\end{array}$ & $\begin{array}{l}\text { - } \text { Focus group interviews } \\
\text { - } \text { ISTAG } \\
\text { - } \text { CREST } \\
\text { - } \text { OECD ICT Outlook } \\
\text { - } \begin{array}{l}\text { Trendchart, IST policies of } \\
\text { Member States }\end{array}\end{array}$ & \\
\hline $\begin{array}{l}\text { 5. Has the } \\
\text { implementation of } \\
\text { the Programme } \\
\text { been satisfactory? } \\
\text { - Were the } \\
\text { activities } \\
\text { carried out } \\
\text { efficiently and } \\
\text { were they cost } \\
\text { effective? } \\
\text { Did } \\
\text { activities the } \\
\text { constitute the } \\
\text { best way of } \\
\text { achieving the } \\
\text { objectives set? } \\
\text { Were the } \\
\text { overall legal } \\
\text { framework }\end{array}$ & $\begin{array}{l}\text { - Synthesis of information from established } \\
\text { mechanism for structured reflection on } \\
\text { implementation dimensions } \\
\text { - Benchmarking study comparing } \\
\text { managerial aspects of EU-funded } \\
\text { consortia and other collaborative RTD } \\
\text { projects } \\
\text { - Study on appropriateness and effectiveness } \\
\text { of Instruments } \\
\text { STReP Report } \\
\text { [Reports for IPs, JTIs, NOEs necessary] } \\
\text { Expert Panel deliberations and report }\end{array}$ & $\begin{array}{l}\text { - Administrative data on level of } \\
\text { overhead at programme and } \\
\text { project level, speed of } \\
\text { processing applications and } \\
\text { contracts, other bureaucratic } \\
\text { hurdles, etc } \\
\text { - Qualitative indicators of } \\
\text { efficiency, trust, management } \\
\text { improvement, } \\
\text { effectiveness } \\
\text { - } \\
\text { Indicators of clarity of } \\
\text { Commission } \\
\text { addressing documents } \\
\text { applicants and of extent of } \\
\text { absorption by applicants }\end{array}$ & $\begin{array}{l}\text { - Mechanism for structured } \\
\text { reflection on the different } \\
\text { dimensions of implementation } \\
- \text { process for continuous } \\
\text { process improvement }(* *) \\
\text { - Survey of client satisfaction } \\
\text { (participants and of non- } \\
\text { participants, including non- } \\
\text { applicants, rejected applicants, } \\
\text { 'near misses') regarding } \\
\text { managerial aspects of consortia } \\
\text { (EU funded and not) (**) } \\
\text { Focus groups of participants, } \\
\text { stakeholders } \\
\text { Public consultation }\end{array}$ & \\
\hline
\end{tabular}




\begin{tabular}{|c|c|c|c|c|}
\hline $\begin{array}{c}\text { Evaluative } \\
\text { Questions }\end{array}$ & Analytical Methodologies & Principal Indicators & Sources of Data & Timing \\
\hline $\begin{array}{l}\text { (including rules } \\
\text { for } \\
\text { participation } \\
\text { and contracts), } \\
\text { policy } \\
\text { instruments and } \\
\text { the modalities } \\
\text { for } \\
\text { implementation } \\
\text { clear, } \\
\text { appropriate } \\
\text { and effective? } \\
\text { Were the level } \\
\text { of funding and } \\
\text { other available } \\
\text { resources } \\
\text { adequate? } \\
\text { Were } \\
\text { targeted the } \\
\text { industrial and } \\
\text { research } \\
\text { communities, } \\
\text { including } \\
\text { SMEs, able to } \\
\text { respond } \\
\text { appropriately? }\end{array}$ & & & $\begin{array}{l}\text { - Interviews with } \\
\text { officials (RTD } \\
\text { management) }\end{array}$ & \\
\hline $\begin{array}{l}\text { 6. Has the } \\
\text { Programme affected } \\
\text { the industrial } \\
\text { organization and } \\
\text { behaviour of } \\
\text { individual players in } \\
\text { the affected sectors? }\end{array}$ & $\begin{array}{l}\text { Study to define critical mass (theory and } \\
\text { application to IST-RTD by Thematic Area, } \\
\text { SO if appropriate) } \\
\begin{array}{l}\text { Network analysis focusing on } \\
\text { organizations }\end{array}\end{array}$ & $\begin{array}{l}\text { - Critical mass indicators } \\
\text { (economies of scale, } \\
\text { economies of scope, other) } \\
\text { - Network indicators such as the } \\
\text { creation / strengthening of } \\
\text { 'hubs', network positioning, }\end{array}$ & $\begin{array}{l}\text { - } \begin{array}{l}\text { Publicly available statistical } \\
\text { information on industry } \\
\text { structure, conduct and } \\
\text { performance }\end{array} \\
\text { - } \begin{array}{l}\text { Commission administrative } \\
\text { data on projects and }\end{array}\end{array}$ & \\
\hline
\end{tabular}




\begin{tabular}{|c|c|c|c|c|}
\hline $\begin{array}{l}\text { Evaluative } \\
\text { Questions }\end{array}$ & Analytical Methodologies & Principal Indicators & Sources of Data & Timing \\
\hline $\begin{array}{l}\text { These could be } \\
\text { reflected in: } \\
\text { - Achieving } \\
\text { critical mass } \\
\text { - Disseminating } \\
\text { knowledge } \\
\text { more efficiently } \\
\text { - Integrating } \\
\text { core } \\
\text { organizations } \\
\text { with more } \\
\text { peripheral ones } \\
\text { Integrate } \\
\text { European } \\
\text { organizations } \\
\text { with global } \\
\text { "knowledge } \\
\text { hubs" } \\
\text { Advancing } \\
\text { regional } \\
\text { innovativeness } \\
\text { and } \\
\text { entrepreneurshi } \\
\text { p } \\
\text { Advancing ERA }\end{array}$ & $\begin{array}{l}\text { Study on the evolving organization of } \\
\text { industries related to IST RTD } \\
\text { Comparative study on regional } \\
\text { innovativeness and entrepreneurship } \\
\text { Progress report on advancing ERA } \\
\text { Other??? }\end{array}$ & $\begin{array}{l}\text { status, competitiveness } \\
\text { - } \begin{array}{l}\text { Network evolution indicators } \\
\text { emphasizing graphical } \\
\text { representation }\end{array} \\
\text { - Overlapping structures of FP- } \\
\text { funded and other regional / } \\
\text { national networks, especially } \\
\text { for deployment of ICTs } \\
\text { - Indicators of industrial } \\
\text { organization such as entry, } \\
\text { exit, concentration, } \\
\text { competition, market } \\
\text { penetration, technology } \\
\text { diffusion and utilization, etc } \\
\text { - Matching funds by national / } \\
\text { regional governments } \\
\text { (including own funds and other } \\
\text { non-FP such as Structural } \\
\text { Funds) } \\
\text { - Planning coordination between } \\
\text { the Commission and regional } \\
\text { authorities }\end{array}$ & $\begin{array}{l}\text { participants (Cordis) } \\
\text { - EPO (and USPTO?) data. } \\
\text { Extant processed versions of } \\
\text { patent data allowing extensive } \\
\text { searches by company and } \\
\text { providing all citations to all } \\
\text { patents for long periods of time } \\
\text { - ISI scientific publications data } \\
\text { - Regional activity data sources } \\
\text { (local/national governments, } \\
\text { think tanks, regional } \\
\text { development associations) } \\
\text { - Interviews with regional } \\
\text { government and industry } \\
\text { leaders }\end{array}$ & \\
\hline
\end{tabular}




\subsection{FINAL REPORT FOR EX-POST OF IST-RTD IN FP6}

The final report will be the outcome of the deliberations of a high-level expert Panel whose members must be composed by technical and evaluation experts and experts in the areas of S\&T policy, strategy, and economic/business. A mixture of representatives from the ICT industries and academia is advised.

The deliberations of the Panel should be largely based on the evidence from the supporting studies outlined for the various funding instruments in the previous subsections. The Panel should also have available some resources to commission a limited number of studies according to the judgment of the Panel members.

Given the time needed to compile existing and commission supplementary studies, it is advisable to install the panel immediately after the completion of the Programme. Previous evaluation exercises were very often hard pressed on time and resource constraints which put a limit to the questions being asked. The panel would start with an inventory of existing studies and could raise questions and communicate with current evaluation studies. Sub-groups of the panel could be given the task and the resources to carry out (individual or group) interviews with stakeholders. 


\section{Interim Evaluation IST RTD in FP7 (2010)}

The proposal of the Commission for FP7 calls for a mid-term evaluation of the programme to be carried out with the assistance of external experts to focus on the quality of the research activities under way, the quality of implementation and management, and progress towards the objectives set. Given the extended length of the Programme, this mid-term evaluation becomes of critical importance, not least for calibrating purposes with respect to efficiency in implementation and effectiveness in orientation towards the programme objectives. The Interim Evaluation of FP7 can build on the Ex-post Evaluation of FP6 (scheduled for completion in 2008). It should also naturally build on the on-going annual monitoring of the Framework Programme undertaken by the Commission.

The Interim Evaluation should concentrate on the following aspects of the IST-RTD Programme (evaluation themes, Figure A4):

- Research Quality: The extent to which the Programme sponsors world-class research that helps propel Europe to a leadership position globally

- Efficiency: The extent to which the Programme has been managed and operated efficiently, whether there has been good communication of objectives and progress, and the ability to address problems as they arose.

- Effectiveness: The progress towards meeting the objectives set.

Clearly, programme implementation by the Commission is at the core of this evaluation exercise. An additional relevant evaluation theme underlying those listed above is acceptability, referring to the extent that stakeholders accept the IST-RTD programme as a whole, the ICT technology challenges and the ICT research challenges driven by socio-economic goals, and the corresponding funding schemes. In contrast, consistency, ${ }^{24}$ economy ${ }^{25}$, and allocative/distributional effects ${ }^{26}$, which are also promoted by Commission services as major evaluation themes (Figure A4), are considered premature at this stage. While some of these latter themes will certainly be covered in some of the supporting evaluative studies, they are probably not going to be of the same stature as the three major evaluation themes listed above.

24 The extent to which positive spillovers onto other economic, social or environmental policy areas are being maximized.

25 The extent to which the resources were available in due time, in appropriate quantity and quality at the best price.

26 The extent to which disproportionate positive/negative distributional effects are being maximized/minimized. 
It is important to realize that at the time of this evaluation, very few, if any, of the research projects funded under FP7 will have been completed. In terms of Figure A2, we are still in the yellow region with some outputs flowing out of projects. That is to say that we can only start addressing the initial effects on the direct recipients of the financial assistance. In terms of Figure A3, we can only initiate the discussion regarding the efficiency of the Programme in delivering outputs and its effectiveness in making the correspondence between "results" and Programme "objectives". It is in this sense that this evaluation, in combination to external information regarding the evolution of the general socio/economic context affecting ICTs, will allow an examination of the continuing relevance of the initial objectives for the remaining second half of the Programme.

Broad evaluative questions to be addressed by the Interim Evaluation should include: ${ }^{27}$

- Is the quality of the research activities under way satisfactory?

- Has the implementation of the Programme been satisfactory? (Efficiency) Particular questions may include:

$\rightarrow$ Has the implementation of the Programme by the Commission been satisfactory and has it lessened the burden to the constituents?

$\rightarrow$ Were the activities carried out efficiently and were they cost effective?

$\rightarrow$ Did the activities constitute the best way of achieving the objectives set?

$\rightarrow$ Were the overall legal framework (including rules for participation and contracts), policy instruments and the modalities for implementation clear, appropriate and effective? Has the overall framework been simplified?

$\rightarrow$ Were the level of funding and other available resources adequate?

$\rightarrow$ Were the targeted industrial and research communities, including SMEs, able to respond appropriately?

- Has there been progress towards achieving the objectives set for the IST-RTD Programme? (Effectiveness)

The questions above cannot be addressed in an one-shot evaluative appraisal of the IST-RTD activities. A series of more focused evaluative studies must be launched to allow a concerted view on the various aspects of the IST-RTD programme and support the Interim Evaluation. It is the view of this Panel that these evaluative studies must be stratified on the basis of two basic axes:

i. the seven "challenges" (each incorporating several strategic objectives of the IST-RTD programme), and

ii. funding scheme (CP, NOE, JTI)

A third axis of potential importance would relate to methodological approaches.

27 Notice the similarity to questions posed in the last 5-Year Assessment exercise for the Framework Programme (1999-2003). 
Various analytical methodologies can be utilized in the supporting studies. While the overall analytical approach will probably lean quite heavily on the side of qualitative and descriptive, there can be significant empirical investigations to support several arguments as well. One such strand of empirical investigation that we can see, for example, is social network analysis that can describe the features of the networks formed by the IST-RTD funding and their relative positioning in the global networks in their respective fields. It would also be appropriate and feasible to address other aspects of "behavioural additionality" at this stage.

The available sources of information would include both objective data - primarily DG INFSO on the composition of the RTD consortia, contracts and internal processes - and subjective data primarily stakeholder opinions on the Programme. Subjective data collection methodologies would include surveys (also including the annual reports of programme participants), interviews, focus groups, and case studies. An important innovation would also be to collect information from a control group of non-participants, i.e., organizations that for one reason or another decided against participating in the FP or did not know about the possibilities of participating.

Four funding schemes are defined in the work programme for ICT during 2007-2008:

- Collaborative Projects (CP) provide support to research projects carried out by consortia aiming at developing new knowledge, new technology, products, demonstration activities or common resources for research. Included here are two types of projects that we saw earlier: Specific Targeted Research Projects (STRePs) and Integrated Projects (IPs)

- Networks of Excellence (NoE), as described in the previous section, are large projects with much more internal flexibility to pursue 'portfolio' exploration from a range of alternatives. They are primarily intended to combine and cross-fertilize existing strands of research around a common core field/issue in the framework of longer term cooperation. They are more likely to involve publicly-funded research organizations and to have less centralized or hierarchical structures.

- Coordination and Support Actions (CSA) provide support or coordination to ongoing research efforts in other funding schemes and policies (networking, exchanges, coordination of funded projects, transnational access to research infrastructures studies, conferences, etc.)

- Joint Technology Initiatives (JTI) are a new funding scheme of FP7 with the specific role to implement the research programme of a European Technology Platform (ETP). ETPs help industrial and academic research communities in specific technology fields to coordinate their research and tailor it to a common strategic research agenda, which sets out research and development goals, time frames and action plans for technological advances that are relevant to industry and society. ETPs typically seek to overcome barriers to the development, deployment and use of new technologies. ETPs are research policy 
cooperation actions, which pave the way for larger European technology initiatives based on private-public partnerships. They are industry-driven. JTIs will allow to pool together the required funding from the private sector, from the member states and from the Community to support the Platform's research agenda. They will facilitate the cooperation between all stakeholders in order to improve Europe's competitive position and respond to Europe's societal needs.

In what follows we address the set of supporting evaluative studies that will provide the necessary background analytical input to the Interim Evaluation of IST-RTD. We start with Cooperative Projects that we will consider as the benchmark instrument. We then discuss deviations from this funding scheme for NOEs and JTIs. The Chapter concludes with a brief discussion regarding the prioritization among the suggested supporting evaluative studies.

\subsection{EVALUATING IST-RTD CPS}

Table 5 below focuses on the supporting studies for the Interim Evaluation and presents a correspondence of the main evaluative questions with the appropriate analytical methodologies and respective principal indicators. 
Table 5: CP: Evaluative Questions, Analytical Methodologies, Principal Indicators - Interim Evaluation FP7

\begin{tabular}{|c|c|c|c|c|}
\hline Evaluative Questions & Analytical Methodologies & Principal Indicators & Sources of Data & Timing \\
\hline $\begin{array}{l}\text { 1. Is the quality of the research } \\
\text { activities under way satisfactory? }\end{array}$ & $\begin{array}{l}\text { - Science benchmarking at } \\
\text { "Challenge" level - SO level } \\
\text { if appropriate } \\
\text { - Case studies of representative } \\
\text { consortia, organizations } \\
\text { - (Social) Network analysis for } \\
\text { individual scientists at } \\
\text { Thematic Area, SO, and/or } \\
\text { IST RTD level }\end{array}$ & $\begin{array}{l}\text { - } \begin{array}{l}\text { Conference appearances, } \\
\text { conference proceedings }\end{array} \\
\text { - Scientific papers, working } \\
\text { and published } \\
\text { - Patent applications } \\
\text { - HR dimension (attracting } \\
\text { PhDs, leading scientists in } \\
\text { the programmes, etc) } \\
\text { - European knowledge hubs } \\
\text { at global level }\end{array}$ & $\begin{array}{l}\text { - } \begin{array}{l}\text { RTD project and participant data } \\
\text { from Commission }\end{array} \\
\text { - } \begin{array}{l}\text { Entry Survey of programme } \\
\text { participants }(* *)\end{array} \\
\text { - } \begin{array}{l}\text { Annual Reports of RTD projects } \\
(*)\end{array} \\
\text { - } \quad \begin{array}{l}\text { Exit Survey of programme } \\
\text { participants (**) }\end{array} \\
\text { - } \begin{array}{l}\text { EPO patent databases (maybe, } \\
\text { too early?) }\end{array} \\
\text { - USPTO patent databases (maybe, } \\
\text { too early?) } \\
\text { - } \begin{array}{l}\text { ISI bibliometric databases } \\
\text { (maybe, too early?) }\end{array}\end{array}$ & \\
\hline
\end{tabular}


Table 5 (cont): CP: Evaluative Questions, Analytical Methodologies, Principal Indicators - Interim Evaluation FP7

\begin{tabular}{|c|c|c|c|c|}
\hline Evaluative Questions & Analytical Methodologies & Principal Indicators & Sources of Data & Timing \\
\hline $\begin{array}{l}\text { 2. Has the implementation of the } \\
\text { Programme been satisfactory? } \\
\text { - Has the implementation of the } \\
\text { Programme by the Commission } \\
\text { been satisfactory and has it } \\
\text { lessened the burden to the } \\
\text { constituents? } \\
\text { - Were the activities carried out } \\
\text { efficiently and were they cost } \\
\text { effective? } \\
\text { - Did the activities constitute the } \\
\text { best way of achieving the } \\
\text { objectives set? } \\
\text { Were the overall legal } \\
\text { framework (including rules for } \\
\text { participation and contracts), } \\
\text { policy instruments and the } \\
\text { modalities for implementation } \\
\text { clear, appropriate and effective? } \\
\text { Were the level of funding and } \\
\text { other available resources } \\
\text { adequate? } \\
\text { Were the targeted industrial and } \\
\text { research communities, including } \\
\text { SMEs, able to respond } \\
\text { appropriately? }\end{array}$ & 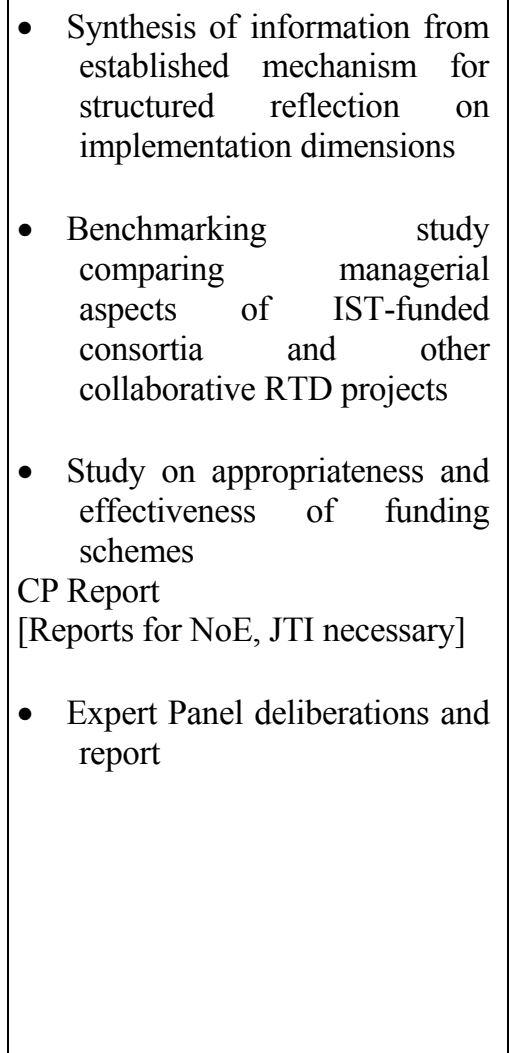 & $\begin{array}{l}\text { - Administrative data on } \\
\text { overhead expenditure at } \\
\text { programme and project } \\
\text { levels, speed of processing } \\
\text { applications and contracts, } \\
\text { other bureaucratic hurdles, } \\
\text { etc } \\
\text { - Qualitative indicators of } \\
\text { efficiency, trust, } \\
\text { management improvement, } \\
\text { contractual effectiveness } \\
\text { - Indicators of clarity of } \\
\text { Commission documents } \\
\text { addressing prospective } \\
\text { applicants and of extent of } \\
\text { absorption by applicants }\end{array}$ & 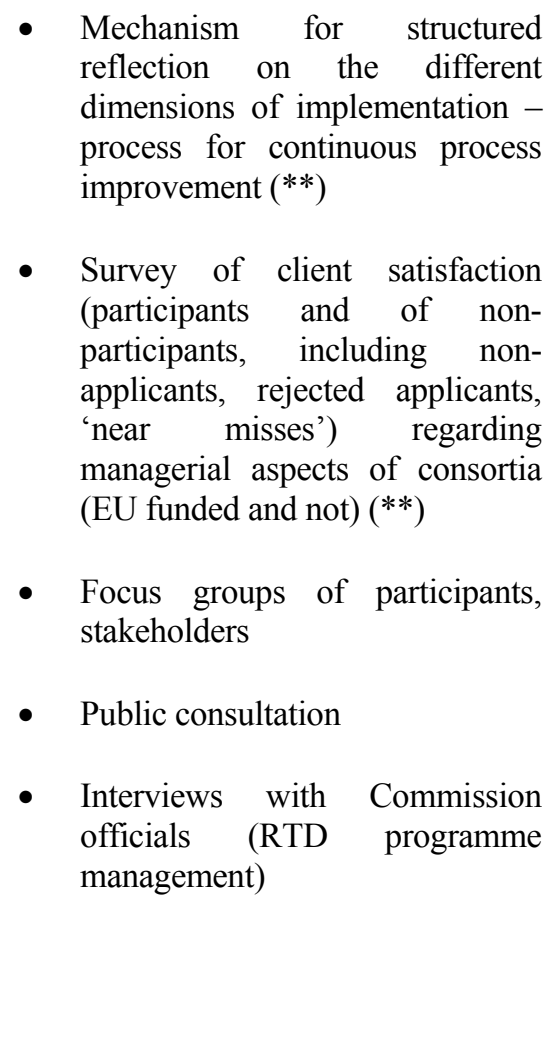 & \\
\hline
\end{tabular}


Table 5 (cont): CP: Evaluative Questions, Analytical Methodologies, Principal Indicators - Interim Evaluation FP7

\begin{tabular}{|c|c|c|c|c|}
\hline Evaluative Questions & Analytical Methodologies & Principal Indicators & Sources of Data & Timing \\
\hline $\begin{array}{l}\text { 3. Has there been progress towards } \\
\text { achieving the objectives set for the } \\
\text { IST-RTD Programme? }\end{array}$ & $\begin{array}{l}\text { - Case Studies at "Challenge", } \\
\text { SO, and consortium levels } \\
\text { (selectively) } \\
\text { - Network analysis } \\
\text { - Focus group reports } \\
\text { - Study on relative (and } \\
\text { changing) competitiveness of } \\
\text { private sector participants } \\
\text { - Study on market effects of IST } \\
\text { RTD }\end{array}$ & $\begin{array}{l}\text { - Importance of the IST RTD } \\
\text { programme for the } \\
\text { strategies of participants } \\
\text { - Progress towards } \\
\text { technology application, } \\
\text { deployment } \\
\text { - Creation, expansion, } \\
\text { maintenance of important } \\
\text { networks } \\
\text { - European knowledge hubs } \\
\text { at global level } \\
\text { - Competitiveness indicators } \\
\text { for private sector } \\
\text { - Indicators of ICT usage by } \\
\text { the public and private } \\
\text { sectors and by households }\end{array}$ & $\begin{array}{l}\text { - Annual Monitoring by the } \\
\text { Commission of IST-RTD } \\
\text { programmes } \\
\text { - Focus groups of industry, } \\
\text { stakeholders at "Challenge" or } \\
\text { SO level (participation of non } \\
\text { European experts highly } \\
\text { desirable) } \\
\text { - Interviews with Commission } \\
\text { officials (RTD programme } \\
\text { management) } \\
\text { European Competitiveness } \\
\text { Report }\end{array}$ & \\
\hline
\end{tabular}

* Extant data collection instrument: needs standardization, restructuring to produce simple, quantifiable, standardized information

** New data collection instrument: standardized 


\section{Highlighted Data Collection Instruments}

Table 5 stresses the role of four data self-reporting instruments that the Panel strongly advises the Commission to adopt. They include:

- The Annual Reports of RTD projects must be turned into a critical source of information. Regrettably, such annual self-reporting instruments as TIPs (FP5) and PUDKs (FP6) are unreliable and generally unusable for evaluative purposes. They have not been applied uniformly across programmes, and are based on open ended questions that invite a lot of prose from the respondents but little substance. Since replies are not standardized, use is quite limited. The Panel strongly recommends that the annual reporting system be overhauled as it provides a unique opportunity to garner information on the expectations, evolution, and outputs of projects. It can be standardized, with fixed choices for answers, and harmonized with other surveys (see below).

- An Entry Survey must be instituted, to be required by all programme participants at the initiation of their RTD projects. The survey instrument will be simple and will focus on the expectations of the respondents for the RTD project they are about to engage in. It is critical that the Entry Survey instrument is harmonized with the Annual Report and the Exit Survey instrument.

- An Exit Survey must be instituted, to be required by all programme participants at the completion of their RTD projects. The survey instrument will be simple and will focus on the effects of the project on the responding participant, the obtained or expected outputs, issues of management of the consortium, and impressions of the functioning of the programme. It is critical that the Exit Survey instrument is harmonized with the Annual Report and the Entry Survey instrument.

- Case Studies of individual participating organizations as well as of consortia focusing on incentives to participate in IST-RTD and on the management aspects of collaboration are expected to provide very valuable information.

It is worth pointing out here the differences between the Exit Survey and the Ex-post Participant Survey which has been typically carried out in the course of the 5-Year Assessment of the Framework Programme. The Ex-post Participant Survey differs from the Exit Survey in that the Expost survey is much more elaborate and extensive, addresses more strategic issues, is not required but reaches a carefully drawn sample of participants, and is coupled with a survey of "finalist" organizations that were not supported by the Commission. It is difficult to imagine what better instrument could be devised to collect detailed information on outputs and outcomes sometime after the end of an RTD project from participating organizations. These surveys have been greatly 
improved over the years and they are now able to handle particularly important features of the programme. By definition, however, they are tools suited to Ex-post evaluations. Both the Ex-post Survey and the Exit Survey suffer from the problem of scale up to the industry or technology level.

Finally, several points with respect to data collection and usage ought to be stressed. In the opinion of this Panel, these issues are imperative for conducting high quality, effective evaluations (ex ante, interim, ex post).

1. It is imperative to harmonize the various survey instruments distributed for FP evaluation exercises (and, thus IST-RTD) at two levels: (a) the unit of analysis and (b) the type of questions asked. These surveys include the Entry Survey, the Exit Survey, the Annual Reports, and the Ex-Post Survey.

2. It is imperative to harmonize the unit of analysis of the surveys mentioned previously with the unit of analysis of the Community Innovation Survey (CIS) which is administered regularly every three years across all EU Member States and beyond.

3. It is imperative to harmonize the unit of analysis of all these surveys mentioned above with the unit of analysis in the official statistical series of Member States.

4. As regional development aid such as the Structural Funds have engaged in activities relating to RTD, there is a need for the overseeing agencies to try to harmonize their record keeping with that of the European Commission.

\section{Simplification, Lessening of Burden to Programme Participants}

The Panel understands that there is a very pressing need to decrease the general complexity of the Framework Programme in terms of the application, legal, and reporting requirements that the participants must respond to. He address only the reporting requirements here.

In order to decrease duplication and survey fatigue by respondents, the survey instruments endorsed by the Commission must be institutionalized and communicated to project applicants during application, or even at the time of the call for proposals. The content of these surveys must be harmonized and simplified, taking into consideration also the Community Innovation Survey (CIS) which may be used in parallel for certain evaluative questions.

On the other hand, the collected data must be made available to qualified researchers under strict confidentiality agreements. (Guarded) Communication of the collected information among Commission Services should greatly decrease the need for duplicative ad hoc survey exercises. The Panel believes it is the ad hoc surveys that are haphazardly commissioned during the lifetime of the Framework Programme that are primarily responsible for the reported survey fatigue symptoms. The system of surveys laid out above can actually be less complicated than what already exists - 
based largely on the Ex-post survey and a large number of uncoordinated (ad hoc) surveys of programme participants - which results in a great waste of information and duplication.

\subsection{EVALUATING IST-RTD JOINT TECHNOLOGY INITIATIVES (JTIS)}

Joint Technology Initiatives are in a category by themselves. The definition provided in an earlier section implies that these are substantial, integrated efforts to place resources that assist industrial and academic research communities in specific technology fields to coordinate their research and tailor it to a common strategic research agenda, including research and development goals, time frames and action plans for technological advances that are relevant to industry and to society. The development, deployment and use of new technologies are important in JTIs as are the pooling of the required funding from the private sector, from the member states and from the Community under the overall leadership of industry. Only a small number of them are envisioned.

The single most difficult challenge in the evaluation of JTIs is the problem of "attribution". This is not a new issue in evaluation (Annex VI). But due to the multiplicity of sources of funding, the evaluators of JTIs will have a particularly hard time in deciphering/isolating the additional value that the Commission's funding and coordination provides.

The need for appraising portfolio effects, based on knowledge and network spillovers among participants and synergies among technology fields and markets, becomes very strong for JTIs. The delineation of the various kinds of synergies and spillovers becomes a core part of the evaluation. In the opinion of this Panel, the evaluation of the (few) IST JTIs must be handled differently than the more traditional CPs, requiring a new setup and teams of evaluators focusing on one JTI per time. Lessons can be learned from the evaluation of EUREKA "technology clusters".

Given the size and intended breadth of JTIs, however, it is considered that little more than describing their objectives and intended operational/organizational approach can be achieved at the time of this Interim Evaluation. Much more will be done in the Ex-post Evaluation of FP7 (2015).

\subsection{EVALUATING IST-RTD NETWORKS OF EXCELLENCE (NOES)}

Networks of Excellence are quite different instruments from CPs and JTIs. The largest differences are that NOEs: (a) concentrate on the maintenance and expansion of research networks; (b) they do not underwrite with own resources a whole lot of research; and (c) attract primarily (if not exclusively) universities and other research institutes rather than industry. NOEs are not focused on marketable outputs (products, services, processes).

The evaluation of NOEs will diverge significantly from the evaluation of all other instruments. It should focus on success in maintaining strong research communities, research cross-fertilization, and researcher networking. That is to say that the two strong elements of NOE evaluation will be a typical science benchmarking, on the one hand, and social network analysis (behavioural additionality), on the other. 
In the opinion of this Panel, the evaluation of NoEs must be handled differently than the more traditional CPs, requiring a new setup and teams of evaluators focusing on one NoE each time.

Again, given the relative size and intended breadth of NoEs, it is considered that little more than describing their objectives and intended operational/organizational approach can be achieved at the time of this Interim Evaluation. Much more can be done in the Ex-post Evaluation of FP7 (2015). 


\section{Ex-Post Evaluation IST RTD in FP7 (2015)}

The proposal of the Commission for the Seventh Framework Programme calls for an external evaluation concentrating on the Programme's rationale, implementation and achievements. This Expost Evaluation of FP7 will be carried out by external experts and will be completed by 2015 .

The evaluative questions would be formulated as follows in order to reflect the three foci of the evaluation:

1. Programme Rationale

- Objectives, rationale and intervention logic for the IST-RTD Programme

- Policy Mix / Portfolio

2. Programme Implementation

- Has the implementation of the Programme been satisfactory?

$\rightarrow$ Has the implementation of the Programme by the Commission been satisfactory and has it lessened the burden to the constituents?

$\rightarrow$ Were the activities carried out efficiently and were they cost effective?

$\rightarrow$ Did the activities constitute the best way of achieving the objectives set?

$\rightarrow$ Were the overall legal framework (including rules for participation and contracts), policy instruments and the modalities for implementation clear, appropriate and effective?

$\rightarrow$ Were the level of funding and other available resources adequate?

$\rightarrow$ Were the targeted industrial and research communities, including SMEs, able to respond appropriately?

3. Programme Achievements

- What have been the outcomes/outputs and early ${ }^{28}$ impacts of the IST-RTD Programme?

- Has the Programme affected the industrial organization and behaviour of individual players in the affected sectors? These could be reflected in:

$\rightarrow$ Achieving critical mass

$\rightarrow$ Inducing participants to activities that would not have been carried out without the Programme (input and behavioural additionality)

$\rightarrow$ Disseminating knowledge more efficiently

28 Commercial impacts of R\&D projects typically materialize some time after the completion of the research (if at all). An ex-post evaluation strategy should, therefore, include not only an assessment shortly after the completion of the Programme but also a more long-term follow up (e.g. some 7-10 Years later). 
$\rightarrow$ Integrating core organizations with more peripheral ones and integrating European organizations with global "knowledge hubs"

$\rightarrow$ Advancing regional innovativeness and entrepreneurship

$\rightarrow$ Advancing ERA

These evaluative questions drive the partial evaluative studies that should be commissioned in order to support the final evaluative report. In what follows we first address the set of supporting evaluative studies that will provide the necessary background analytical input to the Ex-Post Evaluation of IST-RTD in FP7. We start with Cooperative Projects and then discuss deviations from this funding scheme for NOEs and JTIs. The Chapter concludes with a brief discussion regarding the prioritization among the suggested supporting evaluative studies and the organization for the overall evaluation activity (Expert Panel).

\subsection{EVALUATING IST-RTD CPS}

Table 6 below focuses on the supporting studies for the Ex-Post Evaluation and presents a correspondence of the main evaluative questions with the appropriate analytical methodologies and respective principal indicators. 
Table 6: Evaluative Questions, Analytical Methodologies, Principal Indicators - Ex-Post Evaluation FP7

\begin{tabular}{|c|c|c|c|c|}
\hline Evaluative Questions & Analytical Methodologies & Principal Indicators & Sources of Data & Timing \\
\hline $\begin{array}{l}\text { 1. Objectives, rationale and } \\
\text { intervention logic for the IST- } \\
\text { RTD Programme }\end{array}$ & $\begin{array}{l}\text { - Partly overlapping with } \\
\text { impact question (\#4) } \\
\text { - Identification of market / } \\
\text { systemic failure as a } \\
\text { rationale for the intervention } \\
\text { - Logic chart analysis of the } \\
\text { relations between objectives, } \\
\text { and instruments } \\
\text { - Analysis of rationales from } \\
\text { national programmes from } \\
\text { countries } \\
\text { - individual and group) } \\
\text { interviews and case studies } \\
\text { - Study on relative (and } \\
\text { changing) competitive-ness } \\
\text { of private sector participants } \\
\text { Study on market effects of } \\
\text { IST RTD }\end{array}$ & $\begin{array}{l}\text { - Partly overlapping with impact } \\
\text { question (\#4) } \\
\text { - Importance of the IST RTD } \\
\text { programme for the strategies of } \\
\text { participants } \\
\text { - Progress towards technology } \\
\text { application, deployment } \\
\text { - Creation, } \\
\text { maintenance of important } \\
\text { networks } \\
\text { - European knowledge hubs at } \\
\text { global level } \\
\text { Competitiveness indicators for } \\
\text { private sector } \\
\text { Indicators of ICT usage by the } \\
\text { public and private sectors and } \\
\text { by households }\end{array}$ & 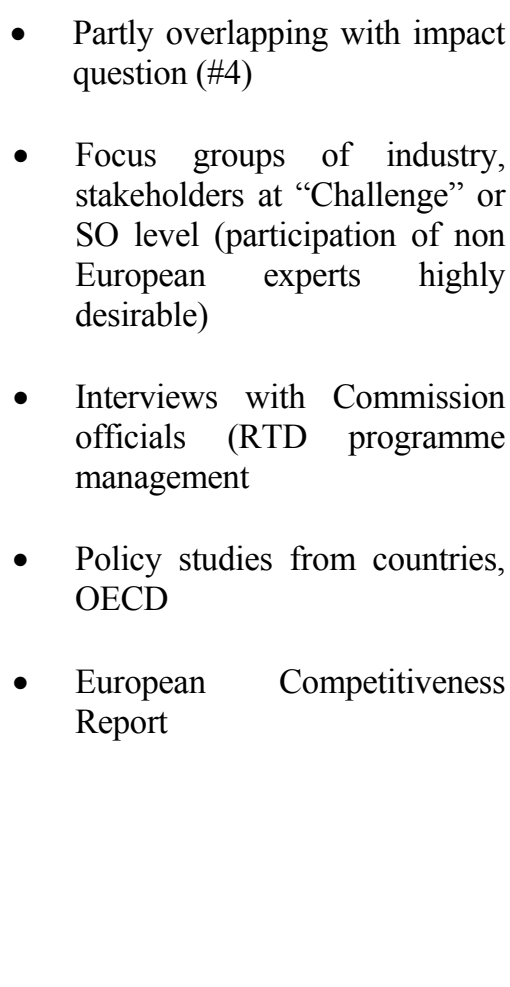 & \\
\hline 2. Policy Mix / Portfolio & $\begin{array}{l}\text { - Analysis of the } \\
\text { national/sectoral innovation } \\
\text { system }\end{array}$ & $\begin{array}{l}\text { - Qualitative analysis of policy } \\
\text { goals attached to individual } \\
\text { instruments } \\
\text { - Global context of IST RTD } \\
\text { policies vs diffusion oriented }\end{array}$ & $\begin{array}{l}\text { - } \text { Focus group interviews } \\
\text { - } \text { ISTAG } \\
\text { - CREST }\end{array}$ & \\
\hline
\end{tabular}




\begin{tabular}{|c|c|c|c|c|}
\hline Evaluative Questions & Analytical Methodologies & Principal Indicators & Sources of Data & Timing \\
\hline & $\begin{array}{l}\text { - Focus groups with } \\
\text { programme administrators, } \\
\text { policy makers (e.g. those } \\
\text { involved in i2010 } \\
\text { articulation) } \\
\text { - } \begin{array}{l}\text { Policy studies from member } \\
\text { countries }\end{array}\end{array}$ & policies & $\begin{array}{l}\text { - } \text { OECD ICT Outlook } \\
\text { - Trendchart, IST policies of } \\
\text { Member States }\end{array}$ & \\
\hline 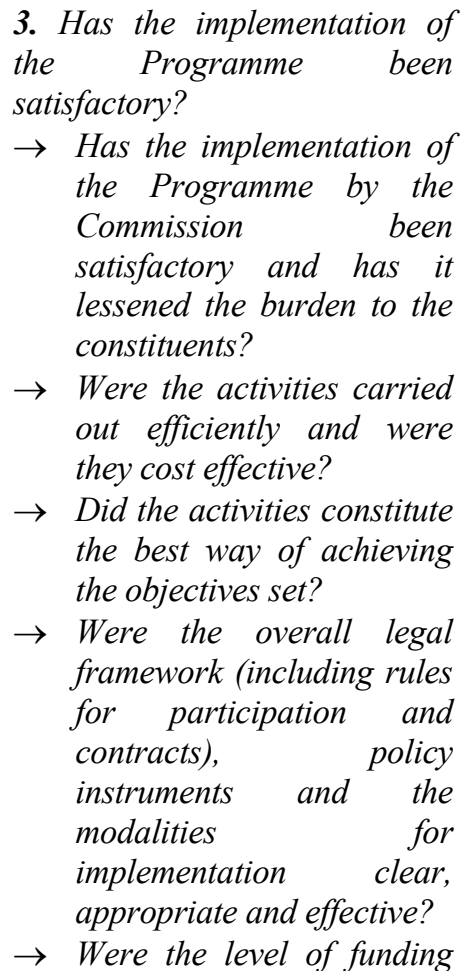 & $\begin{array}{l}\text { - Synthesis of information } \\
\text { from established mechanism } \\
\text { for structured reflection on } \\
\text { implementation dimensions } \\
\text { - Benchmarking r managerial } \\
\text { comparing otudy } \\
\text { aspects of EU-funded } \\
\text { consortia and other } \\
\text { collaborative RTD projects } \\
\text { - Study on appropriateness and } \\
\text { effectiveness of Funding } \\
\text { Schemes } \\
\text { CP Report } \\
\text { [Reports for JTIs, NoEs } \\
\text { necessary] } \\
\text { Expert Panel deliberations } \\
\text { and report }\end{array}$ & $\begin{array}{l}\text { - Administrative data on level of } \\
\text { overhead at programme and } \\
\text { project level, speed of } \\
\text { processing applications and } \\
\text { contracts, other bureaucratic } \\
\text { hurdles, etc } \\
\text { - Qualitative indicators of } \\
\text { efficiency, trust, management } \\
\text { improvement, contractual } \\
\text { effectiveness } \\
\text { - Indicators of clarity of } \\
\text { Commission } \\
\text { addressing documents } \\
\text { applicants and of extent of } \\
\text { absorption by applicants }\end{array}$ & $\begin{array}{l}\text { - Mechanism for structured } \\
\text { reflection on the different } \\
\text { dimensions of implementation } \\
\text { - process for continuous } \\
\text { process improvement } \\
\text { - Survey of client satisfaction } \\
\text { (participants and of non- } \\
\text { participants, including non- } \\
\text { applicants, rejected applicants, } \\
\text { 'near misses') regarding } \\
\text { managerial aspects of consortia } \\
\text { (EU funded and not) } \\
\text { - Focus groups of participants, } \\
\text { stakeholders } \\
\text { Public consultation } \\
\text { Interviews with Commission } \\
\text { officials (RTD programme } \\
\text { management) }\end{array}$ & \\
\hline
\end{tabular}




\begin{tabular}{|c|c|c|c|c|}
\hline Evaluative Questions & Analytical Methodologies & Principal Indicators & Sources of Data & Timing \\
\hline $\begin{array}{l}\text { and other available } \\
\text { resources adequate? } \\
\rightarrow \text { Were the targeted } \\
\text { industrial and research } \\
\text { communities, including } \\
\text { SMEs, able to respond } \\
\text { appropriately? }\end{array}$ & & & & \\
\hline $\begin{array}{l}\text { 4. What have been the } \\
\text { outcomes/outputs and early } \\
\text { impacts of the IST-RTD } \\
\text { Programme? }\end{array}$ & $\begin{array}{l}\text { - Surveys among participants - } \\
\text { but differentiated between } \\
\text { the SOs } \\
\text { - Case studies of } \\
\text { representative consortia, } \\
\text { organizations } \\
\text { - aggregative econometric } \\
\text { analyses as well as advanced } \\
\text { statistical analysis based on } \\
\text { combinations of publicly } \\
\text { available subjective data } \\
\text { (CIS) and increasingly } \\
\text { differentiated and } \\
\text { customized survey data. } \\
\text { - CBA and social CBA } \\
\text { for larger projects such as } \\
\text { selected IPs. (maybe also } \\
\text { NoEs) } \\
\text { market studies on industry } \\
\text { level and by technology } \\
\text { area }\end{array}$ & $\begin{array}{l}\text { - Indicators for scientific } \\
\text { achievements: } \\
\text { - Conference appearances, } \\
\text { conference proceedings } \\
\text { - Scientific papers, working } \\
\text { and published } \\
\text { - } \text { HR dimension (attracting } \\
\text { PhDs, leading scientists in } \\
\text { the programmes, etc } \\
\text { - Indicators for innovative } \\
\text { performance and innovation } \\
\text { capacity ("CIS indicators"): } \\
\text { - patents } \\
\text { - products at planning stage, } \\
\text { - prototypes, } \\
\text { - newly introduced products, } \\
\text { - turnover from these } \\
\text { products,(expected/realize } \\
\text { d),etc. } \\
\text { Indicators for broader impacts: } \\
\text { (measures of welfare effects): } \\
\text { - consumer and producer } \\
\text { - rents, spillover effects } \\
\text { - positive and negative }\end{array}$ & $\begin{array}{l}\text { - Project data (reporting and } \\
\text { monitoring) developed and } \\
\text { maintained by the Commission } \\
\text { - CIS } \\
\text { - Surveys among participants } \\
\text { - International statistics about } \\
\text { relevant markets and } \\
\text { technology areas }\end{array}$ & \\
\hline
\end{tabular}




\begin{tabular}{|c|c|c|c|c|}
\hline Evaluative Questions & Analytical Methodologies & Principal Indicators & Sources of Data & Timing \\
\hline & & $\begin{array}{ll} & \text { externalities, } \\
\text { - } & \text { WPA, WTA, } \\
\text { - } & \text { hedonic prices }\end{array}$ & & \\
\hline $\begin{array}{l}\text { 5. Has the Programme affected } \\
\text { the industrial organization and } \\
\text { behaviour of individual players } \\
\text { in the affected sectors? These } \\
\text { could be reflected in: } \\
\rightarrow \text { Achieving critical mass } \\
\rightarrow \text { Inducing participants to } \\
\text { activities that would not } \\
\text { have been carried out } \\
\text { without the Programme } \\
\text { (input and behavioural } \\
\text { additionality) } \\
\rightarrow \text { Disseminating knowledge } \\
\text { more efficiently } \\
\rightarrow \text { Integrating core } \\
\text { organizations with more } \\
\text { peripheral ones and } \\
\text { integrating European } \\
\text { organizations with global } \\
\text { "knowledge hubs" } \\
\rightarrow \text { Advancing regional } \\
\text { innovativeness and } \\
\text { entrepreneurship } \\
\text { Advancing ERA }\end{array}$ & 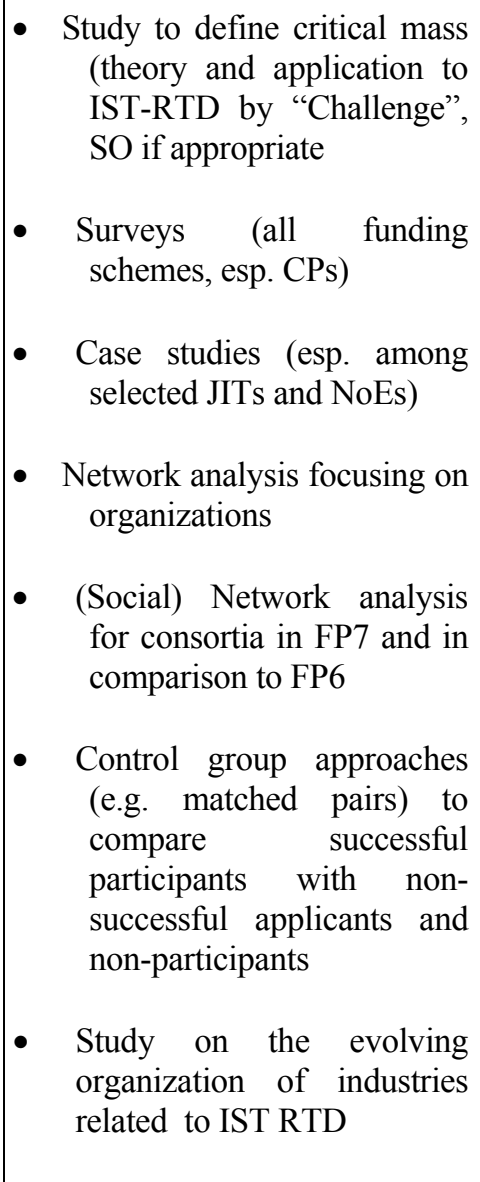 & 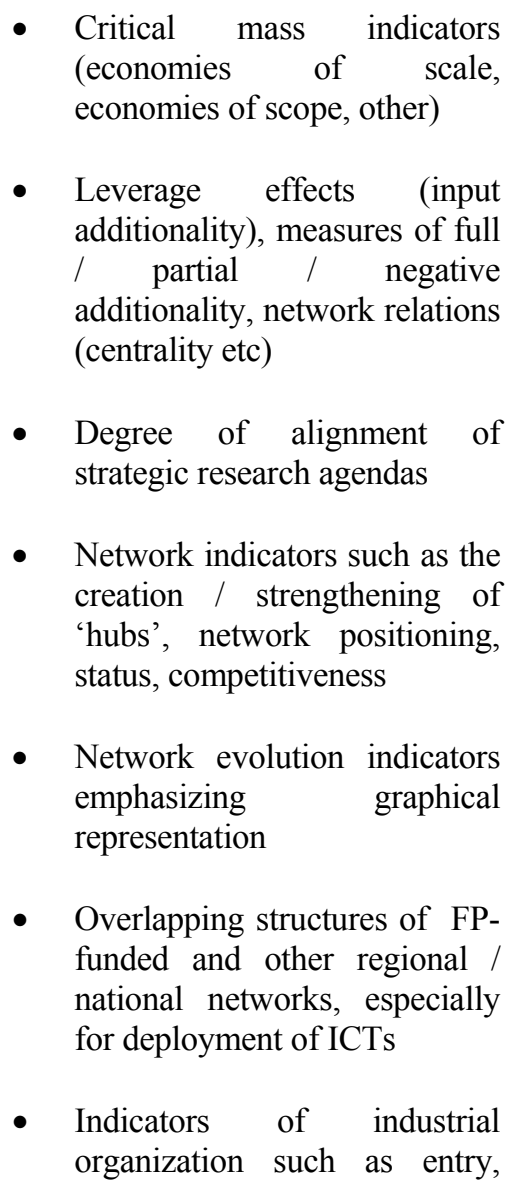 & 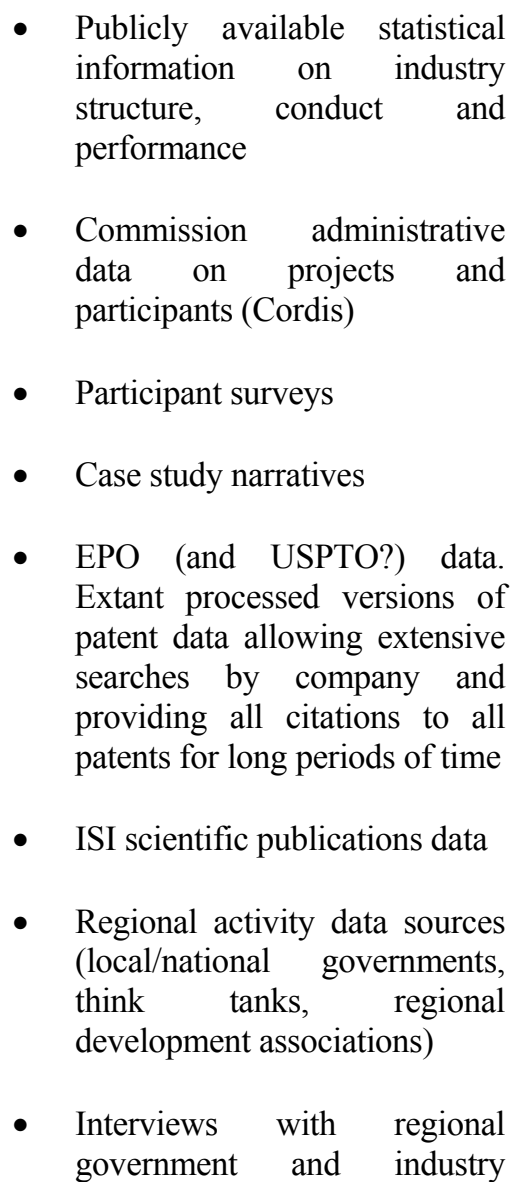 & \\
\hline
\end{tabular}




\begin{tabular}{|c|c|c|c|c|}
\hline Evaluative Questions & Analytical Methodologies & Principal Indicators & Sources of Data & Timing \\
\hline & $\begin{array}{llr}\text { - } & \begin{array}{l}\text { Comparative study on } \\
\text { regional innovativeness and } \\
\text { entrepreneurship }\end{array} \\
\text { - } & \begin{array}{l}\text { Progress report on } \\
\text { advancing ERA }\end{array}\end{array}$ & 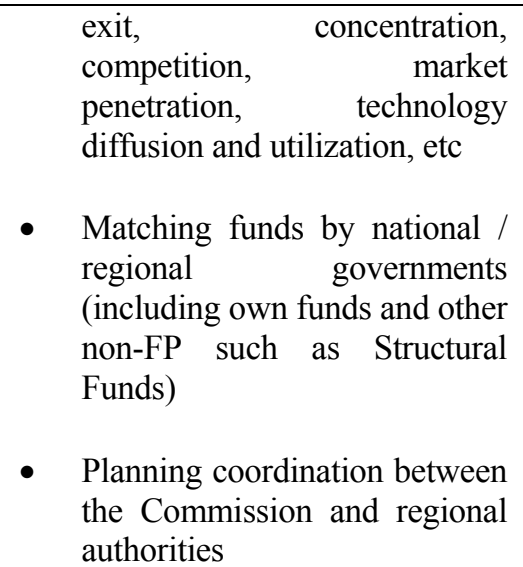 & leaders & \\
\hline
\end{tabular}




\subsection{EVALUATING IST RTD JOINT TECHNOLOGY INITIATIVES (JTIS)}

As also discussed in the Chapter on the Interim Evaluation of FP7, Joint Technology Initiatives are a special category of programmes. They are integrated efforts to place resources that assist industrial and academic research communities in specific technology fields to coordinate their research and tailor it to a common strategic research agenda relevant to industry and to society. The development, deployment and use of new technologies are important in JTIs as are the pooling of the required funding from the private sector, from the member states and from the Community under the overall leadership of industry.

The single most difficult challenge in the evaluation of JTIs is the problem of "attribution" (Annex VI). Due to the multiplicity of sources of funding, the evaluators of JTIs will have a particularly hard time in deciphering/isolating the additional value that the Commission's funding and coordination provides.

The need for appraising portfolio effects, based on knowledge and network spillovers among participants and synergies among technology fields and markets, becomes very strong for JTIs. The delineation of the various kinds of synergies and spillovers becomes a core part of the evaluation. In the opinion of this Panel, the evaluation of the (few) IST JTIs must be handled differently than the more traditional CPs, requiring a new setup and teams of evaluators focusing on one JTI per time. Lessons can be learned from the evaluation of EUREKA "technology clusters".

The size and intended breadth of ICT JTIs, as well as their projected small number (possibly only two), justify their evaluation separate from CPs and NoEs. The Ex-post evaluation of a JTI is currently envisioned as an extensive case study which, in addition to extensive description of the organizational structure, time evolution, and objectives, will be based on both quantitative and qualitative investigation. Empirical investigation will be of the form of cost-benefit analysis, social network analysis, and econometric analysis. Qualitative investigation will be based on structured interviews with key players and focus group approaches.

\subsection{EVALUATING IST RTD NETWORKS OF EXCELLENCE (NOES)}

Networks of Excellence are quite different instruments from CPs and JTIs. The largest differences are that NOEs: (a) concentrate on the maintenance and expansion of research networks; (b) they do not underwrite with own resources a whole lot of research; and (c) attract primarily (if not exclusively) universities and other research institutes rather than industry. NOEs are not focused on marketable outputs (products, services, processes).

The evaluation of NOEs will diverge significantly from the evaluation of all other instruments. It should focus on success in maintaining strong research communities, research cross-fertilization, and researcher networking. That is to say that the two strong elements of NOE evaluation will be a typical science benchmarking, on the one hand, and social network analysis (behavioural additionality), on the other. 
In the opinion of this Panel, the evaluation of NoEs must be handled differently than the more traditional CPs, requiring a new setup and teams of evaluators focusing on one NoE each time. That is to say, as in the case of JTIs, the evaluation of a single NoE is currently envisioned as an extensive case study. The difference with the JTIs, however, will be that in the case of NoEs, the case studies will be based on much more qualitative analysis drawing information from structured interviews with key individuals and organizations. The definition of a "key" node in the network will be determined by social network analysis which will probably be the only type of empirical investigation to be used to a great extent. The case will, of course, will contain extensive narrative to describe the organizational structure and objectives of the NoE.

\subsection{FINAL REPORT FOR EX-POST OF IST RTD IN FP7}

The final report will be the outcome of the deliberations of a high-level expert Panel whose members must be composed by technical and evaluation experts and experts in the areas of S\&T policy, strategy, and economic/business. A mixture of representatives from the ICT industries and academia is advised.

The deliberations of the Panel should be largely based on the evidence from the supporting studies outlined for the various funding instruments in the previous subsections. The Panel should also have available some resources to commission a limited number of studies according to the opinion of the Panel members.

The core evaluative questions for the Expert Panel can be delineated from the objectives of the ICT thematic priority in FP7 as enhanced by the objectives of the new Lisbon agenda and i2010, as well as potential follow-ups). A potential formulation is:

- What has been the overall contribution of IST-RTD towards achieving the overall objectives set for the ICT thematic priority in FP7 in terms of:

$\rightarrow$ Improving the competitiveness and productivity of European industry through ICT use

$\rightarrow$ Helping drive and stimulate innovation in Europe through ICT use

$\rightarrow$ Strengthening Europe's scientific and technological base in ICT

$\rightarrow$ Contributing to securing Europe's global leadership in ICT

$\rightarrow$ Helping achieve world-class performance in ICT RTD

$\rightarrow$ Modernizing public services

$\rightarrow$ Addressing key social challenges including health, ageing, and inclusion

$\rightarrow$ Closing the gap with Europe's leading competitors

Given the time needed to compile the extant and commission supplementary studies, and in view of the past experience with time constraints, it is advisable to install the Expert Panel immediately after the completion of the Programme in 1013. So constituted, the Panel members can meet once at the very beginning of their term to decide on the major axes of their work - for instance the core evaluative questions listed in the previous paragraph - and then meet once or twice per year at maximum to oversee progress with the continuing evaluation of the Programme. The Panel should 
assume its regular meetings 6-8 months before the deadline for the completion of the final Ex-post Evaluation report.

The Panel would start with an inventory of existing studies and could raise questions and communicate with current evaluation studies. Sub-groups of the panel could be given the task and the resources to carry out (individual or group) interviews with stakeholders. 


\section{Monitoring}

The Annual Monitoring of the IST RTD programme must continue in conformance with the mandate by the legal base of FP7. ${ }^{29}$ Annual Monitoring is an integral part of the overall evaluation of the programme to best meet public demands for transparency, accountability and costeffectiveness.

The Panel recognizes three main objectives for the Annual Monitoring exercise:

i. To appraise progress with respect to the work programme for the IST thematic priority and its specific programmes;

ii. To appraise the overall effectiveness and management of key aspects of the programme implementation and especially the Calls for research proposals, including the efficiency of the process of proposal evaluation and selection;

iii. To ensure the continuing collection of data as-you-go that will then feed into the Interim and Ex-Post Evaluations of the thematic priority.

A natural drawback of the annual monitoring of a multi-annual programme is that it limits the scope of the exercise and does not provide the full picture of the dynamics of the implementation process. The Annual Monitoring should, therefore, work as a complement to the Interim and Ex-Post Evaluations. Whereas the objective of the Ex-Post evaluation is to assist strategy and policy decision making, the main objective of the Annual Monitoring is to assist management do its job better and improve management processes. A core objective is also to make sure that reliable, structured, and usable quantitative and qualitative data is produced for these other forms of evaluations. The objectives of the Interim Evaluation are an amalgam of those of the Monitoring and of the Ex-post Evaluation.

\subsection{MONITORING APPROACHES}

There are essentially four approaches for programme monitoring the Commission can choose from:

1. New policy of annual monitoring currently being phased-in, based on the collection of a set of output and impact indicators.

2. Monitoring of the implementation of key processes, notably the calls for proposals and proposal selection.

29 "The Commission shall continually and systematically monitor the implementation of the Framework Programme and its Specific Programmes and regularly report and disseminate the results of this monitoring". European Commission (2006a): Amended proposal for a decision of the European Parliament and the Council concerning the 7th Framework Programme of the European Community for Research, Technological Development and Demonstration activities (2007-2013) [COM(2006)364]. 
3. Ad hoc monitoring exercises to appraise specific aspects of the Programme as the need arises.

4. Self-assessment as implemented until recently.

These four approaches are not mutually exclusive. We argue that a combination of the first three approaches is the most sensible to adopt. The last approach may be the least desired alternative as it has been proven over the years to have significant weaknesses and can be considered only with the important modifications that we suggest below.

\section{A. Monitoring through Universal Output and Impact Indicators ${ }^{30}$}

A first alternative consists of collecting longitudinal performance indicators as adopted in 2005 . These include two specific results (output) indicators of the supported ICT RTD and two broader outcome (impacts) indicators.

The currently adopted output indicators include:

- Number of patents, trademarks, registered design or other protected applications;

- Number of peer-reviewed publications authored by project participants

As indicated earlier in this report, an extensive literature has discussed the advantages and limitations of patent and publication counts. Refined versions have been discussed both in terms of quality - for instance, citation weighted - and in terms of inclusion - for instance, sensitizing the indicators to different publication patterns in different scientific fields and engineering. However, refinement may complicate analysis to an extent that may not be appropriate to an annual exercise and may be better left for approach \#3 discussed below.

Outcome (impact) indicators can be used to assess the performance of the supported IST RTD activities in terms of their long-term effects on the society or economy (impacts). They could include:

- World leadership improvement as a result of the project work; and

- Benefit to citizens.

These are composite indicators that will need better refinement for application. For example, "world economic and scientific leadership" could be indicated by increased market share, increased sales, increased exports, creation of new/improved products and services, issuing of new patents, publications, and so forth. Different indicators can also be used for capturing "benefit to citizens" -

30 Based on: European Commission, DG Information, Society and Media (2007): Monitoring of the ICT RTD Implementation: Output and Impact Indicators - Draft Terms of Reference; and discussions with Commission staff. 
essentially quality of life indicators - including the availability and use of new/improved products and services, working conditions, education, access to information, etc.

The collection of data for the output and impact indicators could either be done by the Evaluation Unit or by the IST RTD operation services. We would argue for the first option because (a) it reduces the administrative overheads for Project Officers and (b) ensures uniformity of collected data. Collection of data by the operation services would, on the one hand, allow Programme Offices to maintain their own explicit communication channel with the project co-ordinators but would, on the other, require the set up of very clear guidelines on the type of data to be collected and raise costs.

The processing of the resulting information must be done centrally, either internally by the Evaluation Unit or contracted out. The former solution is more appropriate for straight forward presentation of the results. For more involved analyses of specific issues the second solution is preferable. The latter also links to the third monitoring approach ( $\mathrm{ad}$ hoc exercises).

\section{B. Monitoring of the Implementation of Key Processes}

The most important process requiring continuous monitoring is the call and evaluation of research proposals. The project selection phase of each Call is a crucially important event - one that has dramatic bearing on the eventual success of a specific Call - and a phase that has invariably been subject to detailed evaluation. In recent years (throughout the period in which FP6 has been operational), the proposal evaluation and project selection phase of each Call has been accompanied by an independent evaluation that produces an 'External Evaluation' report. These reports focus on problems, bottlenecks and successes in proposal evaluation and project selection procedures and constitute a basis for the development of improved procedures.

This process has worked well and should continue. Moreover, with the launch of FP7, DG INFSO must review its evaluation processes to configure enhanced procedures and an even better coordinated proposal evaluation cycle. Key aims here are to ensure that (a) the process is simpler and more manageable for evaluators, (b) guidelines and criteria are clear and comprehensible, (c) training and systems are adequate for the task, and (d) the recruitment of appropriate and sufficiently experienced evaluators can be achieved without significant impediment.

The Evaluation Unit is already acting in this respect, keen to ensure that the process is reconfigured to reflect changed priorities, new and emerging concerns (of a social, economic and technological nature) and broader changes in the policy and operational environment in which the FP Calls will be realized. Among these shifting priorities and concerns, a number are worth noting here:

- There has been an increasing recognition that FPs will (and should) result in system level effects, i.e., the impacts of projects funded under the FPs will be seen in the shifting profiles of social and economic systems. However, such impacts will only become evident with the passage of time (perhaps ten years or more). Evaluation in previous FPs has been directed towards medium-term 'outcomes' from projects, e.g., development or diffusion of new technologies and applications, or emergence of networks of expertise. It can be argued that attention to such outcomes ought to be accompanied now with attention to longer-term or 
systemic impacts. In other words, in the forthcoming calls of FP7 proposals should be evaluated in terms of their potential to deliver longer-term, system-level impacts (as far as this is possible) in addition to outcomes that might appear in the medium-term.

- There has been an increasing recognition that the potential for producing change is much greater in research projects that are executed in combination compared to projects unfolding in isolation. Researchers have noted the existence of portfolio effects wherein the impacts of two or more projects overlap in a mutually reinforcing manner, leveraging positive outcomes that would not have been gained if projects had operated in isolation. Therefore, rather than reviewing project proposals solely in terms of their individual merits, an argument has been advanced to identify proposals that might interact and overlap, thus resulting in impacts beyond those anticipated from the operation of a single project.

- A debate has grown on the forms of impacts that should be sought from large-scale RTD programmes. Whilst much emphasis has been placed hitherto on outcomes/impacts for supply-side actors (i.e., technology producers), this notion has recently faced significant challenge. Consumers are now being placed centre-stage with attention focusing increasingly on the mechanisms whereby consumer desires/needs enter into the market development process. At the level of project selection, this implies that greater emphasis is placed on issues of demand and consumer needs and on the ways in which these needs are expressed and met via market mechanisms. In short, the 'technology push' orientation of project selection in previous rounds might usefully be complemented by a 'demand-pull' component.

- FP7 introduces a simplified and more straightforward set of funding schemes and a range of new elements (including Technology Platforms and Joint Technology Initiatives). It also introduces greater flexibility with respect to the operation of funding schemes. While this does not necessarily imply a radical break with the past, it does have implications for the proposal selection process and the application of selection criteria in relation to specific schemes and elements.

\section{Ad Hoc Monitoring Exercises}

A third approach consists of introducing ad hoc monitoring exercises for specific aspects of the Programme as called for by the rules for participation in the Programme. ${ }^{31}$ These aspects may be less mainstream or more innovative than usual and, therefore, need closer attention. For instance, these might include particular initiatives for dissemination of results, particular project management

\footnotetext{
31 Regulation (EC) No 1906/2006 of the European Parliament and of the Council (18/12/2006) laying down the rules for the participation of undertakings, research centres and universities in actions under the Seventh Framework Programme and for the dissemination of research results (2007-2013). See especially article 27.
} 
and reporting procedures, new funding facilities, activities linked to specific target groups (e.g., SMs), or particular financing or responsibility-sharing schemes within the programme.

The rationale for this type of evaluation would be to early pinpoint difficulties that might arise and enable corrective actions, analysis and adjustment of procedures. Independent experts or groups of experts could be appointed for carrying out these ad hoc evaluations. As these evaluations will concern issues of high interest and criticality, it is of utmost importance that they take place in an efficient and coherent manner across the $7^{\text {th }}$ Framework Programme, supported by an information system and clear templates for the monitoring exercise.

\section{Self-Assessment}

Self-assessments have been regularly carried out in the recent past by DG INFSO for programme monitoring purposes. The lessons from the independent examination of the most recent selfassessment exercise for the IST-RTD activities implemented in 2005 are pertinent to integrate here. Operating units prepared self assessments on the basis of a questionnaire addressing the following issues:

1. What were the main research objectives and activities in your service?

2. To what extent your service carried out activities contributing to:

- Identification of the needs for future ICT research;

- Preparation for the $7^{\text {th }}$ Framework Programme;

- Facilitation of the participation of organisations of particular interest and stimulation of the participation of new entrants;

- Effective project management (specifically: the effectiveness of the review and reporting arrangements);

- Strengthening the synergy (co-ordination, collaboration, integration) between the supported research activities and other public or private research efforts or other EU policy initiatives such as eEurope, CIP, etc.;

- Follow-up, dissemination and exploitation of the results of the previous Framework Programmes, notably of the $3^{\text {rd, }} 4^{\text {th }}$ and $5^{\text {th }}$;

- Enhancing the communication of results and raise awareness a) within the Programme itself and its stakeholders; b) to groups indirectly related with the IST Programme; and c) to the general media and public; and

- Considering key socio-economic issues such as gender issues and ethics.

3. What were the main successes and the underlying factors contributing to these successes? (recommendations sharing good practices)

4. What were the main constraints to progress towards objectives and the reasons behind these constraints? (lessons learnt and recommendations to addressing problems)

5. What is the evidential basis of the self-assessment? (quantitative information and data, results and impact indicators from project reviews and reports, etc.)

The independent evaluation of the resulting self-assessment reports offered a number of remarks: 
- Heterogeneity in the Unit self-assessments. A big challenge is the heterogeneity of the different Unit reports on the dimensions of structure, content, format and length. This makes the preparation of the synthesis at Directorate level, as well as the overall synthesis, very difficult tasks.

- Lack of formal benchmarking. It is difficult to actually judge the quantity and quality of projects as there are no formal benchmarking data given on, e.g., the number of projects running in total, their key objectives, their budgets and their time frame of running. The reports are mainly qualitative. Some standardized figures and indicators could also be useful to assess the activities more objectively.

- Lack of common understanding. The report format (questions listed above) is followed only loosely in the Unit reporting. This - together with the heterogeneity in the actual reports suggests that there is not a common understanding among the Units of the interest and role of the self-assessment. Some Units seem to treat it as a purely administrative exercise; others as a way to "showcase" what they have achieved; only few as an opportunity for a critical self-appraisal.

- No judging against objectives. The self-assessment reports look more like activity reports than assessment reports. For the different topics, the Units report on activities they conducted without critical review or benchmark. One difficulty to is that there is no indication of the initial objectives. If the objectives are not referred to, it is difficult to assess if what was conducted unfolded in the right direction or not.

The self-assessment approach has, thus, proven over the years to have significant weaknesses. If pursued to some extent in the future, the following improvements should be considered: ${ }^{32}$

- Structure, objectivity and comparability. Overall, the objective should be to make the evaluations more structured and comparable, more objective and detailed on specific issues.

- Formal analysis based on performance criteria. All projects should be formally and objectively analyzed on a grid of specific pre-defined performance criteria reflecting the issues considered to be important.

- Indicators. For each performance criteria defined, a number of quantifiable indicators should be defined in order to get a more objective and complete picture of all projects.

- Best practices. It might be useful to indicate, e.g., five best practice projects and five problematic projects - something like the top and bottom five - and provide an in-depth analysis of key success and key problem factors explaining the sort of these projects. This

32 For more details see: Papaconstantinou, G., Baudouin, P. (2006): Self-Assesment: IST Implementation 2005, Report, DG Information, Society and Media 
analysis could be more qualitative, as in a case study, and focus on cause-effect relationships and explanatory analysis.

\subsection{CONCLUSION}

Given the problems of self-assessment, the Panel considers a combination of the first three approaches to be the better way for arriving at a more effective and useful monitoring for the project evaluation exercise as a whole.

- Monitoring of longitudinal performance indicators enables collection of aggregated data on the key output and outcome indicators within and across programmes. This will produce an evolutionary picture of the developments and directions of changes emerging from the programmes, thus enabling the monitoring of progress towards the goals set.

- Monitoring of the implementation of key processes enables to control, evaluate and improve the critical processes of call for proposals, proposal evaluation and proposal selection. Besides monitoring the critical operational aspects of these processes (e.g., clarity, transparency, and effective use of expert panels), this exercise should emphasize the potential of projects to deliver longer-term, system-level impacts stemming from portfolio effects of related projects being executed in parallel, and a better than hitherto balance of technology push and market pull dynamics.

- Ad hoc monitoring studies, finally, enable rapid and/or more in-depth evaluation of particularly critical characteristics, aspects or procedures of specific programmes.

Taken together, these three approaches have the potential of making up a holistic and between complementary perspectives and procedures mutually supportive monitoring framework. 


\section{Progress Report and (Science) Quality Assessment $(2009,2011)$ [European Parliament]}

These two prospective reports to the Parliament immediately precede and immediately follow the scheduled mid-term evaluation of the Programme by the Commission (Chapter 5). They are supposed to focus on the progress of implementing the Programme and to assess the quality of the research supported by it. One can further imagine that the Parliament would emphasize its ability to comment on the appropriateness of the Programme's objectives and consider adjustments, if necessary. However, the main questions of these reports would probably not differ considerably from those of the mid-term evaluation of the Commission.

The supporting evaluation studies for the Interim Programme Evaluation of the Commission (Chapter 5) should be initiated at the start of 2009. It is only logical to consider that progress reports from these studies will also provide input to the first progress report for the Parliament. The Commission's Interim Programme Evaluation will provide basic input to the second progress report for the Parliament. 


\section{ANNEX I: Seventh Framework Programme - Structure and New Developments}

\section{THE BASIC IDEA BEHIND THE FRAMEWORK PROGRAMMES}

The Framework Programmes (FPs) have been the main financial tools through which the European Union supports research and development activities covering almost all scientific disciplines. The FP is proposed by the European Commission and adopted by Council and the European Parliament following a co-decision procedure. ${ }^{33}$

FPs have been implemented since 1984 and cover a period of five years with the last year of one FP and the first year of the following FP overlapping. The current FP6 will be running up to the end of 2006. The proposed FP7 is planned to run for seven years. It will be fully operational as of 1 January 2007 and will expire in 2013. It is designed to build on the achievements of its predecessor towards the creation of the European Research Area, and carry it further towards the development of the knowledge economy and society in Europe. The adoption of the work programmes and first calls is planned to take place in autumn.

In the Commission's amended proposals for FP7, it was proposed that the maximum overall amount for Community financial participation in the EC Seventh Framework Programme should be EUR 50521 million for the period 2007 - 2013. In the preparation of the present proposals, the Commission took into account the views expressed during a very broad consultation with other EU institutions, as well as by the scientific community, industry. The proposals also rely on an impact assessment which was based upon inputs from stakeholders, internal and external evaluation and other studies, and contributions from recognized European evaluation and impact assessment experts.

While building on the achievements of its predecessor, the Seventh Framework Programme will not be "just another Framework Programme". In its content, organization, implementation modes and management tools, it is designed as a key contribution to the re-launched Lisbon strategy. Key underlying features of FP7 include the following:

- Emphasis on research themes rather than on "instruments"

- Significant simplification of its operation

- Focus on developing research that meets the needs of European industry, through the work of Technology Platforms and the new Joint Technology Initiatives

- Establishment of a European Research Council, funding the best of European science

- Integration of International cooperation in all four programmes

- Development of Regions of Knowledge

- A Risk-Sharing Finance Facility aimed at fostering private investment in research

33 Annex II lists the policies that have underlined the debate over the Seventh Framework Programme. 


\section{BASIC STRUCTURE AND THEMES OF THE FP7}

The proposed Seventh Framework Programme will be organized in four programmes corresponding to four basic components of European research:

\section{Cooperation}

Support will be given to the whole range of research activities carried out in trans-national cooperation, from collaborative projects and networks to the coordination of national research programmes. International cooperation between the EU and third countries is an integral part of this action. The action is industry-driven and organized in four sub-programmes:

- Collaborative research will constitute the bulk and the core of EU research funding

- Joint Technology Initiatives will mainly be created on the basis of the work undertaken by the European Technology Platforms

- Coordination of non-Community research programmes

- International Cooperation

\section{Ideas}

This programme will enhance the dynamism, creativity and excellence of European research at the frontier of knowledge in all scientific and technological fields, including engineering, socioeconomic sciences and the humanities. This action will be overseen by a European Research Council

\section{People}

Quantitative and qualitative strengthening of human resources in research and technology in Europe by putting into place a coherent set of Marie Curie actions.

\section{Capacities}

The objective of this action is to support research infrastructures, research for the benefit of SMEs and the research potential of European regions (Regions of Knowledge) as well as to stimulate the realization of the full research potential (Convergence Regions) of the enlarged Union and build an effective and democratic European Knowledge society.

Each of these programmes will be the subject of a Specific Programme. In addition, there will be a Specific Programme for the Joint Research Centre (non-nuclear activities) and one for Euratom nuclear research and training activities.

FP7 presents strong elements of continuity with its predecessor, mainly as regards the themes which are covered in the Cooperation programme. The themes identified for this programme correspond to major fields in the progress of knowledge and technology, where research must be supported and strengthened to address European social, economic, environmental and industrial challenges. The overarching aim is to contribute to sustainable development. 
The nine high level thematic areas proposed for EU action are the following:

- Health

- Food, agriculture and biotechnology

- Information and communication technologies

- Nanosciences, nanotechnologies, materials and new production technologies

- Energy

- Environment (including climate change)

- Transport (including aeronautics)

- Socio-economic sciences and the humanities

- $\quad$ Security and Space

\section{EUROPEAN TECHNOLOGY PLATFORMS AND JOINT TECHNOLOGY INITIATIVES}

Of the new elements the most interesting and challenging for IST in particular are the Technology Platforms (ETP) and the new Joint Technology Initiatives (JTI). ETPs adopt a long standing, familiar approach commonly used in the ICT domain as most major European successes are the result of partnerships and consensus building exercise between industry and academia. This is how Europe built its industrial strengths in areas such as mobile communications and several areas of microelectronics.

European Technology Platforms help industrial and academic research communities in specific technology fields to coordinate their research and tailor it to a common strategic research agenda (SRA), which sets out research and development goals, time frames and action plans for technological advances that are relevant to industry and society. SRAs typically seek to overcome barriers to the development, deployment and use of new technologies. Examples of such barriers might include how research is organized, outdated regulations, lack of common technical standards or a need for new ones, shortfall in funding, disinclination to accept new technologies, or a shortage of skills and training.

The European technology platforms are research policy cooperation actions, which pave the way for larger European technology initiatives based on private-public partnerships. The ETPs are industrydriven. They are expected to lead to greater certainty in planning and larger involvement and commitment of industry. However, also national and European public authorities, research organisations, the academia and the financial sector are encouraged to participate.

The implementation of the European Technology Platforms will involve using many different funding sources at the European and EU Member State level. The parts of the SRAs that are found to be relevant for the EU can be funded through the Framework Programme. To this end, the thematic priorities of the FP7 have partly been shaped by the SRAs. The majority of EU funding will be allocated through the regular funding instruments of the Framework Programme. 
Currently, there are in total twenty eight ETPs recognised by the European Commission. ${ }^{34}$ The number of ETPs proposed by the European industry is somewhat higher. So far, eight ETPs have been launched in the ICT domain:

- $\quad$ ENIAC - European Nanoelectronics Initiative Advisory Council

- ARTEMIS - Advanced Research and Technology for Embedded Intelligence and Systems

- NESSI - Networked European Software and Services Initiative

- NEM - Networked and Electronic Media European Technology Platform

- eMobility - Mobile and Wireless Communications Technology Platform

- EUROP - European Robotics Platform

- Photonics 21 - Photonics for the $21^{\text {st }}$ Century

- ISI - The Integral Satcom Initiative

The ETP concept shares many similarities with the EUREKA clusters, including the bottom-up operating principle, the important role of the industrial sector, and the use of road mapping techniques to achieve a common research agenda. In most areas also many of the key participants are involved in both cooperation platforms, including the representatives of the national financing organisations. In relation to ETPs, EUREKA can be seen as one of the mechanisms through which parts of the SRAs produced by the ETPs can be implemented.

For large-scale initiatives, for which the regular instruments are insufficient, it is possible to establish a dedicated legal structure, a Joint Technology Initiative, on the basis of Article 171. JTI is a new instrument to be introduced in the FP7 with a specific role: to implement a programme of research in its specific technological area.

The basic idea behind JTIs is that they will allow to pool together funding from the private sector, from the member states and from the Community to support the relevant ETP's research agendas. They will facilitate the cooperation between all stakeholders in order to improve Europe's competitive position and respond to Europe's societal needs.

At the time of this writing, the European Commission had initially recognised six areas where parts of the SRA could be implemented through a JTI. The details of their implementation were, however, yet undecided. Candidates for JTIs were:

- Aeronautics and Air Transport (ACARE)

- Advanced Research and Technology for Embedded Intelligence and Systems

- (ARTEMIS)

- Global Monitoring for Environment and Security (GMES)

- Hydrogen and Fuel Cells

- Innovative Medicines for Europe (IMI)

- European Nanoelectronics Initiative Advisory Council (ENIAC)

34 CORDIS: European Technology Platforms. 
Two of these areas are most relevant to IST: ARTEMIS, which focuses on embedded systems, and ENIAC21, which focuses on nanoelectronics. Overall, it appears that the JTIs can be seen as parallel cooperation platforms in relation to EUREKA clusters. The distinguishing factor between RTD carried out in EUREKA vis-à-vis research efforts in the Framework Programme has usually been 'distance to market'. It appears that this does not, however, apply to the relationship between the proposed JTIs and EUREKA clusters .RTD carried out under EUREKA clusters has a more long-term orientation than individual EUREKA projects. The technological focus of the JTIs does not seem to differ significantly from that of the EUREKA clusters.

In the long term there seems to be a need for only one such cooperation platform at the European level, which may lead either to the decline of one of the platforms or a merging of the two. Both platforms appear to have advantages and disadvantages: EUREKA clusters have demonstrated their viability and continuity as industry-led, bottom-up instruments but they lack central public financing. On the other hand, JTIs propose to provide coordinated financing from national sources with a top-up from the European Commission but involve many uncertainties regarding their management and administrative structures.

Regarding our concentration in this report, it is important to realize that the new (JTI), or newer (IP, NOE), instruments of the Framework Programme are significantly different than the typical funding instruments of the past (STRePs, SSAs, CAs) to require new thinking in terms of evaluation especially as it relates to portfolio effects. The evaluation of some of these instruments may also borrow from the evaluation of related EUREKA instruments. 


\section{ANNEX II: Policy Developments Impacting Upon IST in the Seventh Framework Programme}

- 2000 Lisbon European Council set goal of becoming by 2010

- "the most competitive and dynamic knowledge-based economy in the world, capable of sustainable economic growth with more and better jobs and greater social cohesion"

- 2002 Barcelona European Council, reviewing progress towards Lisbon goal

- agreed that investment in European RTD must be increased with the aim of approaching $3 \%$ of GDP by 2010

- also called for an increase of the level of business funding to two-thirds of total RTD investment

- 2004 Wim Kok group reviewed progress

- "disappointing delivery" is due to "an overloaded agenda, poor co-ordination and conflicting priorities". Main blame lack of political will by the member states

- 2005 Spring Council re-launches Lisbon Strategy

- More focus on growth and employment, simplification and national ownership via national action plan

- 2006 Aho Group Report on Creating an Innovative Europe commissioned by Council

- argues that Lisbon Strategy will fail without a broad integrated approach including demand side policies to create a market friendly to innovation, investment in research and innovation and accompanying structural and social changes

- Insufficient application of ICT is major drag on productivity growth

- 2006 ICT Competitiveness Task Force of industry leaders plus

- Remit to identify barriers to competition and competitiveness of ICT sector 


\section{ANNEX III: Justification of Public Funding of RTD}

\section{JUSTIFICATION OF GOVERNMENT INTERVENTION}

Public support for research and technological development (RTD) has been justified by economists on the basis of market failures and system failures.

The first clear rationale for a public role due to market failures was clearly articulated in the 1950s and 1960s. Richard Nelson, for example, argued that the social returns to research investment exceeded the private returns accruing to the individual firm undertaking the investment. In other words, scientific and technical knowledge were said to posses a public good dimension due to externalities: the benefits from advancements in science and technology spill over to other firms and to consumers. Spillovers increase dramatically as we move from the more applied to the more basic types of research. As a result, the private sector could be expected to underinvest in scientific research, necessitating the addition of public investment to achieve a socially optimal level of research activity.

In addition to imperfect appropriability of RTD benefits, market failure was argued by Kenneth Arrow to be the result of the uncertainties associated with RTD investment and innovation more generally, including both technical and market uncertainty. Such uncertainties can only be partly insured - as when, for example, an innovative company sells stock, thus, spreading the risk among multiple owners. Finally, market failure can also be the result of factor indivisibilities - certain investments can only be undertaken above a certain scale - and information asymmetries between the various stakeholders.

These traditional economic rationales for public support of RTD have, more recently, been supplemented by newer approaches coming from evolutionary and institutional economics, the theory of complexity, and the study of innovation systems. These approaches have focused on system failures due to technological complexity and more general systemic complexity involved in scientific and technological advancements and their market application. For example, one line of argument, associated with the work of Brian Arthur and Paul David, suggests that the economies of scale realized by firms that are first to introduce a new technology may result in a "lock-in" of the initial technological trajectory, which may dominate even though alternative paths of technological developments might be more efficient. A second line of argument emphasizes the institutional constraints on the utilization and diffusion of knowledge. In this view, it is insufficient for the government to support the generation of new knowledge and technology. Greater weight should be given to more effective institutional arrangements for the transfer of technology. As a result of the systemic nature of innovation, there are many feedback loops between the various stages of innovation process. Institutional relationships and the flows of knowledge between actors in the system are of critical importance. The innovative performance of a country/region is argued to depend upon the development of a balanced system of knowledge production and distribution. Government intervention is thus justified to avoid coordination and institutional failures that may occur. The role of the government is also related to the necessary investments in human capital and in mechanisms to intensify the flows and absorption of knowledge. 
Basic research, in particular, can be considered as an input that enhances the productivity of applied research and technology development. If applied research can be thought of as a process of sampling from a distribution of potential processes or products, basic research can be thought of as expanding the distribution of attributes within which the sampling occurs. By expanding the distribution basic research raises the probability of discovering technically and economically viable research outcomes and of reducing the cost of the research process. Basic research can be viewed as enhancing the productivity of scientific effort in closely related fields and of applied research and technology development.

On the supply side, the systems approach argument for policy intervention can be summarized as follows. A major challenge today is the complexity of modern technology. Most important technologies, including information and communication technologies (ICT), are essentially systems of components that must work efficiently together. The components themselves are often based on scientific knowledge from several disciplines. Industry has found the development of such technological systems increasingly challenging. Several barriers to attaining long-term competitive advantage have emerged:

- An increased segmentation of RTD across industries making up the various supply chains results in private sector RTD that is more specific and less coordinated. This implies a failure to capture both economies of scale and scope, with a major consequence being underinvestment in new, broadly applicable technology platforms.

- Private sector investment is pushed forward in the RTD cycle, resulting in the magnification of traditional funding gaps found in the early phases of RTD.

- More pronounced private sector underinvestment in a range of critical technical infrastructure and standards.

Moreover, the issue of investment timing has gained attention in an era of shrinking technology lifecycles. Technologies appear, mature, and become obsolete in a series of evolutionary phases, which greatly affect RTD decisions. Thus, an important economic factor is the timing of RTD investments relative to the evolution of a technology. The timing issue has two dimensions: investment decisions directed at attaining market share within a technology's life cycle and those focused on making the transition between life cycles.

As the market for a product technology expands and this technology is integrated into larger systems, successive improvements in both design and process technologies increase total market value, standardize production processes, dominant designs emerge, and a subset of firms that have participated in this market come to dominate. Eventually, opportunities to apply the underlying or generic technology decline and the product's structure takes on a commodity character (e.g., personal computer). Competition shifts to efficiency in production processes and hence to price and service as increasingly important determinants of market performance.

This process disadvantages high-cost, developed economies. Sustained economic growth, then, requires not only constant attention to competitive factors over a life cycle, it demands advance planning for access to the next generation technology. This transition between two generic technology life cycles presents a different set of competitive threats and policy complications. The 
greater the differences between two generations of a technology are, the greater the investment risk for individual companies and entire industries. Transitions to new technology life cycles typically demand different sets of research skills than those of existing firms. Hence, these firms tend to assign higher technical and market risk valuations to the prospective research program, with the result that necessary investments are postponed. ${ }^{35}$

Figure A1. Transition Between Two Technology Life Cycles

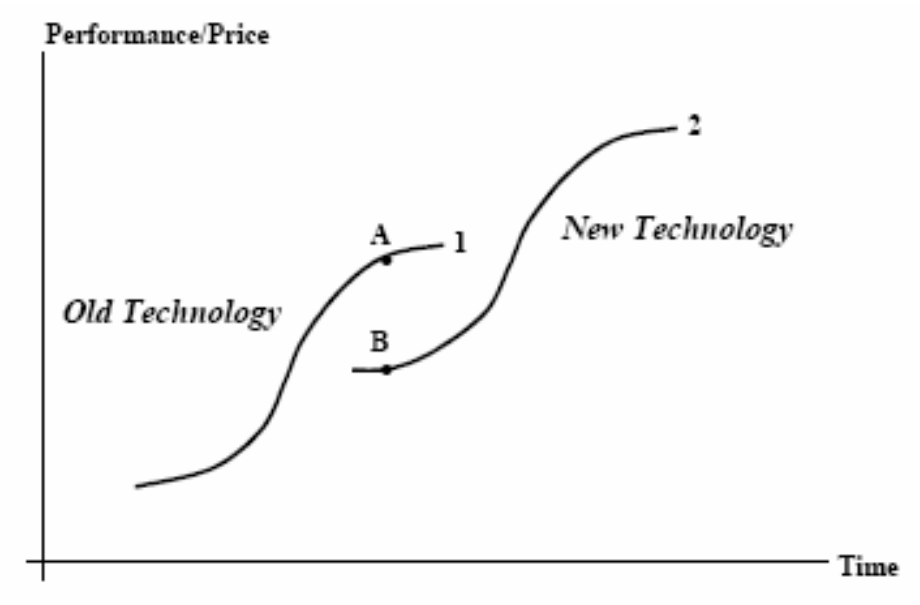

Source: G. Tassey, The Economics of R\&ED Policy, Quorum Books, 1997, Chap. 7

Figure A1 provides an illustration. A company appraising the risk of investing in the new technology faces a projected potential performance pattern such as curve 2. Initially, the performance of the new technology (especially relative to cost and hence the price charged) is often below that of the defender technology represented by curve 1 (compare points A and B). The probability of lower technical or economic performance, possibly for some time, adds to the risk associated with the dynamics of the marketplace. ${ }^{36}$

The above arguments on the technology life cycle raise two key policy concerns related to the role of government in facilitating efficiency within life cycles and facilitating the critical transitions between cycles. First, within a life cycle, the amount and speed of technological advance achieved by a domestic industry over a technology's economic life is critical, because such gains in performance determine economic returns. Second, transitioning between technology life cycles is an even more difficult issue. A number of high-tech companies manage transitions among successive product life cycles effectively. However, the transition to a radically new generic technology disruptive technology - is infrequently achieved by firms championing the defender technology. Most of these companies lose out to new companies. This process of "creative destruction" should

35 This enhances the dominant firms' tendency to avoid jeopardizing profitable production lines in the prevailing technology life cycle.

36 In addition, as Nathan Rosenberg has eloquently argued, the defenders of the old technology seldom give up without a fight, meaning that curve 1 may become steeper under intense competition. This further compounds the innovator's risk and has accounted for several new technology failures in the past. 
only be a problem for policy makers if the new industry players reside outside the domestic economy, implying a loss of value added (jobs and profits). In addition, changes in competitive dynamics are altering the reward/risk ratio for RTD investments within and between technology life cycles. As lifecycles compress, RTD at the company level can no longer exist in isolation of a supporting network.

\section{EUROPEAN VALUE ADDED}

EU RTD funding is justified when it can produce value over and above that which could be achieved through regional or national programmes. European added value (EAV) can be manifested in four principal ways:

- Pooling and leveraging resources. As discussed above, important RTD activities are often of such a scale and complexity that no member state can provide the necessary financial or personnel resources. They need to be carried out at the EU level in order to achieve the required minimum critical mass. Economies of scale and scope are increasingly important. EU RTD funding can, thus, increases the social return of the expenditure.

- Integrating European RTD for pan-European policy challenges. Issues such as the environment, climate change, health, and food safety can be handled more effectively at the EU level. EU funding could exercise a catalytic effect in terms of coordination of national initiatives in areas of common interest among member states. Again, enhanced social benefit is the result.

- Developing human capital and promoting mobility. There are strong arguments in favor of the number and quality of the human research pool through training, mobility, career enhancement, and competition at European level. National schemes have not played a strong role in promoting transnational actions of this kind. FP activities have emerged as the primary driver. Such actions underpin the development of a genuine European research labor market.

- Speeding up knowledge dissemination. EU research can be instrumental in transferring skills and knowledge across national/regional frontiers.

National-level studies of the Framework Programme have reported various sources of EAV including the augmentation of national RTD funds for research infrastructures, pooling of resources to raise RTD investment on Europe-wide issues, access to foreign resources and capabilities, facilitation of international mobility of researchers, and support to EU policy such as regulation and health issues. These fall pretty much in the categories above. 
Regarding our concentration in this report, future evaluations of the IST-RTD activities must, then, reflect an overall underlying concern for the justification of public intervention at the EU level on the basis of: ${ }^{37}$

- Investment in RTD where the "public/social return" is greater than the "private return" to the researchers or technology developers;

- Investment in "technology pillars", or "integrated systems", where there is a need for harmonization within the EU (or global) markets (notably for infrastructure technologies), or where the critical mass can be assured only at the EU level;

- Investment in emerging technology development before the market potential is clear but where the potential for EU-wide application is substantial and of strategic importance.

37 European Commission, DG Information, Society and Media (2006): Evaluating the Impact of IST RTD - Intervention Logic, Evaluation and Monitoring, Notes for a meting with the European Court of Auditors. 


\section{ANNEX IV: Logic Modeling as an Evaluation Framework}

Logic modeling is one approach in the challenge to link the broader policy objectives with the programme's diverse range of effects. The normal role for a logic model in evaluation is to map the sequence of activities that define a programme. The structures vary, but almost always set out the linkage between a programme's activities and outputs, outcomes or impacts in the short, medium and long term. Before the activities begin, the initial components of the model sometimes emphasize inputs and resources, and sometimes objectives, potentially at multiple levels. Overall the model sets out the "theory" or assumptions underpinning a programme.

In almost all cases the model is presented as visualization. As an ex ante evaluation tool it can provide a common ground for stakeholders to agree on what is intended, and what kind of road map exists for them to try to follow. In this respect it is a communication tool. More often, evaluators need to reconstruct the programme logic or theory in retrospect. ${ }^{38}$

\section{SKETCHING AN ALTERNATIVE APPROACH}

Many logic model approaches have a tendency to generalize causality, leaving linkages as something implied by positioning on a particular level, rather than exploring specific connections and the mechanisms that underpin them. The approach set out in Figure 1 (Chapter 1) emphasizes such connections, in the context of constructing intervention logic for the Information Society and Technology theme in the European Commission's Seventh Framework Programme.

\section{HORIZONTAL, VERTICAL AND SYSTEMIC LOGIC}

There are three different logics implicit in Figure 1:

- Horizontal logic: exploring interdependency between high-level objectives or between intermediate-level actions (i.e., the proposals for FP7).

- Vertical logic: exploring interdependency between an objective and the relevant parts of FP7. These linkages can be isolated as binary links, or could be considered in terms of which aspects of a programme impact a selected objective, or conversely, which objectives are affected by a single programme activity.

- Systemic logic: considering the implications of change across the whole system.

How then to proceed? Putting aside for the moment the need for an overview, the way forward is to examine elements of the system in isolation, allowing more detailed arguments to be developed.

38 Leeuw, F.L. (2003): Reconstructing Program Theories: Methods Available and Problems to be Solved, in: American Journal of Evaluation, Vol. 24, No. 1, pp. 5-20 
Let us explore some specific vertical, binary links in more detail. A pair of such links connects first the ICT Technology Pillars research activity to the objective of increasing RTD in firms, and then, these firms to the high-level growth objective. The overall Lisbon strategy sees increased RTD as a necessary condition for growth, making business more innovative and productive. Within ICT Technology Pillars (bottom left Figure 1), the principal FP7 activity is sponsorship of "precompetitive" collaborative RTD.

We need to know the rationales for these linkages. The stated rationale for spending public resources on this research is twofold:

- "European industry lags in investment in comparison with major competitors";

- "More intensive cooperation makes the most out of current capabilities".

This rationale links to broader economic arguments in favour of public support for cooperative research (see also Annex III). One is the well-known "market failure" rationale, tracing back to Arrow's work ${ }^{39}$, which sees knowledge as a non-rival, non-excludable public good; firms underinvest in a situation where social return justifies investment, but the private return does not. Information asymmetries, and the uncertainty of RTD and innovation investment, complete the argument in favour of public support.

Another rationale, "system failure", rests upon the need to create technological opportunities through support for basic research, and then to correct gaps or errors in the innovation system (such as sectoral lock-ins to the wrong technologies), while providing infrastructure to correct institutional gaps (for example, via the formation of cooperative networks, or supplying the necessary coordination for standards-setting ${ }^{40}$ ). A third, more specific rationale lies in the concept of "European Added Value", which is used to justify why an action should be taken at the European rather than national or regional levels.

For the case of industrial RTD, the sequence of rationales is that a European programme should incentivise the organization of consortia that have sufficient critical mass and complementary skills to achieve their technological and market goals. This in turn will leverage private support and create technologies in the context of a wider pool of eventual users/markets, thereby increasing the eventual return on RTD - and with it, incentives for investors. Furthermore, the programme may create technologies relevant to European-level social issues (such as the environment), and once again generate an incentive for investments aimed at a larger market. A further effect may be to spread RTD capabilities (through more and better trained people in more countries/firms).

Application of these ideas to the linkage of ICT Technology Pillars research activity with RTD in firms, and of firms to the European growth objective, allows the construction of a specific logic

39 Arrow, K., (1962): Economic welfare and the allocation of resources for invention, in: Nelson, R. (ed): The Rate and Direction of Inventive Activity

40 Smith, K. (2000): Innovation as a Systemic Phenomenon: Rethinking the Role of Policy. Enterprise and Innovation Management Studies, Vol.1, No.1, pp. 73-102. 
model, shown in Figure A2. The model tells us that by following through on the instrument of collaborative projects, we might reasonably expect certain short-term results. One will be the formation of new consortia. Companies will have to invest their own resources, as there is a matching funding requirement. Researchers will be hired (or redeployed), and it may be the case that participants are attracted to work in new technology areas. At the end of the project, intermediate effects may be evident. New technologies may lead firms into new markets, employed researchers will have acquired new skills, and a set of outputs will have been produced. The assumption is that increased sales and cost reductions will increase the rate of return on RTD in this area, and hence motivate firms to increase RTD. We see a direct effect of matching funding, and a possible effect arising from a supply of trained researchers.

There is thus a clear logical path between the policy instrument and the goal. The empirical task for the evaluation is to establish whether and how well this implementation path was followed. Each of the "boxes" in the chart represents a possible area for measurement.

Figure A2: Logic chart of expected impacts and outcomes en route to increased RTD

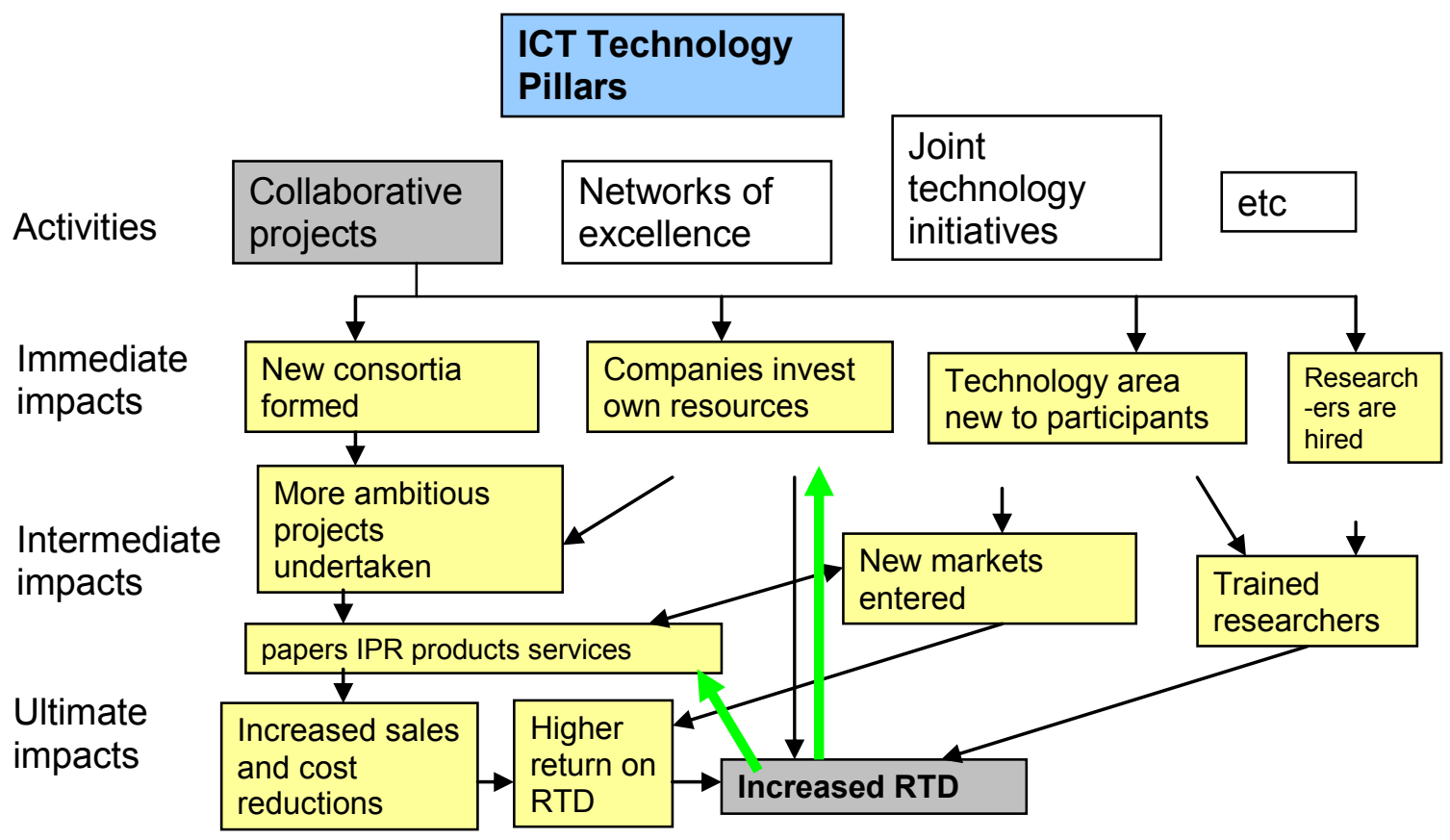

This approach to modeling the connection between research activities and broader political or economic objectives is best used during the programme design phase, to help ensure that there is a viable rationale. The underlying issue is that in a knowledge economy and society, it is necessary to understand and account for knowledge and human capital. That, in turn requires making visible and tangible underlying assumptions and rationales, as well as linkages among inputs and effects. Evaluation thus acquires the potential to generate knowledge as well as measure its impacts. 


\section{ANNEX V: Current Concepts of RTD Evaluation in Europe}

Guidance on the basic principles and questions for the whole evaluation cycle has been presented in a document released by DG Budget. ${ }^{41}$ Figure A3 was used to illustrate the intervention logic.

Figure A3: Intervention Logic and Evaluation

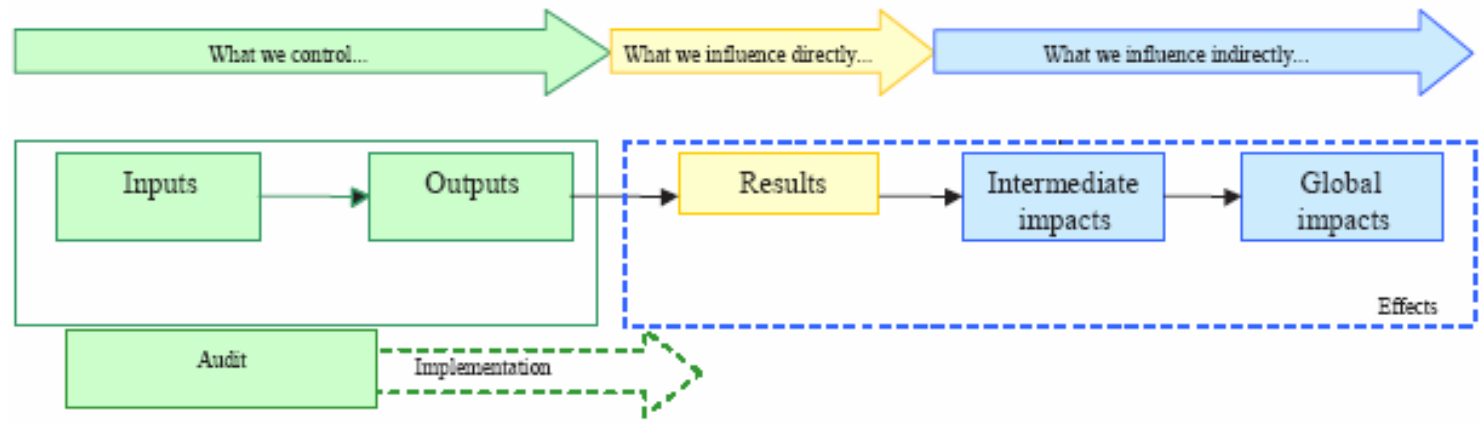

Ensuring the i) reliablity and integrity of information, ii) compliance with policies, iii) safeguarding of assets, iv) the economical and efficient use of resources, and v) the accomplishment of established objectives

\section{Monitoring}

Assessing progress in implementation for mansgement purposes

\section{Evaluation}

Judging an intervention on the basis of results and impacts at the level of addressees

Source: Evaluating EU Activities: A Practical Guide for the Commission Services, DG Budget, Evaluation Unit, July 2004.

The ex ante evaluation will come before the program is initiated and will address the required level of resources. It purports to gather information in relation to a new or renewed RTD programme and to carry out analyses to ensure that the programme will successfully deliver its objectives and that the instruments are cost-effective and appropriate. It also sets the stage for subsequent evaluations. ${ }^{42}$

41 European Commission, DG Budget (2004): Evaluating EU Activities: A Practical Guide for the Commission Services, July 2004. The basic documents on evaluation on which this document is based are: The Financial Regulation, Council regulation 1605/2002, articles 27, 28 and 33; the Implementing Rules of the Financial Regulation, Commission regulation 2342/2002, article 21; the Communication on Evaluation, SEC (2000) 1051; and the Communication on Evaluation Standards and Good Practices, SEC (2002) 5267: http://europa.eu.int/comm/budget/evaluation/keydocuments_en.htm.

42 The impact assessment process addresses many of the same elements as an ex ante evaluation and is also carried out before the proposed activity is adopted. The impact assessment applies to regulatory proposals or other proposals having an economic, social and/or environmental impact which are presented by the Commission in its Annual Policy Strategy or its Work Programme (Communication on Impact Assessment COM(2002) 276 final). 
Monitoring, on the other hand, is a continuous and systematic process implemented concurrently that assesses the progress in implementing the programme and in achieving its operational objectives. Its basic purpose is to support programme management, improve the programme's performance, and facilitate subsequent evaluations. The interim evaluation examines an ongoing programme. Two specific cases of interim evaluation are commonly recognized: mid-term evaluation, which is carried out at the half-way stage of the intervention, and final evaluation, which is conducted towards the end of the programme. These two forms of interim evaluation can build on the ex ante appraisal and examine the continuing relevance of the objectives and pose questions relevant to the delivery of initial outputs and the early effects of the programme. Finally, the ex post evaluation looks at the entire intervention period, is carried out sometime after the completion of the programme, and emphasizes the impacts, efficiency and effectiveness of the intervention. It also assesses the sustainability of the realized impacts and the main factors accounting for the success or failure of the programme.

Figure A4 provides the Framework for developing an objectives hierarchy and for considering appropriate indicators. All kinds of objectives will be addressed in the ex ante evaluation and impact assessment. Inputs, outputs, and results will be the subjects of monitoring and interim evaluation exercises. Intermediate and global impacts will be the subject matter of ex post evaluations.

Figure A4. Framework for Developing an Objectives Hierarchy and Indicators

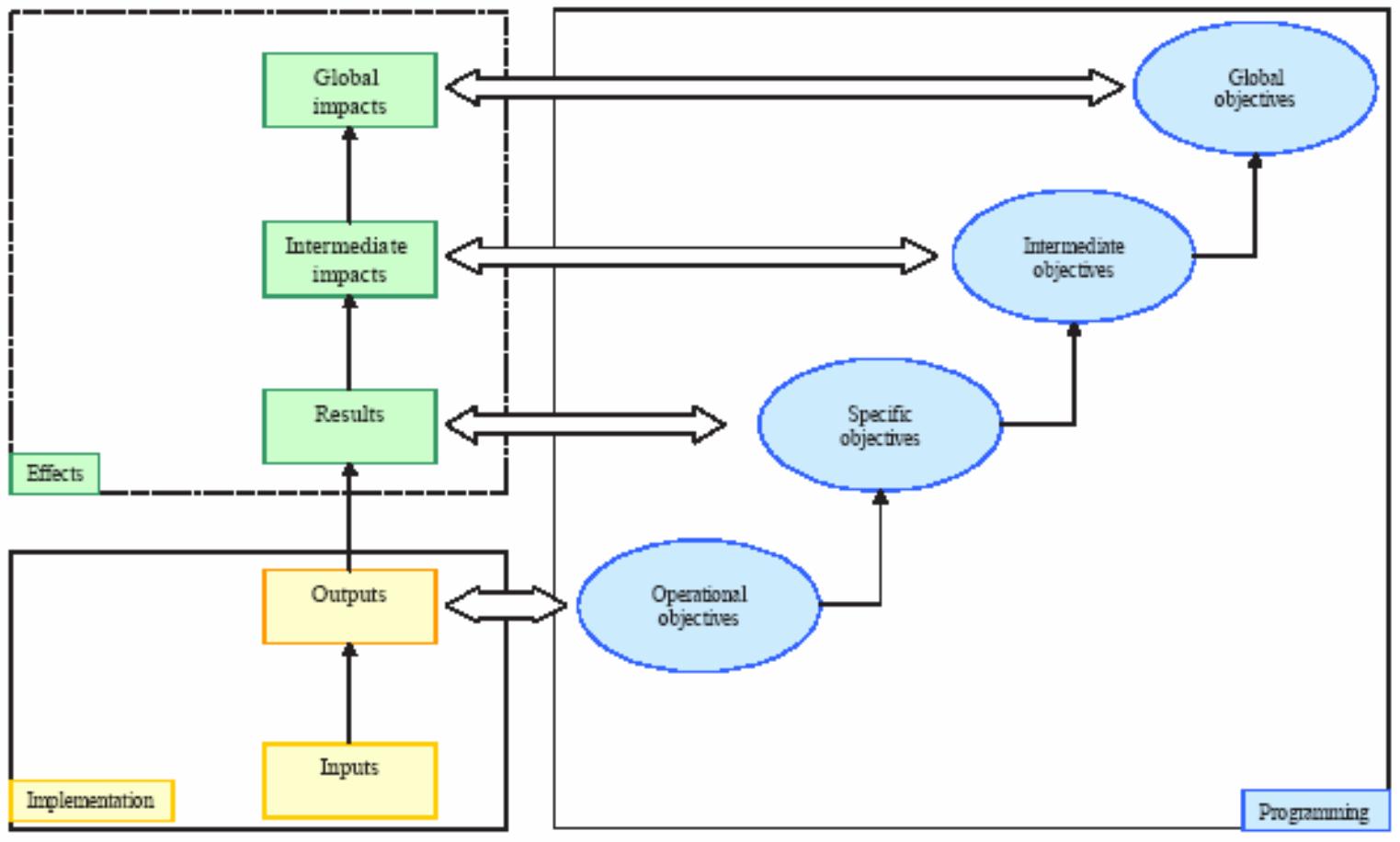

Source: Evaluating EU Activities: A Practical Guide for the Commission Services, DG Budget, Evaluation Unit, July 2004. 
The different categories of objectives can be described as follows:

- Operational objectives refer to the direct outputs of the intervention (what is produced, supplied during implementation). The relevant indicators at this level are output indicators.

- Specific objectives refer to the short-term results of the intervention that occur at the level of direct beneficiaries/recipients of assistance. The relevant indicators at this level are results indicators.

- Intermediate objectives refer to the short- to medium-term effects of the intervention (intermediate impacts) on both direct and indirect beneficiaries/recipients of assistance. The relevant indicators at this level are intermediate impact indicators.

- Global objectives refer to the longer term and more diffuse effects of the intervention (global impacts). The relevant indicators at this level are global impact indicators.

Another schematic of the framework for developing an objectives hierarchy and appropriate indicators for evaluation is shown in Figure A5 below.

Figure A5: Objectives Hierarchy, Indicators and Evaluation

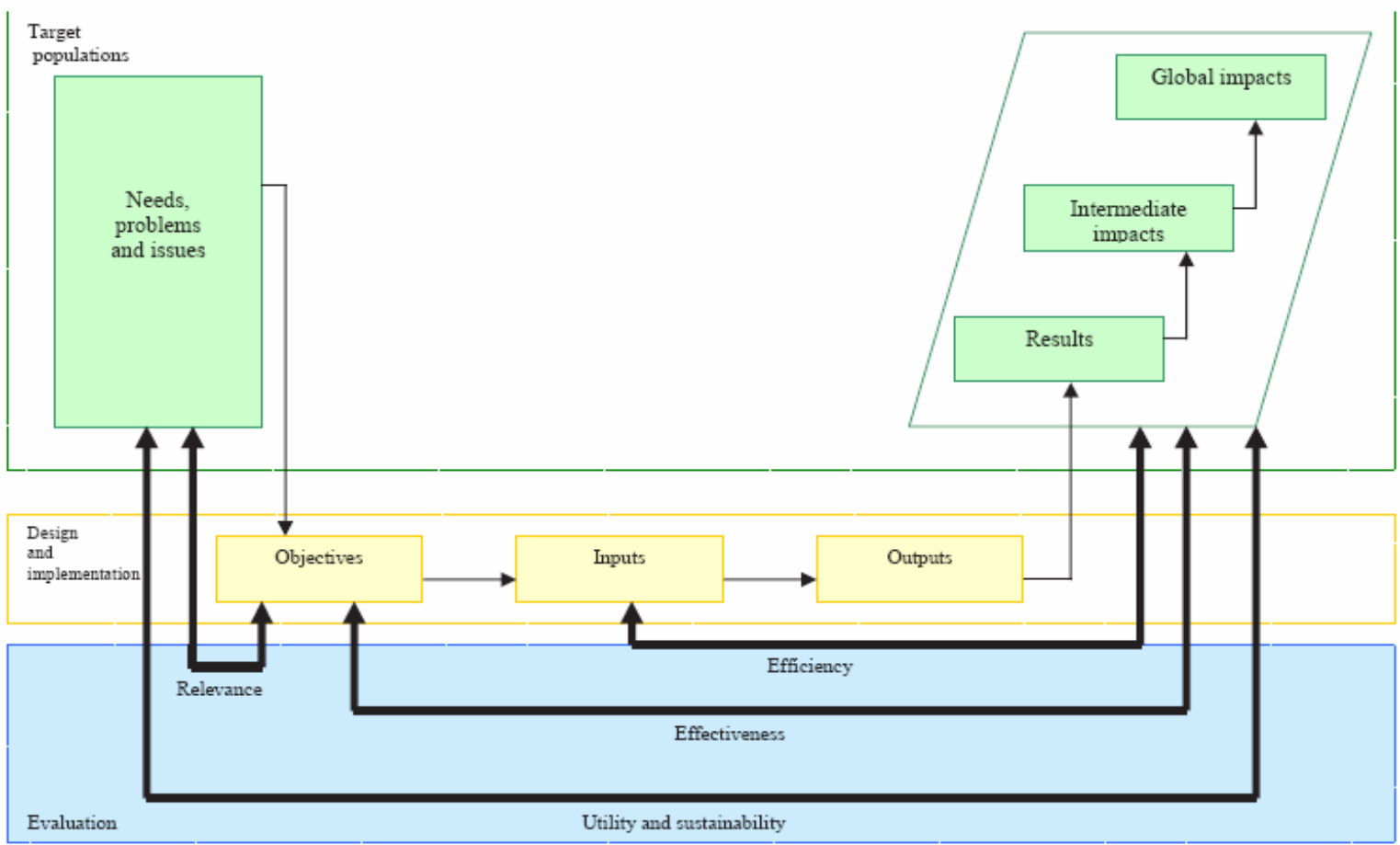

Source: Evaluating EU Activities: A Practical Guide for the Commission Services, DG Budget, Evaluation Unit, July 2004. 
A recent study ${ }^{43}$ has mentioned the following evaluation themes:

- Efficiency: Evaluation can investigate the extent to which the programme was managed and operated efficiently, whether there was good communication of objectives and progress, and ability to address problems as they arose.

- Effectiveness: Evaluation can examine the extent to which the objectives have been met. In assessing programme effectiveness, it is common to use performance indicators.

- Efficacy: Evaluation can consider the extent to which the programme was relevant to the broad policy goals it was designed to contribute to.

- Communication: Evaluation can explain how and why the programme achieved the degree of effect that was realized. It can illuminate issues of programme management. And, it can raise the understanding of the broader innovation system within which the programme has operated.

- Rate of Return: Evaluation may attempt to examine the societal rate of return to the public expenditure.

- Unintended Consequences: Evaluation may shed light on the benefits and costs of the activities related to the programme in questions that were not expected by the programme designers, or not explicitly spelled out as being among the programme objectives.

On a similar vain, Figure A6 below indicates the major evaluation themes that are most relevant to different stages of the evaluation cycle.

43 European Commission, DG Enterprise and Industry (2006): Smart Innovation: A Practical Guide to Evaluating Innovation Programmes, January 2006. 
Figure A6. Major Themes in the Evaluation Cycle

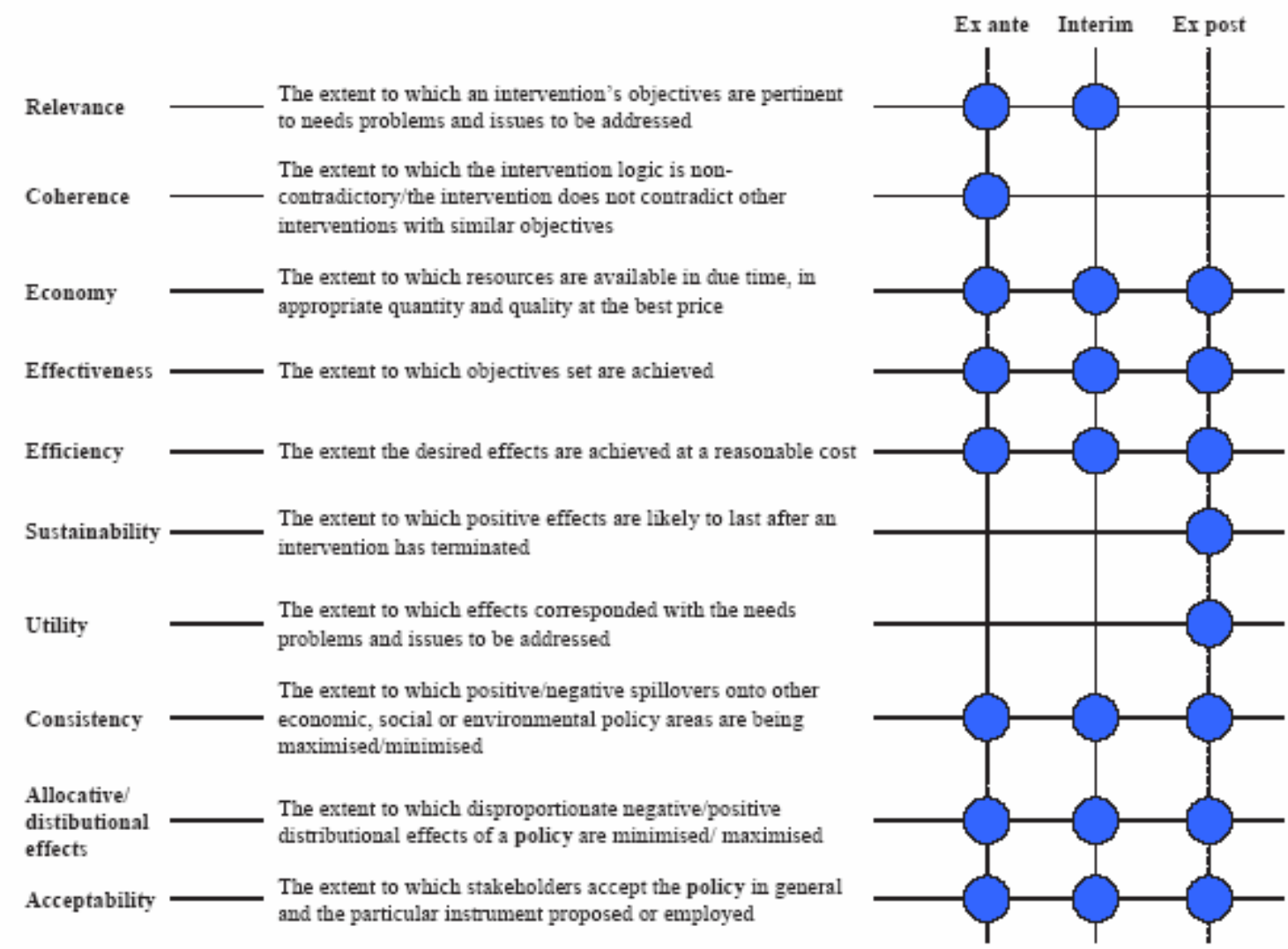

Source: Evaluating EU Activities: A Practical Guide for the Commission Services, DG Budget, Evaluation Unit, July 2004.

It should be stressed that an actual evaluation will deal with these general evaluation themes within the specific context of the programme being evaluated. Specific analytic evaluation questions must be posed and elaborated. In order to do this, it is important first to understand the intervention logic which should have been developed during the ex ante evaluation process. The evaluation questions lead to evaluation criteria and relevant indicators.

Various methods for data collection and analysis exist. Their specific application depends on the evaluation questions, data availability, time and resources available for the evaluation project. Figure A7 presents an overview of some of the tools and techniques that are likely to be used in different evaluation situations. 
Figure A7. Evaluation Tools and Techniques

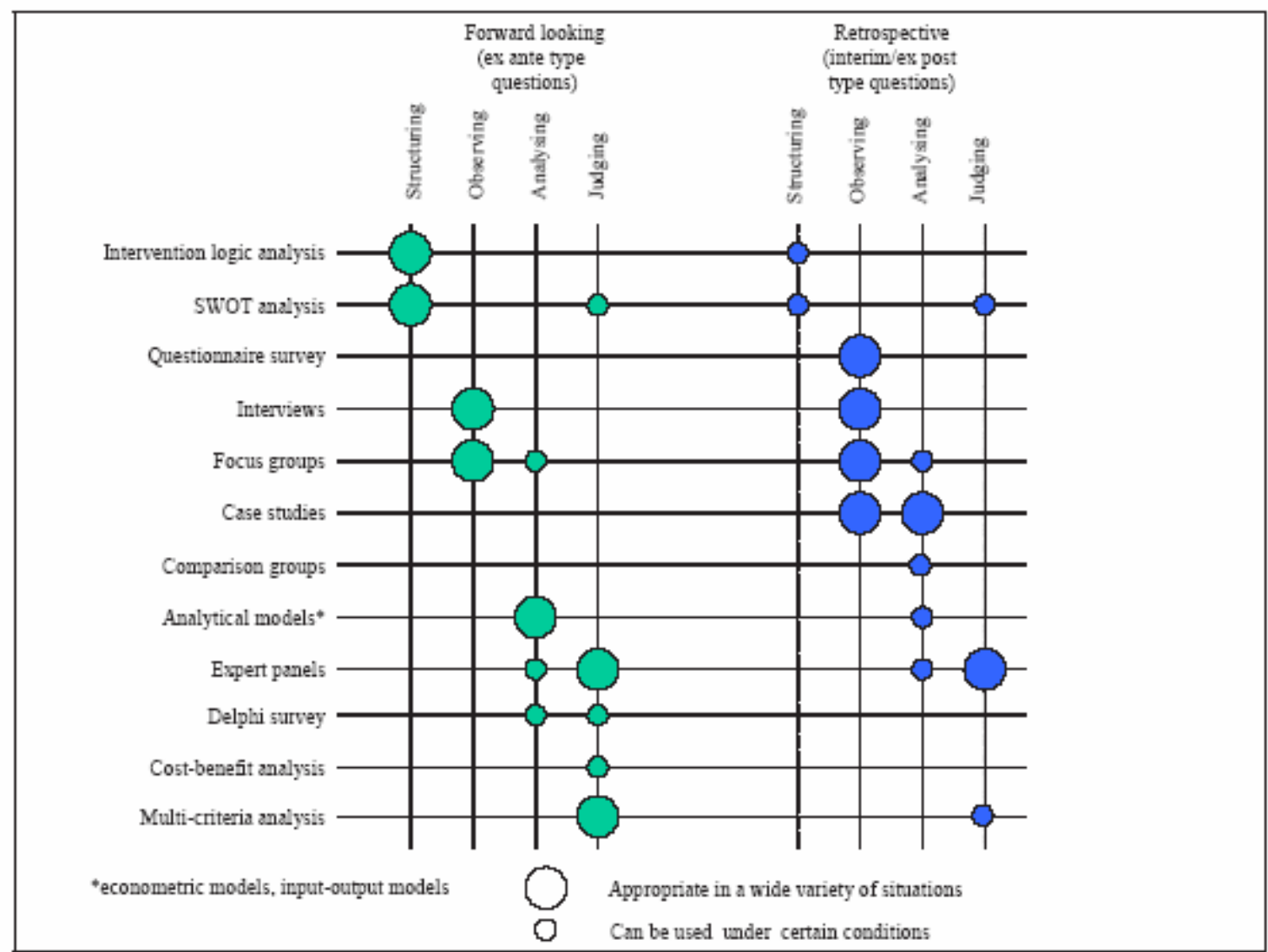

\section{Source: Adapted from MEANS.}

Source: Evaluating EU Activities: A Practical Guide for the Commission Services, DG Budget, Evaluation Unit, July 2004.

The "Tools" Figure must be viewed as indicative. It is neither comprehensive in terms of coverage of analytical techniques nor is the shown allocation of techniques across the evaluation cycle cast in stone. Both techniques and our understanding of how to use them in evaluation evolve and improve all the time. For example, so-called real options models and network analysis that have received a lot of attention more recently are not covered. And, the ways techniques will be aligned to answer specific evaluative questions may vary across programmes for different reasons including the availability of information, resources, and time as well as the preferences of the evaluating unit. 


\section{ANNEX VI: The Challenge of Attribution}

The main question at the core of every evaluation study is: to what extent are the measurable effects really the result of the program, i.e. to what extent are they causally attributable to participation in the program?

This question is anything but trivial especially in contexts with mostly intangible program goals like increasing competence and the formation international networks. For instance a participant can report that a project was a total failure in regard to the technological targets of the research project. Still, a new partner was met in the process and in subsequent activities with that partner a highly successful product has been developed and marketed.

The problem of attribution has different aspects. The following graphic attempts to display this:

Figure A8: The Challenge of Attribution

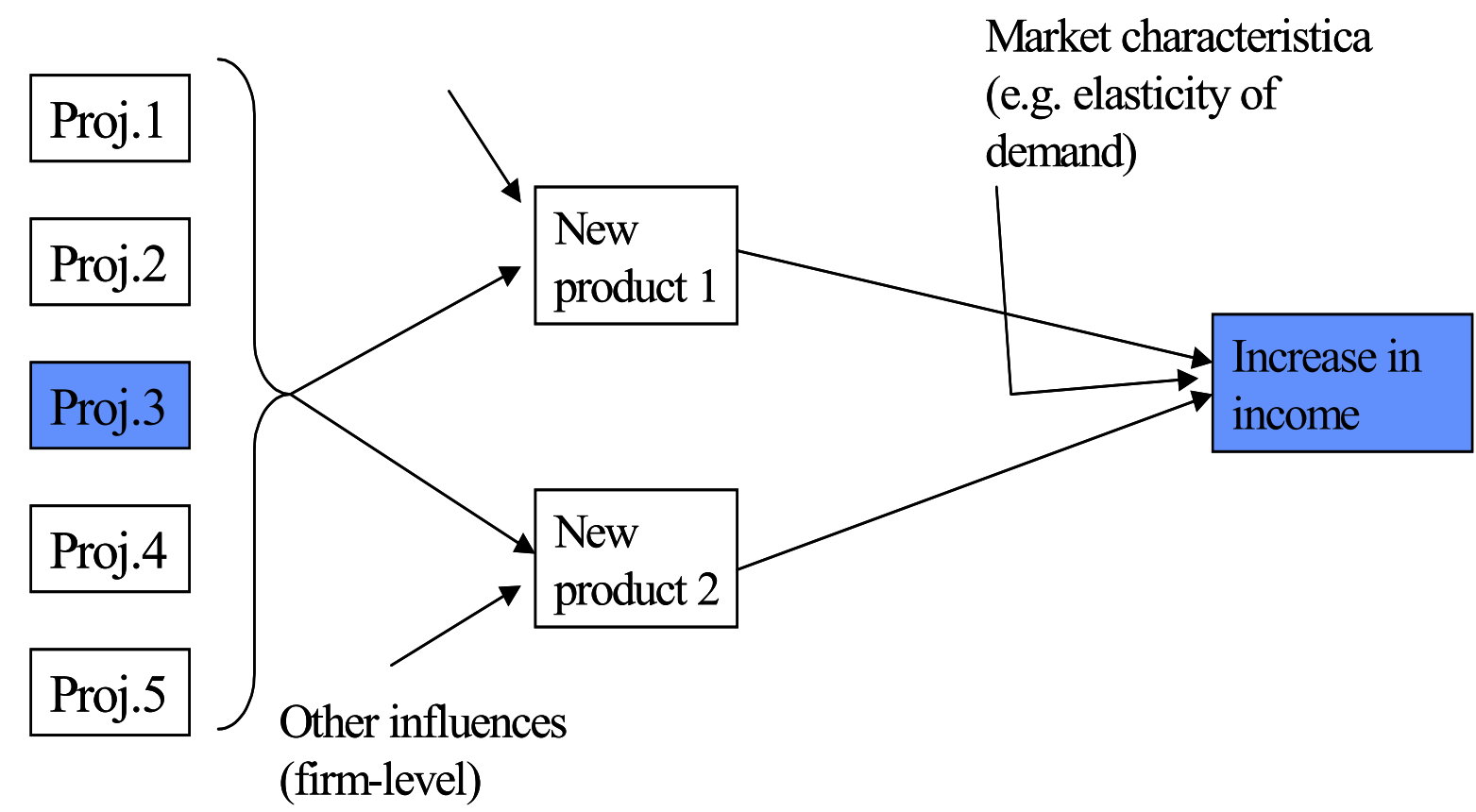

Publicly subsidized research projects frequently turn out to be one of many projects within a company's research portfolio. If these projects are complementary then new products or processes resulting from research activities are hard to attribute to this one project.

Indirect effects can play a major role. While direct effects are directly related to the program goals, indirect effects come about when the effects go beyond the program goals - for instance when the research project enhances the reputation of the firm or contributes to improvements in management. These can lead to an improvement in the company's competitive position. 
Rising turnover, increased value added or cost savings are generally the result of multiple influences both internal and external to the firm. The research activities themselves are generally only a small part of these. Whether or not an improved process or a successfully introduced new product lead to a mid-range increase in value-added is, for instance, greatly dependent upon how quickly competitors react to the new situation or the level of demand elasticity. 


\section{References}

Arrow, K., (1962): Economic welfare and the allocation of resources for invention, in: Nelson, R. (ed): The Rate and Direction of Inventive Activity

Bozeman, B; Melkers, J. (eds.) (1993): Evaluating R\&D Impacts: Methods and Practice.

Conseil Stratégique des Technologies de l'Information (2006): Research and development in information science and technology in large industrialised countries. Statistical analysis of investments. A study commissioned by the Ministère délégué à l'enseignement supérieur et à la recherche. Realized by the Groupement Français de l'Industrie de l'Information (GFII) (French Information Industry Association), http://www.recherche.gouv.fr/rapport/rdsti.htm

ECOTEC (2005): Preliminary analysis of the contribution of EU information society policies and programmes to the Lisbon and Sustainable Development Strategies, Final Report.

European Commission (2000): Communication to the Commission. Focus on results: Strengthening evaluation of Commission SEC(2000)1051

European Commission (2002a): Commission Regulation 2342/2002

European Commission (2002b): Communication on Evaluation Standards and Good Practices, SEC (2002) 5267, http://europa.eu.int/comm/budget/evaluation/keydocuments en.htm

European Commission (2002c): Communication on Impact Assessment COM(2002) 276 final

European Commission (2002d): Council Regulation (EC, Euratom) No 1605/2002 of 25 June 2002on the Financial Regulation applicable to the general budget of the European Communities

European Commission (2006a): Amended proposal for a decision of the European Parliament and the Council concerning the 7th Framework Programme of the European Community for Research, Technological Development and Demonstration activities (2007-2013) [COM(2006)364].

European Commission (2006b): Communication from the Commission to the Council, the European Parliament and Social Committee and the Committee of the Regions: i2010 First Annual Report SEC

European Commission, DG Budget (2004): Evaluating EU Activities: A Practical Guide for the Commission Services

European Commission, DG Enterprise and Industry (2006): Smart Innovation: A Practical Guide to Evaluating Innovation Programmes

European Commission, DG Information Society and Media (2005): Five-Year Assessment 19992003. Research and Technology Development, in: Information Society Technologies, Final Panel Report

European Commission, DG Information, Society and Media (2006): Evaluating the Impact of IST RTD - Intervention Logic, - Evaluation and Monitoring, Notes for a meting with the European Court of Auditors

European Commission, DG Information, Society and Media (2007): Monitoring of the ICT RTD Implementation: Output and Impact Indicators - Draft Terms of Reference

Fahrenkrog, G., Polt, W., Rojo, J., Tubke, A, Zinnoecker, K. (eds) (2002): RTD Evaluation Toolbox: Assessing the Socio-Economic Impact of RTD Policies (EPUB), European Commission, Joint Research Centre

Georghiou, L., Rigby, J., Cameron, H. (eds) (2002): Assessing the Socio-Economic Impacts of the Framework Programme (ASIF), European Commission, DG Research 
Hagedoorn, J., Link, A., Vonortas, N. (2000): Research Partnerships, Research Policy, 29(4-5): 567-586

Hemphill T., Vonortas, N. (2003): Strategic Research Partnerships: A Managerial Perspective, Technology Analysis and Strategic Management, 15(2): 255-271

i2010 High Level Group (2006): The economic impact of ICT : Evidence and Questions

Johnston, P. (2006): A Strategy for Evaluating the Impact of IST-RTD Actions in the EU Framework Programmes, Head - Evaluation and Monitoring, DG Information Society and Media, Speech by Peter Johnston, January 2006

Leeuw, F.L. (2003): Reconstructing Program Theories: Methods Available and Problems to be Solved, in: American Journal of Evaluation, Vol. 24, No. 1, pp. 5-20

Luukkonen, T. et al (2006): Understanding the dynamics of networks of excellence, in: Science and Public Policy, Vol. 33, No. 4. pp. 239-252

Maienschein, J. (2006): On the Value of History of Science for the Social Science of Science Policy", National Science Foundation Workshop, July 13-14

OECD (2006a): Government RTD Funding and Company Behaviour:Measuring Behavioural Additionality

OECD (2006b): Governance of Innovation Systems, Vol. 1: Synthesis Report

OECD (2006c) Governance of Innovation Systems, Vol. 2: Case Studies in Innovation Policy

OECD (2006d), Governance of Innovation Systems, Vol. 3: Case Studies and Cross-Sectoral Policy

Papaconstantinou, G., Baudouin, P. (2006): Self-Assesment: IST Implementation 2005, Report, DG Information, Society and Media

Polt, W., Schibany, A (2001): Innovation and Networks: An Introduction to the Theme, in: OECD Innovative Networks

Polt, W., Streicher, G. (2005): Trying to capture additionality in Framework Programme 5 - main findings, in: Science and Public Policy, 32(5), pp. 367-374

Ruegg, R., Feller, I. (2003): A Toolkit for Evaluating Public RTD Investment, NIST GCR 03-875 (National Institute of Standards and Technology)

Smith, K. (2000): Innovation as a Systemic Phenomenon: Rethinking the Role of Policy. Enterprise and Innovation Management Studies, Vol.1, No.1, pp. 73-102.

Technopolis (2005): Developing a Methodological Framework for High Quality Assessment of the IST-RTD Effects (Results and Impacts) at the "Strategic Objective" Level, Final Report to DG Information, Society and Media

Vonortas, N., Hinze, S. (eds.) (2005): Evaluation of European Union Framework Programmes: The 2004 Five-Year Assessment, Special Issue, Science and Public Policy, 32(5) 